\title{
Coherent scatter x-ray imaging of plastic and water phantoms
}

\author{
by \\ Mohammad Nisar \\ A thesis submitted to \\ the Faculty of Graduate Studies and Research \\ in partial fulfillment of \\ the requirements for the degree of \\ Master of Science
}
Ottawa-Carleton Institute for Physics
Carleton University
Ottawa, Ontario
December 15, 2004

(C) 2005, M. Nisar 


$\begin{array}{ll}\begin{array}{l}\text { Library and } \\ \text { Archives Canada }\end{array} & \begin{array}{l}\text { Bibliothèque et } \\ \text { Archives Canada }\end{array} \\ \begin{array}{l}\text { Published Heritage } \\ \text { Branch }\end{array} & \begin{array}{l}\text { Direction du } \\ \text { Patrimoine de l'édition }\end{array} \\ \begin{array}{l}\text { 395 Wellington Street } \\ \text { Ottawa ON K1A ON4 }\end{array} & \begin{array}{l}\text { 395, rue Wellington } \\ \text { Ottawa ON K1A ON4 } \\ \text { Canada }\end{array}\end{array}$

Your file Votre référence

ISBN: 0-494-00785-0

Our file Notre référence

ISBN: 0-494-00785-0

NOTICE:

The author has granted a nonexclusive license allowing Library and Archives Canada to reproduce, publish, archive, preserve, conserve, communicate to the public by telecommunication or on the Internet, loan, distribute and sell theses worldwide, for commercial or noncommercial purposes, in microform, paper, electronic and/or any other formats.

The author retains copyright ownership and moral rights in this thesis. Neither the thesis nor substantial extracts from it may be printed or otherwise reproduced without the author's permission.
AVIS:

L'auteur a accordé une licence non exclusive permettant à la Bibliothèque et Archives Canada de reproduire, publier, archiver, sauvegarder, conserver, transmettre au public par télécommunication ou par l'Internet, prêter, distribuer et vendre des thèses partout dans le monde, à des fins commerciales ou autres, sur support microforme, papier, électronique et/ou autres formats.

L'auteur conserve la propriété du droit d'auteur et des droits moraux qui protège cette thèse. $\mathrm{Ni}$ la thèse ni des extraits substantiels de celle-ci ne doivent être imprimés ou autrement reproduits sans son autorisation.
In compliance with the Canadian

Privacy Act some supporting forms may have been removed from this thesis.

While these forms may be included in the document page count, their removal does not represent any loss of content from the thesis.
Conformément à la loi canadienne sur la protection de la vie privée, quelques formulaires secondaires ont été enlevés de cette thèse.

Bien que ces formulaires aient inclus dans la pagination, il n'y aura aucun contenu manquant.

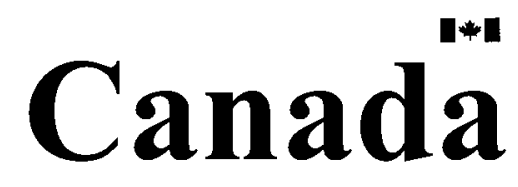




\begin{abstract}
Conventional medical x-ray imaging, based on the transmission of primary photons, works well to distinguish between hard and soft tissues. Up to $90 \%$ of the photons that reach the image receptor, however, are coherently or incoherently scattered, and so there is growing interest in utilizing scattered $\mathrm{x}$ rays for diagnosis. Low-angle scattered photons can only be distinguished from primary on the basis of direction and consequently a well-collimated $\mathrm{x}$-ray system is required. A hexagonal array of seven 1.5 $\mathrm{mm}$ diameter pinholes is designed and tested to record the diffraction patterns of plastics and tissues in air and in a water tank. These materials are amorphous solids and result in rotationally-symmetric diffraction patterns which are characteristic of the materials. The intensities of the diffraction patterns are numerically integrated over concentric rings and the scatter images are made by assigning the ring sums as the pixel values. Test images are made of $1 \mathrm{~cm}$ thick targets in air and the tube is operated with technique factors ranging from $50 \mathrm{kVp} 6000 \mathrm{mAs}$ to $120 \mathrm{kVp} 300 \mathrm{mAs}$ for these measurements. The anglesensitive scatter images exhibit variation of contrast among different materials with angle. To investigate the potential application of the coherent-scatter imaging technique as a diagnostic tool in medical radiology a thick water/plastic phantom is also examined. Using single-beam geometry it has been found that different types and thicknesses of plastics embedded in a $10 \mathrm{~cm}$ and in a $20 \mathrm{~cm}$ thick water phantom at different depths can be distinguished on the basis of the shape of the scatter pattern radial profile and on its relative intensity. For thick phantom measurements the tube is operated with technique factors ranging from $120 \mathrm{kVp} 1500 \mathrm{mAs}$ to $120 \mathrm{kVp} 7000 \mathrm{mAs}$. The scatter patterns are recorded on a storage phosphor image plate.
\end{abstract}




\section{Acknowledgments}

I would like to express my thanks to my supervisor Prof. Paul C. Johns, for his constant support, invaluable guidance and helpful suggestions throughout this project.

Special thanks goes to Prof. Jim Cheetham and Prof. Ken Storey and his students for making the Bio-Rad image plate reader available to us.

My appreciation also goes to the staff of the technical workshop, Department of Physics Carleton University, especially Mr. Philippe Gravelle for his assistance in providing technical help during this work.

The staff of the Science Technology Centre, Carleton University were very helpful in constructing the collimation system which I used in this project. Thanks to all of them.

I would also like to thank Ziaul Hasan who was my lab mate for useful discussions on scattering stuff and matlab codes and Osama Moussa for developing the Matlab image display program. 


\section{Table of Contents}

Acceptance sheet $\quad$ ii

Abstract iii

Acknowledgements

Table of Contents $\quad$ v

$\begin{array}{ll}\text { List of Tables } & \text { ix }\end{array}$

List of Figures $\quad$ X

Chapter 1 Introduction 1

1.1 Conventional x-ray imaging 1

1.2 Scatter imaging 4

$\begin{array}{lll}\text { 1.2.1 Coherent scatter imaging } & 4\end{array}$

$\begin{array}{ll}\text { 1.2.2 Incoherent scatter imaging } & 7\end{array}$

1.3 Concept for making scatter images 9

$\begin{array}{ll}\text { 1.4 Motivation and objectives } & 10\end{array}$

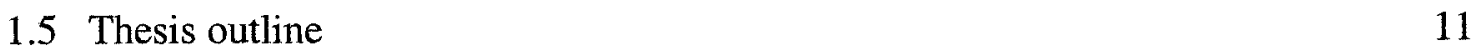

$\begin{array}{llr}\text { Chapter } 2 & \text { Theory } & 12\end{array}$

2.1 Photoelectric effect 13

$\begin{array}{ll}2.2 \text { Coherent scattering } & 13\end{array}$

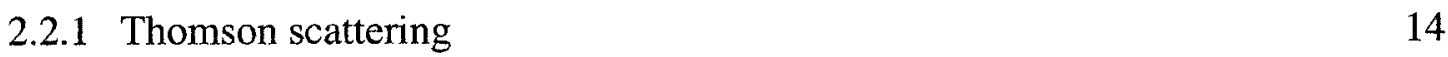

2.2.2 Rayleigh scattering 14

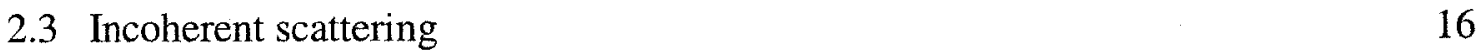

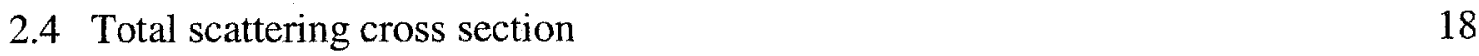


$\begin{array}{ll}3.1 \text { Collimation systems } & 19\end{array}$

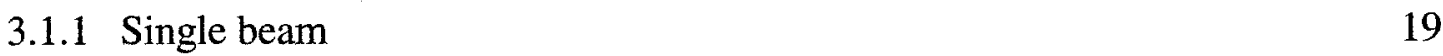

3.1.2 Seven beam hexagonal geometry 20

3.2 Experimental setup for single-beam geometry 24

3.3 Experimental setup for seven-beam hexagonal geometry 26

$\begin{array}{lll}3.4 & \text { Scatter patterns to scatter image display } & 27\end{array}$

\begin{tabular}{ll}
3.5 & Thick water phantom \\
\hline
\end{tabular}

3.6 Detector (CR plate) $\quad 30$

$\begin{array}{lll}3.7 & \text { Target materials } & 31\end{array}$

Chapter 4 Scatter patterns: Single beam geometry 34

4.1 Background (residual) image $\quad 34$

4.2 Effect of primary beam on scatter pattern recording 35

$\begin{array}{lll}4.3 & \text { Results and discussion } & 37\end{array}$

$\begin{array}{lll}\text { 4.3.1 Scatter patterns of plastics } & 37\end{array}$

$\begin{array}{ll}\text { 4.3.2 Scatter pattern of fat } & 40\end{array}$

4.3.3 Scatter patterns of salt and bone $\quad 41$

4.3.4 Scatter pattern of water 43 
5.1 Primary image patterns 44

$\begin{array}{lll}5.2 & \text { Transmission image patterns } & 47\end{array}$

$\begin{array}{ll}\text { 5.3 Making projection transmission image } & 49\end{array}$

5.4 Scatter patterns using seven-beam hexagonal geometry 51

5.5 Variation of mAs versus $\mathrm{kVp}$

5.6 Making projection scatter image by integrating entire ring structure 54

5.7 Comparison of transmission and scatter images 55

5.8 Making projection scatter image by integrating portion of ring structure 56

Chapter 6 X-ray scatter pattern measurements of thick water/plastic $\begin{array}{ll}\text { phantoms } & 59\end{array}$

6.1 Scatter patterns for thick water phantom $\quad 59$

$6.210 \mathrm{~cm}$ thick water/plastic phantoms $\quad 62$

6.2.1 Scatter patterns for $10 \mathrm{~cm}$ thick water/PMMA phantom 62

6.2.2 Scatter patterns for $10 \mathrm{~cm}$ thick water/plastic phantoms 64

$\begin{array}{ll}6.320 \mathrm{~cm} \text { thick water/plastic phantoms } & 67\end{array}$

6.3.1 Scatter patterns for $20 \mathrm{~cm}$ thick water/PMMA phantom 67

6.3.2 Scatter patterns for $20 \mathrm{~cm}$ thick water/plastic phantoms 71

6.3.2.1 Plastics at $10 \mathrm{~cm}$ depth $\quad 71$

$\begin{array}{ll}\text { 6.3.2.2 Plastics at } 15 \mathrm{~cm} \text { depth } & 71\end{array}$

6.4 PMMA of different thickness in a $20 \mathrm{~cm}$ thick water phantom 74 


\section{Chapter 7 Conclusion and future work}

7.1 Conclusion

$\begin{array}{ll}7.2 \text { Future work } & 77\end{array}$

7.2.1 Measurements with thick water/plastic phantoms $\quad 77$

$\begin{array}{ll}\text { 7.2.2 Scanning of an inhomogeneous target } & 77\end{array}$

$\begin{array}{ll}\text { 7.2.3 Improvement in spatial resolution } & 79\end{array}$

$\begin{array}{ll}\text { 7.2.4 Scanning of thick phantom } & 79\end{array}$

$\begin{array}{lr}\text { References } & 80\end{array}$

Appendix Computer code for generating radial profile of scatter pattern 


\section{List of Tables}

Table

3.1 Target materials, their compositions, and the thicknesses used for 32 measurements.

5.1 The average intensity of the primary patterns for seven beams. 


\section{List of Figures}

Figure

1.1 The components of a conventional $\mathrm{x}$-ray imaging system.

1.2 Schematic of Compton scatter scanner for imaging back-scattered photons.

1.3 Schematic illustration of making a scatter projection image.

2.1 The three interaction processes in carbon at different energies. 12

3.1 Construction geometry of the seven-beam collimation system. 21

3.2 Seven pinhole hexagonal shaped collimation system. 23

3.3 Experimental setup for single-beam collimation geometry. 25

3.4 Experimental setup for seven-beam hexagonal collimation geometry. 26

3.5 (a) Schematic illustration of obtaining the radial intensity profile, (b) 28 integration of the intensity profile and using it as a pixel for the scatter image display, (c) the pixel value obtained by integrating the radial profile over angular range $1.5^{\circ}$ to $3.1^{\circ}$.

3.6 The cubical phantom used for thick sample measurements is made of $1.3 \mathrm{~cm}$ thick PMMA. Two locations of $2.6 \mathrm{~cm}$ thick plastic target are shown. (a) Plastic sample at the top in a $20 \mathrm{~cm}$ thick water phantom, (b) plastic sample at $5 \mathrm{~cm}$ depth in a $20 \mathrm{~cm}$ thick water phantom, (c) hollow plastic cylinder used to hold sample in part (b). 
3.7 Arrangement of samples: (a) Sample holder for water, salt and tissues,

(b) plastic sample, (c) arrangement for seven-beam hexagonal geometry.

4.1 Diffraction pattern of polyethylene. (a) Without lead blocker, (b) with 36 lead blocker, (c) radial intensity profile from (b).

4.2 The diffraction patterns of four types of plastics at $50 \mathrm{kVp}, 6000 \mathrm{mAs}$.

The white region in the centre of the ring is due to $\mathrm{Pb}$ blocker, used to stop the primary.

4.3 The radial intensity profiles for the plastic samples obtained by integrating the diffraction patterns of figure 4.2 .

4.4 The scatter pattern of fat and its radial intensity profile.

4.5 The scatter patterns of table salt and bone.

4.6 The radial intensity profiles of table salt and bone.

4.5 The scatter pattern of water and its radial intensity profile. 43

5.1 (a) Primary (without target) $x$-ray spots using 7-beam collimation 46 system, (b) the radial intensity profiles of (a).

5.2 (a) Transmission image (with target) $\mathrm{x}$-ray spots using 7-beam collimation system, (b) the radial intensity profile of (a) after scaling according to table 5.1 .

5.3 Transmission image of seven materials. The locations of the materials are shown at the top.

5.4 Scatter patterns using seven-beam hexagonal geometry. The locations of the seven targets are shown at the left. The patterns are not corrected for relative beam intensity. 
5.5 A series of scatter patterns with varying tube potential from $50 \mathrm{kVp}$ to $120 \mathrm{kVp}$. The materials are arranged as shown in (a). The patterns are not corrected for relative beam intensity.

5.6 Scatter image of seven materials. Each hexagon represents the pixel value obtained by integrating the whole scatter pattern of the material. The locations of the materials are shown at the top.

5.7 (a) Transmission image, (b) scatter image using whole ring.

5.8 Transmission and scatter images of seven different materials. (a) 58 Location of target materials, (b) transmission image, (c) scatter image using whole ring, (d) scatter image using ring with angular range from $1.4^{\circ}$ to $2.2^{\circ}$, (e) scatter image from $2.2^{\circ}$ to $2.9^{\circ}$, (f) scatter image from $2.9^{\circ}$ to $3.5^{\circ}$, (g) scatter image from $3.5^{\circ}$ to $4.3^{\circ}$.

6.1 Scatter patterns from (a) $10 \mathrm{~cm}$ and (b) $20 \mathrm{~cm}$ thick water phantom.

6.2 Radial intensity profile for a $10 \mathrm{~cm}$ and for a $20 \mathrm{~cm}$ thick water phantom.

6.3 The intensity profiles of scatter patterns for $10 \mathrm{~cm}$ thick water/PMMA phantom at $120 \mathrm{kVp}$. PMMA of thickness $2.6 \mathrm{~cm}$ is placed at different depths in a $10 \mathrm{~cm}$ thick water phantom. The intensity profile for $10 \mathrm{~cm}$ water without PMMA is also shown in the panel.

6.4 The intensity profiles of scatter patterns for $10 \mathrm{~cm}$ thick water/plastic phantom at $120 \mathrm{kVp}$. The thickness of the plastics is $1.25 \mathrm{~cm}$ and they are at the depth of $5 \mathrm{~cm}$ in a $10 \mathrm{~cm}$ thick water phantom. The intensity profile of $10 \mathrm{~cm}$ water with no plastics is also shown. 
6.5 The intensity profiles of scatter patterns for $20 \mathrm{~cm}$ thick water/plastic phantom at $120 \mathrm{kVp}$. PMMA of thickness $2.6 \mathrm{~cm}$ is placed at different depths in $20 \mathrm{~cm}$ thick water phantom. The intensity profile for $20 \mathrm{~cm}$ thick water without PMMA is also shown in the panel. (a) Depths of 0 , 5 , and $10 \mathrm{~cm}$.

[continued] (b) Depths of $10,12.5,15$, and bottom which is $17.6 \mathrm{~cm}$.

6.6 The intensity profiles of scatter patterns for $20 \mathrm{~cm}$ thick water/plastic phantom at $120 \mathrm{kVp}$. The thickness of the plastics is $1.25 \mathrm{~cm}$ and they are $10 \mathrm{~cm}$ from the top of a $20 \mathrm{~cm}$ thick water phantom. The intensity profile of $20 \mathrm{~cm}$ water with no plastic is also shown.

6.7 The intensity profiles for scatter patterns of $20 \mathrm{~cm}$ thick water/plastic phantom at $120 \mathrm{kVp}$. The thickness of the plastics is $1.25 \mathrm{~cm}$ and they are $15 \mathrm{~cm}$ from the top of a $20 \mathrm{~cm}$ thick water phantom. The intensity profile for $20 \mathrm{~cm}$ thick water without plastic is also shown.

6.8 The intensity profiles of scatter patterns of $20 \mathrm{~cm}$ thick water/plastic phantom at $120 \mathrm{kVp}$. PMMA of three different thicknesses is placed at the depth of $10 \mathrm{~cm}$ in a $20 \mathrm{~cm}$ thick water phantom. The intensity profile of a $20 \mathrm{~cm}$ homogeneous water phantom is also shown.

7.1 The scanning of a target using seven beam hexagonal collimation geometry. The arrows indicate four movements of the target during the scan. 


\section{Chapter 1}

\section{Introduction}

\subsection{Conventional $x$-ray imaging}

The components of a conventional $\mathrm{x}$ ray imaging system are shown in figure 1.1. The polychromatic beam, energy range $10-150 \mathrm{keV}$, emitted by the $\mathrm{x}$ ray tube is collimated before it enters the patient. In the body $\mathrm{x}$ rays can be scattered, absorbed, or transmitted without interaction. The beam transmitted through the patient is recorded on the detector. The common detectors used for recording the projection image are a screen-film combination, an x-ray image intensifier, and a photo-stimulable phosphor plate which is also known as CR (computed radiography) plate. The intensity of the beam transmitted through the target depends on the thickness and absorbance of the material and the photon energy of the $\mathrm{x}$ rays used. In general, the higher the atomic number of the target, the greater is the absorbing power. In inhomogeneous objects the variation of attenuation with location gives the variation in intensity profile of $x$ rays which is the basis of radiography. This is recorded as a projection image on the detector.

The three main interaction processes of $x$-ray photons with matter in the diagnostic energy range (10-150 keV) are: photoelectric effect, incoherent scattering, and coherent scattering. The probability of these processes varies depending on the photon energy. For example, for $50 \mathrm{keV}$ photons in water the interaction processes occur as: $8.6 \%$ coherent interactions, $80.4 \%$ incoherent, and $11 \%$ photoelectric interactions. ${ }^{1}$ The scattered radiation is always considered to be a problem in the medical x-ray field because it degrades the image contrast (C) and the signal-to-noise ratio (SNR). Since up 
to $90 \%$ of the $\mathrm{x}$ rays leaving the patient on the detector side have been scattered ${ }^{2}, \mathrm{a}$ number of techniques have been devised to minimize the scattered radiation reaching the detector. One of the most effective and common practice is using an anti-scatter grid between the patient and the image receptor as shown in figure 1.1. This is simply a series of lead strips usually tilted towards the source, which will transmit most of the primary but stop most of the scattered radiation. The grid ratio, defined by $R_{G}=\frac{h}{D}$, where $h$ is the height of the lead strip and D is the separation between them, determines the relative number of scatter-to-primary photons that reach the detector. The grid ratio can be improved by increasing $h$ but this will also increase exposure because some of the primary photons are also stopped by increasing $h$. The effect of scattered radiation can also be reduced by increasing the air gap between patient and detector.

In late 1970's Motz and Danos ${ }^{3}$ described quantitatively the information content of conventional $\mathrm{x}$-ray images as a function of patient exposure. They defined the contrast (C) and signal-to-noise ratio (SNR) as

$$
\begin{aligned}
& C=2 \frac{\left|N_{t}-N_{b}\right|}{N_{t}+N_{b}}, \\
& S N R=\frac{\left|N_{t}-N_{b}\right|}{\sqrt{N_{t}+N_{b}}}
\end{aligned}
$$

where $N_{t}$ and $N_{b}$ are the number of $x$-ray photons from the target and the background respectively. 


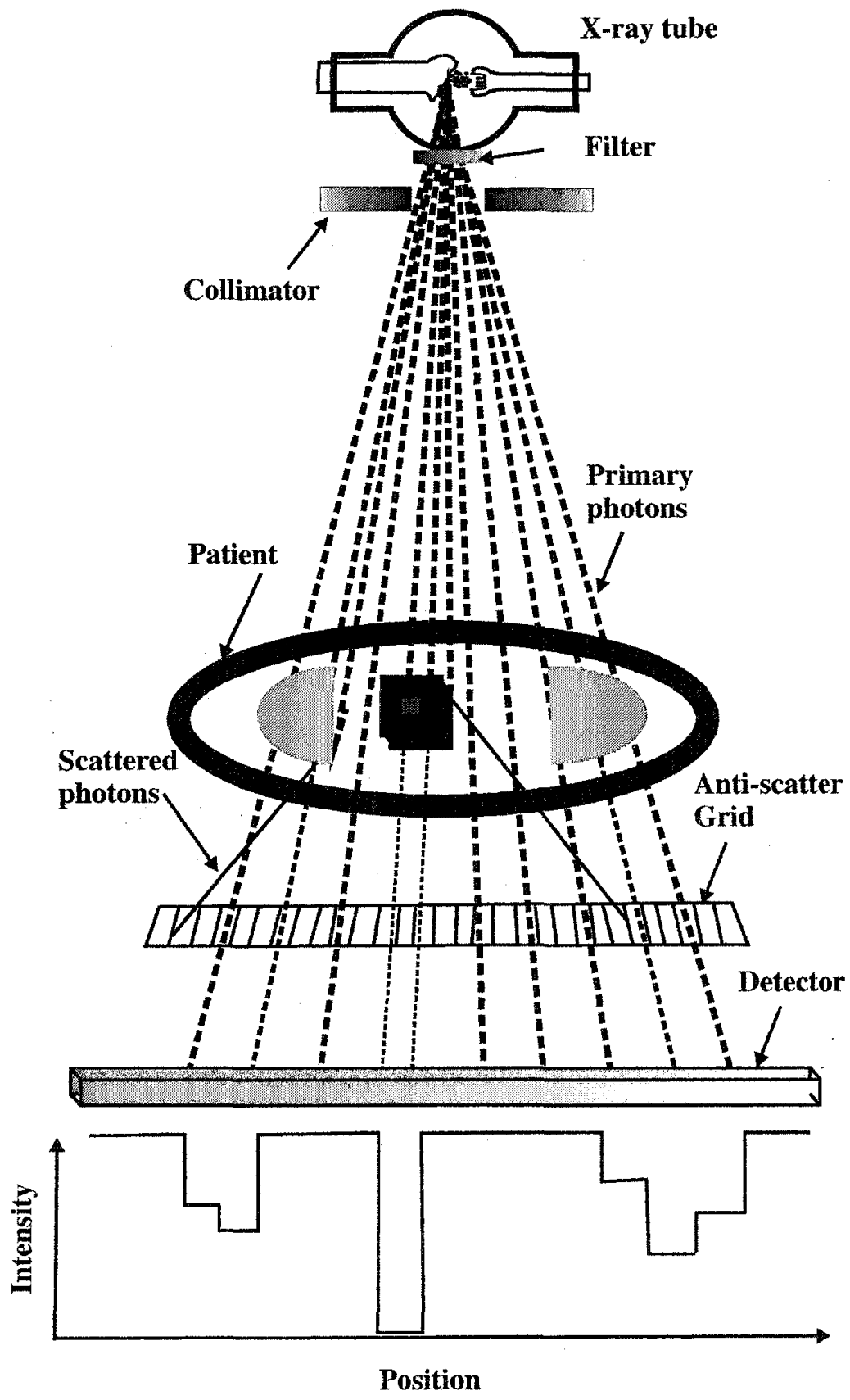

Figure 1.1 The components of a conventional x-ray imaging system. 


\subsection{Scatter imaging}

Since up to $90 \%$ of the $\mathrm{x}$ rays exiting the patient have been scattered, ${ }^{2}$ there is growing interest to utilize these photons for diagnostics of low $\mathrm{Z}$ tissues. In these techniques scattered photons which carry information about the molecular structure are detected. In their review article Speller and Horrocks ${ }^{4}$ described the applications of scattering processes in medicine and biology. There are two types of devices to detect the scattered photons: (a) forward scatter imaging devices which utilize the low-angle coherently scattered photons, and (b) the backscatter imaging devices which detect the incoherently scattered photons.

\subsubsection{Coherent scatter imaging}

The Rayleigh (elastic scattering) effect is a coherent process and gives rise to interference effects. These interference effects are peaked in the forward direction. Though the crosssection for coherent scattering is small, due to its peaked nature in the forward direction, its intensity is higher than that of incoherent scattering at small angles $\left(0-10^{\circ}\right)$. The coherent scattering cross section depends upon the molecular structure of the sample and is useful to differentiate between low $\mathrm{Z}$ materials.

In the early 1980's Johns and Yaffe ${ }^{5}$ studied the divergence of the coherent firstscatter photons from primary and their magnitude as compared to that of primary. They demonstrated that significant numbers of coherent first-scatter photons reach the detector and have sufficient divergence from the primary to be a problem for conventional imaging. Similar conclusions were obtained from independent calculation by Morin and Berroir $^{6}$ and from experimental observation by Muntz et al. ${ }^{7}$ These findings were 
employed by Harding et $a l^{8}$ in a new imaging technique called $\mathrm{x}$-ray diffraction computed tomography. They demonstrated its advantages over conventional CT (computed tomography) by imaging the American Association of Physicists in Medicine (AAPM) phantom. The phantom is composed of plastics in a cylinder of water and has low contrast in a conventional CT image. In this technique they irradiated the target with a collimated $\mathrm{x}$-ray beam and measured the low-angle scattered photons by placing the detectors at different angles with respect to the primary. Their scatter CT images showed the change in contrast of plastics relative to each other and water with the variation of scatter angle. The study of some biological tissues and plastic materials by the same group indicated the potential use of the scatter imaging technique for tissue discrimination and material specification. ${ }^{9}$

Westmore et al. ${ }^{10,11}$ built a tomographic imaging system (coherent-scatter CT, or CSCT) employing an $\mathrm{x}$-ray image intensifier system and polyenergetic $\mathrm{x}$-ray tube source to generate an image of the angular-dependent coherent-scatter cross section for every pixel in the slice. They demonstrated the potential to use CSCT for quantitative measurement of bone-mineral content. Further development on this system by Batchelar and Cunningham ${ }^{12}$ included accurate corrections for exposure fluctuations, temporal response of the detector, and attenuation within the sample, to yield improved accuracy of CSCT for bone mineral densitometry.

There is very little difference in the linear attenuation coefficient of fibroglandular breast tissue ${ }^{13}$ and breast carcinoma so the conventional $x$-ray transmission technique often fails to differentiate them. Kidane et al. ${ }^{14}$ have demonstrated that tissue types can be characterized on the basis of the shape of the coherent-scatter cross section and on its 
relative intensity. Their experimental results revealed that the coherent-scatter cross section for carcinoma is significantly different from fibroglandular tissue which has a small fat component. A diseased tissue has less fat content than the normal tissues so image contrast could be enhanced in mammography by using the scatter imaging technique.

Leclair and Johns ${ }^{15-18}$ developed a semianalytical model and compared quantitatively the performance of an ideal $x$-ray scatter imaging system to an ideal conventional imaging system. Model calculations, experimentally verified using plastics, predicted contrast and SNR for coherent scatter images to exceed those of conventional transmission images, for the same patient dose. These studies predicted scatter imaging to be advantageous in distinguishing soft tissues (e.g., gray versus white brain matter). In reference 19 Johns et al. gave a review of x-ray imaging research conducted by the group at Carleton University in Ottawa.

In order to support the promising field of x-ray scatter imaging it is necessary to have an accurate library of diffraction patterns for tissues, liquids, and phantom materials. In particular, these will allow the design optimization of scatter imaging systems. Therefore, recent work in our laboratory also includes the measurement of scatter cross sections. ${ }^{20,21}$

Using a coherent scatter x-ray imaging system, Luggar and Gilboy ${ }^{22}$ demonstrated the identification of $2 \mathrm{~mm}$ thick plastics like nylon, polyethylene within a $10 \mathrm{~mm}$ thick PMMA block with contrast of up to $28 \%$. It is not possible to distinguish them by using conventional $\mathrm{x}$-ray imaging technique. 
The material-specific nature of the coherent scatter imaging technique also has a variety of industrial applications such as detection of contamination in food, application in the oil industry, in the chemical process industry, airport baggage inspection and the sorting of plastics from waste materials. ${ }^{23}$

In this project the coherent scatter imaging technique is used to make projection scatter images of thin plastic targets. We used projection scatter imaging technique to show the angle sensitive contrast of the low $\mathrm{Z}$ materials. The details of the experimental technique and procedure are given in chapter 3.

\subsubsection{Incoherent scatter imaging}

In the diagnostic energy range, incoherent or Compton scattering is the dominant attenuating process in the human body. A number of investigators over the years engaged to utilize the information carried by the photons scattered incoherently. The Harding group, ${ }^{24,}{ }^{25}$ using tomographic system based on Compton scatter, demonstrated that this system is superior to conventional CT for imaging radiologically thin objects. A schematic diagram of their Compton scatter imaging system is shown in figure 1.2. The collimated x-ray beam is passed through the object and induces scatter events. The scattered photons, after passing through the slit collimators, are detected by a detector array. To image sequentially all voxels along the primary beam the detector array can be moved. They also demonstrated that by using dual-energy Compton scatter imaging technique the time needed for scatter densitometry measurements is substantially reduced.

Different research groups used Compton scatter imaging system with different geometries for imaging backscatter and transverse body sections. Jacobs and Kenney ${ }^{26}$ 
proposed a geometry for backscatter radiography. In their technique, a collimated x-ray beam scanned the object and the uncollimated scattered photons are detected by largearea detectors oriented adjacent to primary beam. Herr et $a .^{27}$ devised a Compton backscatter imaging (CBI) system using a mechanically rastered flying spot $\mathrm{x}$ ray beam and a single detector which consisted of a large area sodium iodide crystal, photomultiplier tube, and a line-focus collimator. Their system is very efficient in detecting the scattered $\mathrm{x}$ rays which means relatively low $\mathrm{x}$-ray exposure is required to image an object.

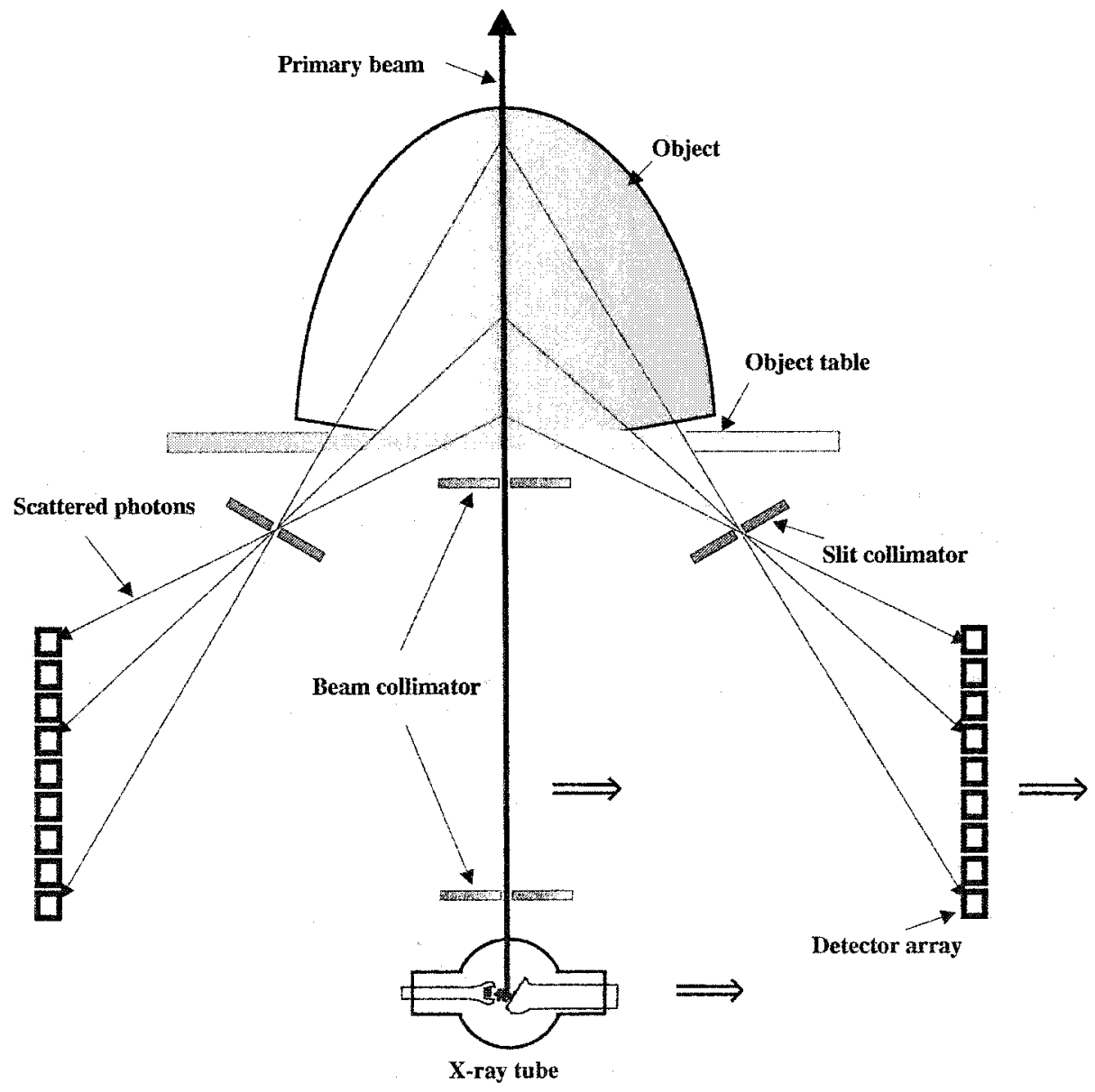

Figure 1.2 Schematic of Compton scatter scanner ${ }^{25}$ for imaging back-scattered photons. 


\subsection{Concept for making scatter images}

A well-collimated $\mathrm{x}$-ray system is the basic requirement for coherent scatter imaging technique. Also for a quick scan of a target to make the projection scatter image a multibeam collimation system is needed. This project was about to design and test a multibeam hexagonal shaped collimation geometry for coherent scatter imaging system.

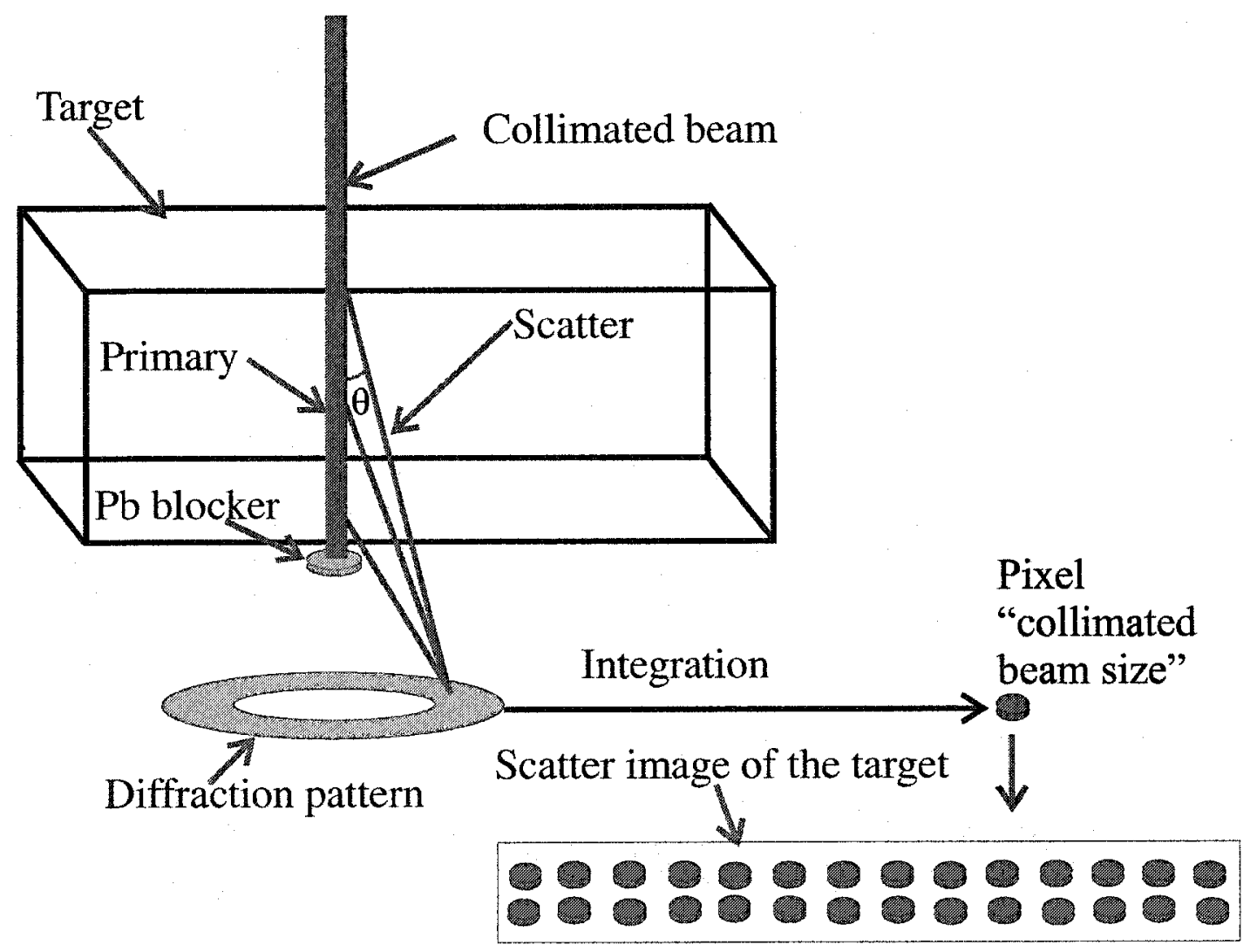

Figure 1.3 Schematic illustration of making a scatter projection image.

The concept for making a scatter image is shown schematically in figure 1.3. The collimated primary $\mathrm{x}$-ray beam after passing through the target is stopped by the lead blocker. The circularly-symmetric diffraction patterns of the targets are recorded on the 
CR storage plate. The intensities of the recorded diffraction patterns are integrated in terms of concentric rings and intensity profiles are obtained as a function of radius (scatter angle). The average of the integrated intensity of the ring selected from each pattern is displayed as a pixel in the scatter image.

To scan a target for making the scatter image both the target and the detector should be moved simultaneously. In the multi-beam hexagonal collimation imaging system the spatial resolution can be improved by moving the target such that the maximum area between the beams is covered.

\subsection{Motivation and objectives}

The objective of the research was to investigate projection imaging using scattered radiation. I designed and tested a seven beam hexagonal geometry collimation system for recording the scatter patterns of $1 \mathrm{~cm}$ thick amorphous materials. The projection scatter images were made from these measurements either by using average intensity of the whole scatter pattern as a pixel in the scatter image display or by integrating a restricted angular range of the scatter pattern and using its average intensity as a pixel. For the potential application of use of scatter imaging technique in the medical field, observations on a thick human size phantom are needed. Therefore, the scatter patterns of thick water phantoms embedded with different types of plastics were also investigated.

Portions of this work were presented at the 2004 annual scientific meeting of the Canadian Organization of Medical Physicists (COMP) ${ }^{28}$ and at the 2004 SPIE: Photonics North conference. ${ }^{29}$ 


\subsection{Thesis outline}

Chapter 2 consists of basic theory related to this project. In the diagnostic energy range the three main interaction processes between photons and matter are discussed briefly.

Chapter 3 discusses the design and experimental techniques for the single beam and the seven beam geometry. The procedure for making a transmission and an anglesensitive projection scatter image is also illustrated.

Chapter 4 is about recording the scatter patterns of thin targets using single-beam geometry and their analysis.

In chapter 5, the results obtained using seven-beam hexagonal geometry are presented and analysed. The transmission and scatter projection images are made from these results. The angle-sensitive property of scatter images is also discussed.

Chapter 6 deals with the analysis of thick water/plastic phantoms. The signals from plastics of different types and different thicknesses placed at different depths in a 10 $\mathrm{cm}$ and $20 \mathrm{~cm}$ thick water phantom are described in this chapter.

Chapter 7 gives conclusions and future work. 


\section{Chapter 2}

\section{Theory}

In its passage through matter, an $\mathrm{x}$-ray photon in the diagnostic energy range $(10-150$ $\mathrm{keV}$ ) is attenuated by photoelectric absorption, incoherent or Compton scattering, and coherent or Rayleigh scattering. In low atomic number materials, the total attenuation cross section is dominated Compton scattering. Figure 2.1 shows the interaction crosssections in carbon at different energies.

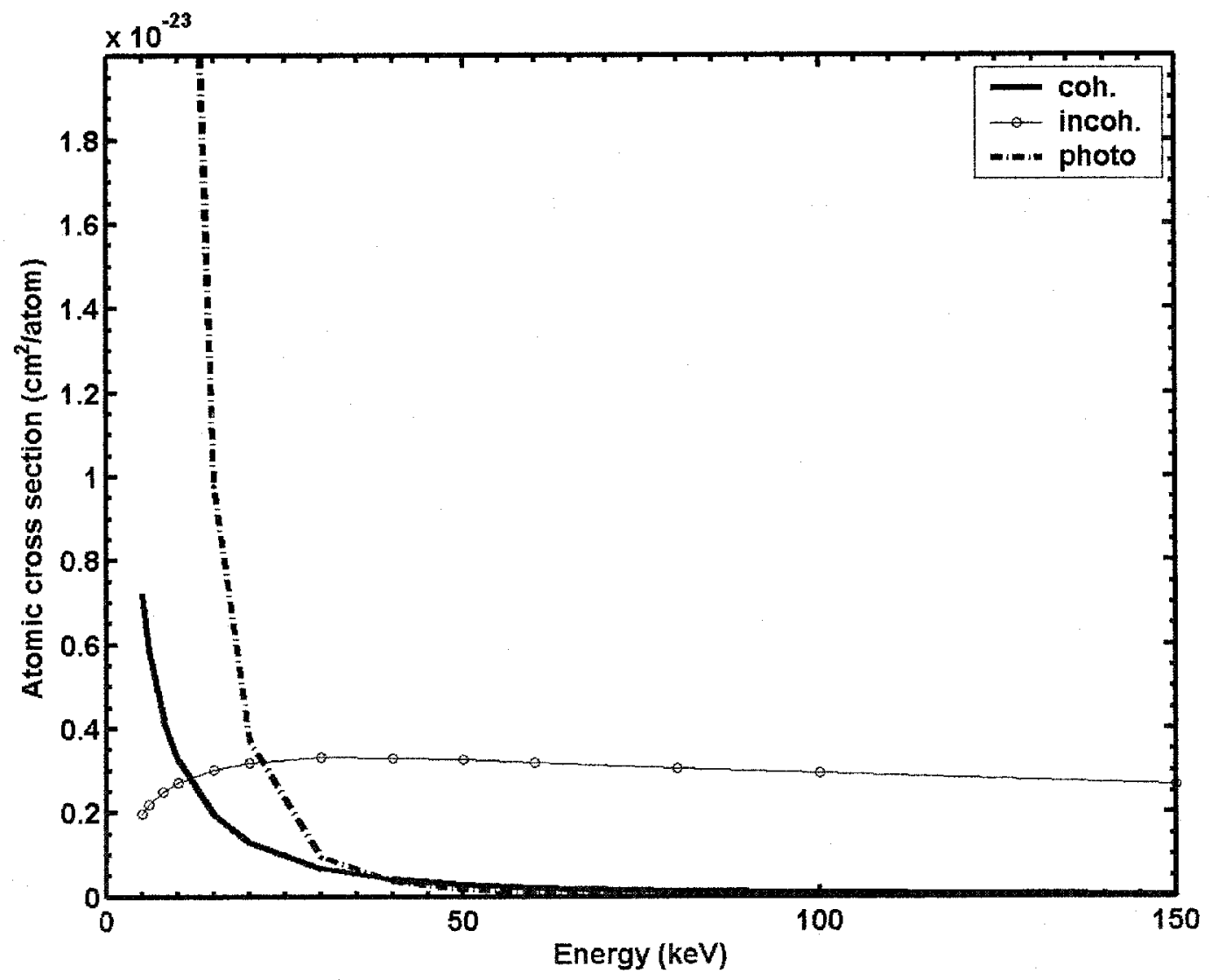

Figure 2.1 The three interaction processes in carbon at different energies (data from Table A-4b of Ref. 1). 


\subsection{Photoelectric effect}

In this process, the incident photon is absorbed by the atom and a bound electron (photoelectron) is emitted from the atomic shell. The kinetic energy of the electron is given by

$$
\mathrm{T}=\mathrm{hv}-\mathrm{E}_{\mathrm{s}}
$$

where $h v$ is the $\mathrm{x}$-ray photon energy and $E_{\mathrm{s}}$ is the binding energy of the shell from which the electron is ejected. The photoelectric process is predominant at relatively low energy. This process also depends upon the atomic number of the interacting material. The photoelectric cross section per electron is given approximately as ${ }^{1}$

$$
\tau \propto \frac{\mathrm{Z}^{\mathrm{n}}}{\mathrm{E}^{3}} \quad\left(\frac{\text { area }}{\text { bound electron }}\right)
$$

where $\mathrm{n}=3$ for high $\mathrm{Z}$ materials and $\mathrm{n}=3.8$ for low $\mathrm{Z}$ materials. There is an increase in cross section at absorption edges.

\subsection{Coherent Scattering}

There are two models for the coherent scattering process. In the simple model, Thomson (Thomson scattering) proposed a relationship for the elastic scattering cross section for electromagnetic waves from a free electron. The scattering of electromagnetic waves from systems of bound atomic electrons is discussed in the model proposed by Rayleigh (Rayleigh scattering). 


\subsubsection{Thomson scattering}

Thomson scattering involves elastic scattering of electromagnetic waves from a free electron. According to electromagnetic theory, when an $x$ - or $\gamma$-ray of frequency $v_{0}$ is incident upon a free electron, the electron vibrates with the same frequency $v_{0}$ and hence emits radiation of the same phase and frequency as the incident beam.

The Thomson scattering cross-section for a free electron is

$$
\frac{\mathrm{d}_{\mathrm{e}} \sigma_{\mathrm{o}}}{\mathrm{d} \Omega}=\frac{\mathrm{r}_{\mathrm{o}}^{2}}{2}\left(1+\cos ^{2} \theta\right) \quad\left(\frac{\text { area }}{\text { free electron } \cdot \mathrm{sr}}\right)
$$

where $r_{0}$ is the classical electron radius and $\theta$ is the scattering angle. The total crosssection is obtained by integrating equation (5) over all solid angles,

$$
\sigma_{\mathrm{o}}=\frac{8 \pi \mathrm{r}_{\mathrm{o}}^{2}}{3}=0.665 \times 10^{-24} \quad\left(\frac{\mathrm{cm}^{2}}{\text { free electron }}\right)
$$

\subsubsection{Rayleigh scattering}

Rayleigh scattering is defined as elastic scattering of electromagnetic waves from bound atomic electrons. This is a complicated process as compared to Thomson scattering. Due to the interference of elastically scattered photons the scattered amplitude from an atom is not simply the amplitude from a single free electron times the number of electrons in the atom. In the low-angular range the scattered amplitudes add up in phase and, as a result of constructive interference, elastic scattering from bound electrons is peaked in the forward direction. As the scattering angle increases the destructive interference also rises. The elastic scattering wave amplitude from an atom is defined as the product of the elastic scattering by a free electron and coherent scattering form factor $F(x, Z)$, where $Z$ 
is the atomic number, i.e., the number of electrons in the atom, and $\mathrm{x}$ is the momentum transfer parameter defined as

$$
\mathrm{x}=\frac{1}{\lambda} \sin \left(\frac{\theta}{2}\right)=\frac{\mathrm{E}}{\mathrm{hc}} \sin \left(\frac{\theta}{2}\right)
$$

where $\theta$ is the scatter angle and $\mathrm{E}$ is the energy of the interacting photons.

The Rayleigh differential atomic scattering cross section from bound electrons of a single atom can be given by,

$$
\frac{\mathrm{d}_{\mathrm{a}} \sigma_{\mathrm{R}}}{\mathrm{d} \Omega}=\frac{\mathrm{d}_{\mathrm{e}} \sigma_{\mathrm{o}}}{\mathrm{d} \Omega} \mathrm{F}_{\mathrm{atom}}^{2}(\mathrm{x}, \mathrm{Z}) \quad\left(\frac{\text { area }}{\text { atom } \cdot \mathrm{sr}}\right)
$$

where $\frac{d_{e} \sigma_{o}}{d \Omega}$ is the Thomson scattering cross-section for a free electron from equation (5). The square of $F_{\text {atom }}(x, Z)$ is a scale factor on the scattered wave intensity. By definition, the atomic form factor is the momentum space Fourier transform of the charge distribution.

When $\mathrm{x}$ rays are scattered by an assembly of atoms ${ }^{30}$ (molecule), there will be an interference effect between those $\mathrm{x}$ rays which are scattered by different atoms but in the same direction. So in a molecule, in addition to intra-atomic interference, inter-atomic interference also affects the resultant scattered signal.

An ideal gas is considered to be the simplest system whose properties can be investigated using scattering as a diagnostic tool. In an ideal gas there is no interaction between the molecules and so intermolecular interference can be neglected. It is easy to deduce information about its molecular structure because interference effects are only from $x$ rays scattered by different parts of the same molecule. Due to the random 
orientation of molecules, the diffraction patterns are circularly symmetric and give information about the structure of a spherically average molecule.

When $\mathrm{x}$ rays are scattered by the molecules in a liquid or solid, in addition to intra-molecular interference, inter-molecular interference also become important. The molecules in liquids and amorphous solids are irregularly arranged but not completely random. As compared to amorphous solids where the positions of molecules are fixed, the molecules in liquid are free to move. The $\mathrm{x}$-ray diffraction pattern gives information about the structure of a scatterer averaged over the time taken to record the pattern. The technique cannot detect the changing position of the molecule in a liquid but only gives information about their average irregular positions. As a result the same effects are observed from the diffraction patterns from liquids and amorphous solids. The arrangements of molecules in these materials are not truly random and interference effects appear in the intensity distribution and because of intensity peaks these materials can be recognized.

\subsection{Incoherent scattering}

The Compton or incoherent scattering process relates the energies of the incident and the scattered photons and the scattering angle $\theta$ as follows:

$$
h v^{\prime}=\frac{h v}{1+\frac{h v}{m_{0} c^{2}}(1-\cos \theta)}
$$

where $\mathrm{m}_{0} \mathrm{c}^{2}$ is the rest mass energy of the electron. Consider a system in which a free electron is at rest and a photon with energy hv and momentum $\frac{h v}{c}$ interacts with the 
electron. After the interaction the electron has energy $\mathrm{T}$ and momentum $\mathrm{p}$ and angle $\phi$ and the photon has less energy $h v^{\prime}$ and momentum $\frac{h v^{\prime}}{c}$ scattered at an angle $\theta$ with respect to the primary direction. Klein and Nishina showed that the differential cross section per unit solid angle per unit solid angle for such interaction can be given as ${ }^{1}$

$$
\frac{\mathrm{d}_{\mathrm{e}} \sigma_{\mathrm{INC}}}{\mathrm{d} \Omega}=\frac{\mathrm{d}_{\mathrm{e}} \sigma_{\mathrm{o}}}{\mathrm{d} \Omega} \mathrm{F}_{\mathrm{KN}}(\mathrm{h} \nu, \theta) \quad\left(\frac{\text { area }}{\text { free electron } \cdot \mathrm{sr}}\right)
$$

where $F_{K N}$ is the Klein-Nishina factor which is given by

$$
\mathrm{F}_{\mathrm{KN}}(\mathrm{h} \nu, \theta)=\left(\frac{1}{1+\alpha(1-\cos \theta)}\right)^{2}\left(1+\frac{\alpha^{2}(1-\cos \theta)^{2}}{\left[1+\alpha(1-\cos \theta)\left(1+\cos ^{2} \theta\right)\right.}\right)
$$

where $\alpha\left(=\frac{\mathrm{h} v}{\mathrm{~m}_{0} \mathrm{c}^{2}}\right)$ is the ratio of the energy of the photon to the electron rest energy. The factor $F_{K N}$ is always less than or equal to 1. During inelastic interaction, the photon energy is transferred to the electron and in this case $F_{K N}$ is less than 1. When the scattering angle $\theta$ is zero or energy ratio $\alpha$ is very small $F_{\mathrm{KN}}=1$. There is no energy exchange between photon and electron during the interaction, and the process is simply Thomson scattering.

The interaction of a photon with a free and stationary electron is an ideal case. In reality the electrons in an atom are in motion and are bound. So the motion of the electron and the energy required for the ejection of the electron is also taken into account. For bound electrons the Klein-Nishina formula is modified by multiplying equation (11) by a factor $S(x, Z)$, where $S$ is called the incoherent scattering function and depends on parameter $\mathrm{x}$ (equation (7)) and the atomic number $\mathrm{Z}$. The total differential incoherent cross section per atom becomes, 


$$
\frac{\mathrm{d}_{\mathrm{a}} \sigma_{\mathrm{INC}}}{\mathrm{d} \Omega}=\frac{\mathrm{d}_{\mathrm{e}} \sigma_{\mathrm{o}}}{\mathrm{d} \Omega} \mathrm{F}_{\mathrm{KN}} \mathrm{S}(\mathrm{x}, \mathrm{Z}) \quad\left(\frac{\text { area }}{\text { atom } \cdot \mathrm{sr}}\right)
$$

\subsection{Total scattering cross section}

The total atomic cross section for scattering processes is the summation of the Rayleigh (coherent) and Compton (incoherent) scattering cross sections, given by,

$$
\frac{\mathrm{d}_{\mathrm{a}} \sigma}{\mathrm{d} \Omega}=\frac{\mathrm{d}_{\mathrm{a}} \sigma_{\mathrm{R}}}{\mathrm{d} \Omega}+\frac{\mathrm{d}_{\mathrm{a}} \sigma_{\mathrm{INC}}}{\mathrm{d} \Omega}
$$

Using equations (8), (12) in equation (13),

$$
\begin{aligned}
\frac{d_{\mathrm{a}} \sigma}{\mathrm{d} \Omega} & =\frac{\mathrm{d}_{\mathrm{e}} \sigma_{\mathrm{o}}}{\mathrm{d} \Omega}\left[\mathrm{F}_{\mathrm{KN}} \mathrm{S}(\mathrm{x}, \mathrm{Z})+\mathrm{F}^{2}(\mathrm{x}, \mathrm{Z})\right] \\
& =\frac{\mathrm{r}_{\mathrm{o}}^{2}}{2}\left(1+\cos ^{2} \theta\right)\left[\mathrm{F}_{\mathrm{KN}} \mathrm{S}(\mathrm{x}, \mathrm{Z})+\mathrm{F}^{2}(\mathrm{x}, \mathrm{Z})\right] .
\end{aligned}
$$




\section{Chapter 3}

\section{Collimation systems design and experimental setup}

The design parameters of single and seven-beam collimation systems are discussed in this chapter. The experimental geometries for recording scatter patterns are explained. The $x-$ ray tube, its operating parameters, and the detector used for these measurements are described. The procedures for recording the diffraction pattern, obtaining the radial intensity profile of the pattern and the corresponding pixel value for the scatter image display are discussed. The contrast of the scatter images changes with angle. The technique for making the angle-sensitive scatter images is also explained in this chapter.

\subsection{Collimation systems}

\subsubsection{Single beam}

The basic requirement for recording the scatter pattern is a precise collimation system so that low-angle scattered photons can be distinguished from the primary. For the single beam geometry, a $1.1 \mathrm{~mm}$ diameter hole was drilled in a $3.2 \mathrm{~mm}$ thick lead sheet to make a pinhole collimator. Even with $120 \mathrm{keV} x$ rays the transmission through the lead sheet is negligible.

To make the beam more clean before it irradiates the target, a second collimator of the above size is positioned a few centimeters from the first one. The experimental setup for single beam geometry will be discussed in section 3.2. Using this single beam geometry, the ring shaped scatter patterns of different amorphous materials are recorded. 


\subsubsection{Seven beam hexagonal geometry}

The scatter patterns and their corresponding radial profiles measured using single beam geometry showed the characteristics of the target and hence provided a useful tool for imaging the low density materials. However, to scan a sizeable inhomogeneous target by the single beam geometry would be a time consuming process. For a quicker scan we designed a seven-beam hexagonal geometry. We used hexagonal shape because it is the most efficient way to use as many beams as possible in a limited space. The size of the scatter patterns obtained using single beam geometry and the form factors measured in our lab provide basic information for the design of a multi-beam collimation system. In our single-beam experiment the peak to peak measured diameter of the water ring was about $54 \mathrm{~mm}$. The distance from the centre of the target to the detector was about 18.5 $\mathrm{cm}$ in this experimental setup. Taking the average energy to be $27 \mathrm{keV}(50 \mathrm{kVp}$ with $\mathrm{Sn}$ filter) the parameter $\mathrm{x}$ is estimated to be about $1.58 \mathrm{~nm}^{-1}$. The ring size can also be predicted by using the measured value of coherent scatter form factor $F(x, Z),{ }^{9,10,20}$

Using $1.58 \mathrm{~nm}^{-1}$ as $\mathrm{x}$ value of water, the ring diameter of water for higher energies can be predicted. For example, for the distance from the centre of the target to the detector $18.5 \mathrm{~cm}$ the estimated ring diameter of water for the average energy of $50 \mathrm{keV}$ ( $70 \mathrm{kVp}$ with Ho filter), is about $29 \mathrm{~mm}$. To avoid the overlapping of scatter patterns in a seven-beam hexagonal collimation system design, the separation between the adjacent primaries in the detector plane was set at $33 \mathrm{~mm}$. The scatter patterns were further separated by reducing the magnification, using a detector to target distance of $14 \mathrm{~cm}$ rather than $18.5 \mathrm{~cm}$ for the seven-beam geometry measurements. 
The distance between adjacent beams on the detector plane is adjusted based on these calculations and measurements such that the scatter patterns produced by different beams will not overlap. To get a clean beam two lead collimators are used, each with seven pinholes in a hexagonal geometry. The holes are drilled in a $3.2 \mathrm{~mm}$ thick lead sheet. Figure 3.1 shows the distance from source to seven beam collimators and source to detector.

Distance from the source to the first seven-beam collimator $=s_{1}=18.7 \mathrm{~cm}$

Distance from the source to the second seven-beam collimator $=\mathrm{s}_{2}=30.7 \mathrm{~cm}$

Distance from the source to the detector $=\mathrm{s}_{3}=51.75 \mathrm{~cm}$

Let $r_{3}$ be the distance between two beams in the detector plane, $r_{3}=3.3 \mathrm{~cm}$.

From figure 3.1, the triangles $\mathrm{SC}_{1} \mathrm{C}_{1}^{\prime}, \mathrm{SC}_{2} \mathrm{C}_{2}^{\prime}$ and $\mathrm{SDD}^{\prime}$ share the angle at the vertex $\mathrm{S}$ and the sides opposite to the angle are parallel so they are similar triangles.

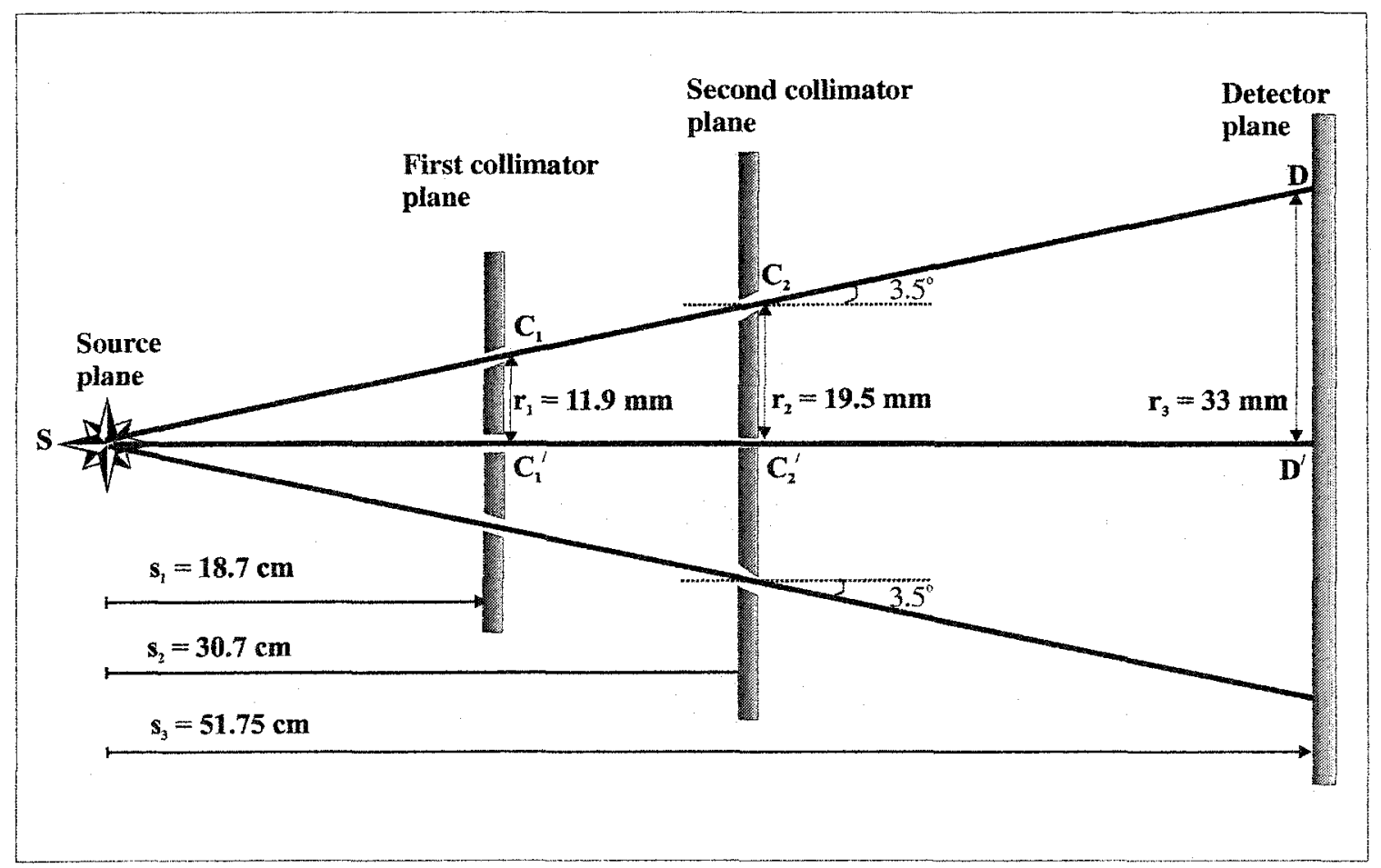

Figure 3.1 Construction geometry of the seven-beam collimation system. 
Let $r_{1}$ and $r_{2}$ be the separation between the beams in the first and second seven-beam collimator plane respectively. Using the similar triangle relation, the separation of primaries on the first and second collimator plane are

$$
\frac{\mathrm{r}_{1}}{\mathrm{~s}_{1}}=\frac{\mathrm{r}_{2}}{\mathrm{~s}_{2}}=\frac{\mathrm{r}_{3}}{\mathrm{~s}_{3}}, \mathrm{r}_{1}=11.9 \mathrm{~mm} \text { and } \mathrm{r}_{2}=19.5 \mathrm{~mm}
$$

Collimator 1: The diameter of each hole is $2.5 \mathrm{~mm}$ and separation between the holes is $11.9 \mathrm{~mm}$. The central hole is straight and the surrounding six holes are at an angle of $3.5^{\circ}$ so as to be focused on the x-ray tube focal spot.

Collimator 2: The diameter of each hole is $1.5 \mathrm{~mm}$ and separation between the holes is $19.5 \mathrm{~mm}$. These holes are the limiting apertures. The central hole is straight but the surrounding six holes are at an angle of $3.5^{\circ}$.

The separation between the collimators is $12 \mathrm{~cm}$ and they are enclosed in a lead cylinder. The collimators were fabricated by the Science Technology Centre (STC) at Carleton University. A schematic of the collimators is shown in figure 3.2 . A $3.17 \mathrm{~cm}$ thick lead disc having a central hole of diameter $2.5 \mathrm{~cm}$ at a distance of $7.5 \mathrm{~cm}$ from the focal spot is also shown. This lead disc not only confines the beam size but also the filters (aluminium, tin, and holmium) used to narrow the emitted spectrum are placed on it. 


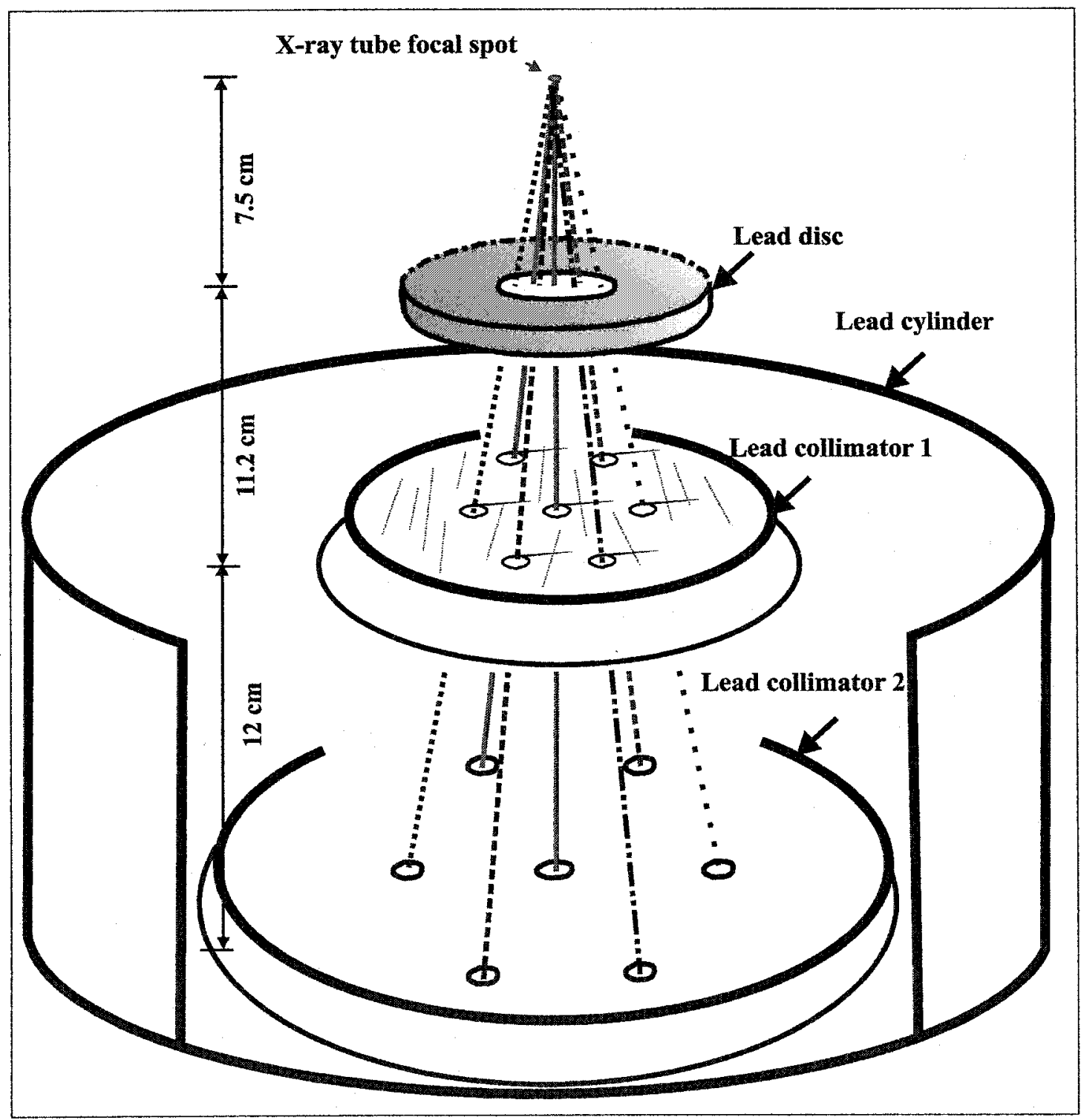

Figure 3.2. Seven pinhole hexagonal shaped collimation system. 


\subsection{Experimental setup for single-beam geometry}

Figure 3.3 shows the experimental configuration for the single-beam geometry used for scatter imaging. Polychromatic $\mathrm{x}$ rays are generated by using a rotating $\mathrm{W}$-anode $\mathrm{x}$-ray tube (Picker Dunlee model PX 412A, insert DU 304) operated at up to $120 \mathrm{kVp}$; the large focal spot (nominal size $1.2 \mathrm{~mm}$ ) is used for these measurements. The $\mathrm{x}$-ray tube is powered by a single phase generator (Picker GX550). For these measurements the tube is operated at $50 \mathrm{kVp} 6000 \mathrm{mAs}$. The distance from the $\mathrm{x}$-ray tube focal spot to the detector is $51 \mathrm{~cm}$ and the distance between the centre of the sample and the detector is $18.5 \mathrm{~cm}$. To narrow the emitted $\mathrm{x}$-ray spectrum, a tin filter $(\mathrm{Z}=50$, K-edge $29.2 \mathrm{keV})$ of thickness $25 \mu \mathrm{m}$ is mounted just outside the exit window of the tube. An aluminium filter of 2.3 mm thickness is used just after the tin filter for the absorption of fluorescence from the tin and also to further suppress low-energy photons in the $\mathrm{x}$-ray tube spectrum. The filtered $\mathrm{x}$ rays are collimated using two collimators each having $1 \mathrm{~mm}$ diameter. The sample material is placed about $1 \mathrm{~cm}$ from the second collimator. The collimated $\mathrm{x}$-ray beam irradiates the $1 \mathrm{~cm}$ thick uniform sample. The transmitted primary beam is stopped using a $3 \mathrm{~mm}$ thick lead blocker and the scattered photons produced by the sample are recorded by the CR plate. ${ }^{31}$ The Matlab ${ }^{32}$ Image Processing Toolbox is used for processing the data and displaying the image. 


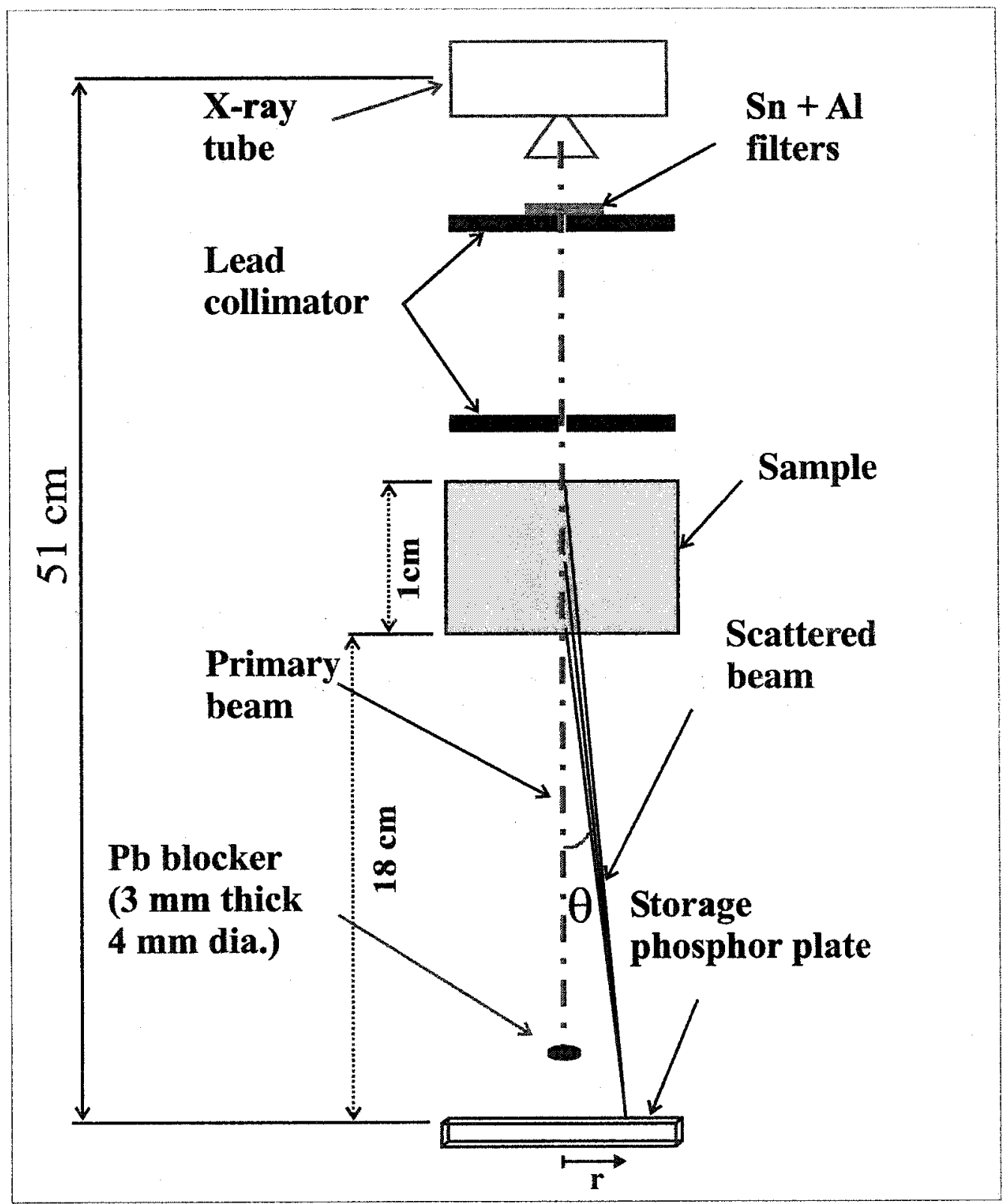

Figure 3.3 Experimental setup for single-beam collimation geometry. 


\subsection{Experimental setup for seven-beam hexagonal geometry}

Figure 3.4 shows the experimental configuration for the seven-beam hexagonal geometry. The tube is operated at $70 \mathrm{kVp} 2500 \mathrm{mAs}$ and a $127 \mu \mathrm{m}$ thick holmium filter $(\mathrm{Z}=67, \mathrm{~K}$ edge $55.6 \mathrm{keV}$ ) is used to narrow the $\mathrm{x}$-ray spectrum. The collimated $\mathrm{x}$-ray beams irradiate the seven homogeneous samples, each having thickness $10 \mathrm{~mm}$. The distance from the $\mathrm{x}$-ray tube focal spot to the centre of the sample is $37.75 \mathrm{~cm}$ and the distance from the centre of the sample to the detector is $14 \mathrm{~cm}$.

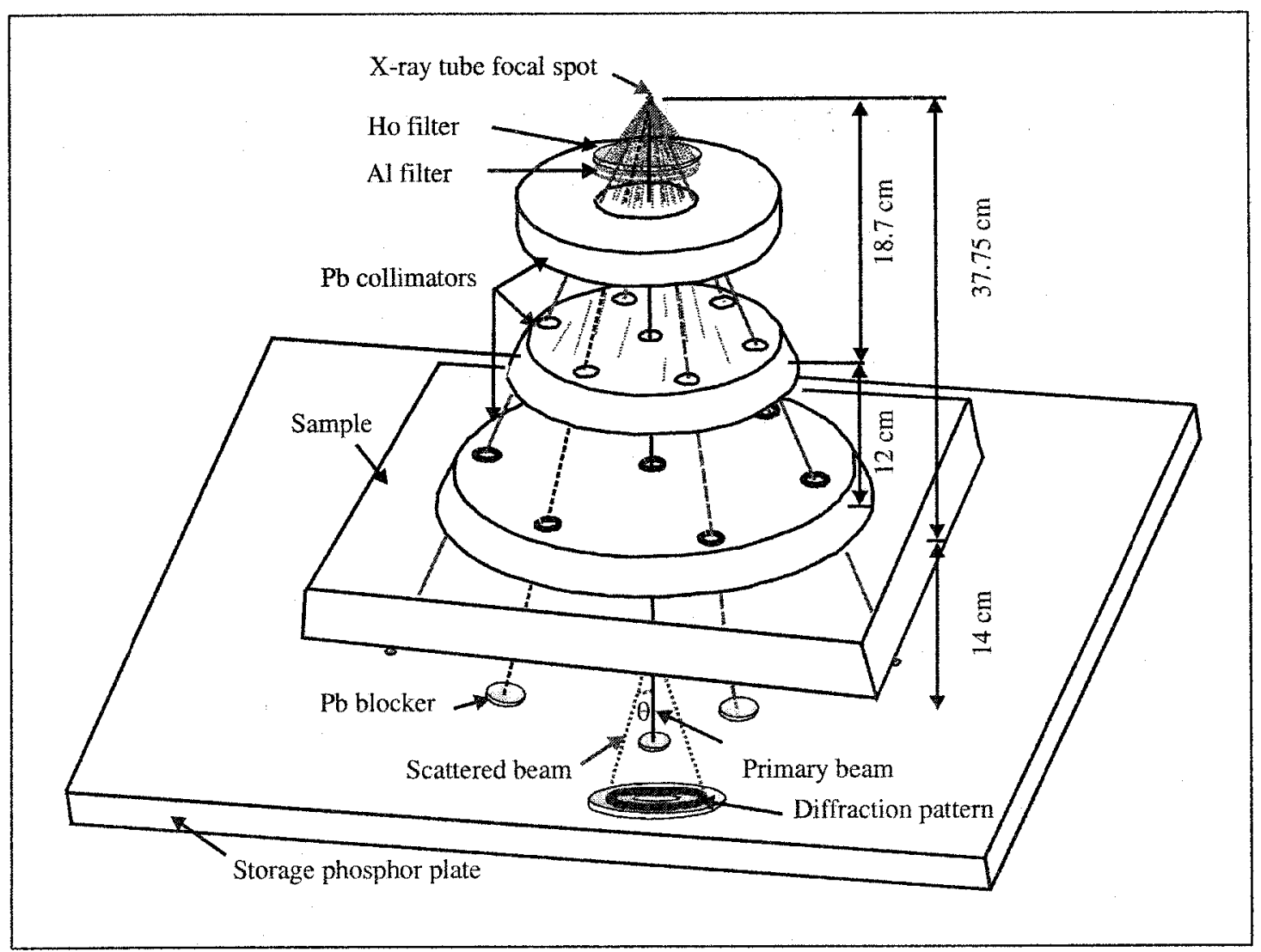

Figure 3.4 Experimental setup for seven-beam hexagonal collimation geometry. 


\subsection{Scatter patterns to scatter image display}

The procedure for making a scatter image from the diffraction patterns is as follows. The intensities of the recorded diffraction patterns are integrated in terms of concentric rings and intensity profiles are obtained as a function of radius (scatter angle). The average of the integrated intensity of the ring selected from each pattern is displayed as a pixel in the scatter image. Figure 3.5(a) shows concentric rings overlaid on a single diffraction pattern. The intensity profile of the pattern as a function of radius (scatter angle) is shown. The integrated intensity is used as a pixel in the scatter image. The pixel width is taken to be the spacing of the beam measurements. To show the material-specific contrast as a function of angle one can integrate the intensity of a portion of the pattern and display its average as a pixel in the scatter image. Figure 3.5(c) shows the pixel obtained for the scatter image by integrating the intensity profile over the angles ranging from $1.5^{\circ}$ to $3.1^{\circ}$.

\subsection{Thick water phantom}

A cubic water phantom is used for thick water/plastic measurements. The dimensions of the phantom are $30 \times 30 \times 30 \mathrm{~cm}$. The cube walls are made of $1.3 \mathrm{~cm}$ thick PMMA. For $10 \mathrm{~cm}$ and $20 \mathrm{~cm}$ thick water phantom measurements the cube was filled with water at the required level. To study the effect of presence of plastic in a water phantom, different types and thicknesses of plastics are positioned in the water phantom. For water/plastic phantom measurements, to support the plastics at different depths hollow plastic cylinders of different length are used. Two locations for $2.6 \mathrm{~cm}$ thick plastic in a $20 \mathrm{~cm}$ thick water phantom are shown in figure 3.6. The distance from the lower end of the phantom to the screen is $15 \mathrm{~cm}$ for these measurements. 

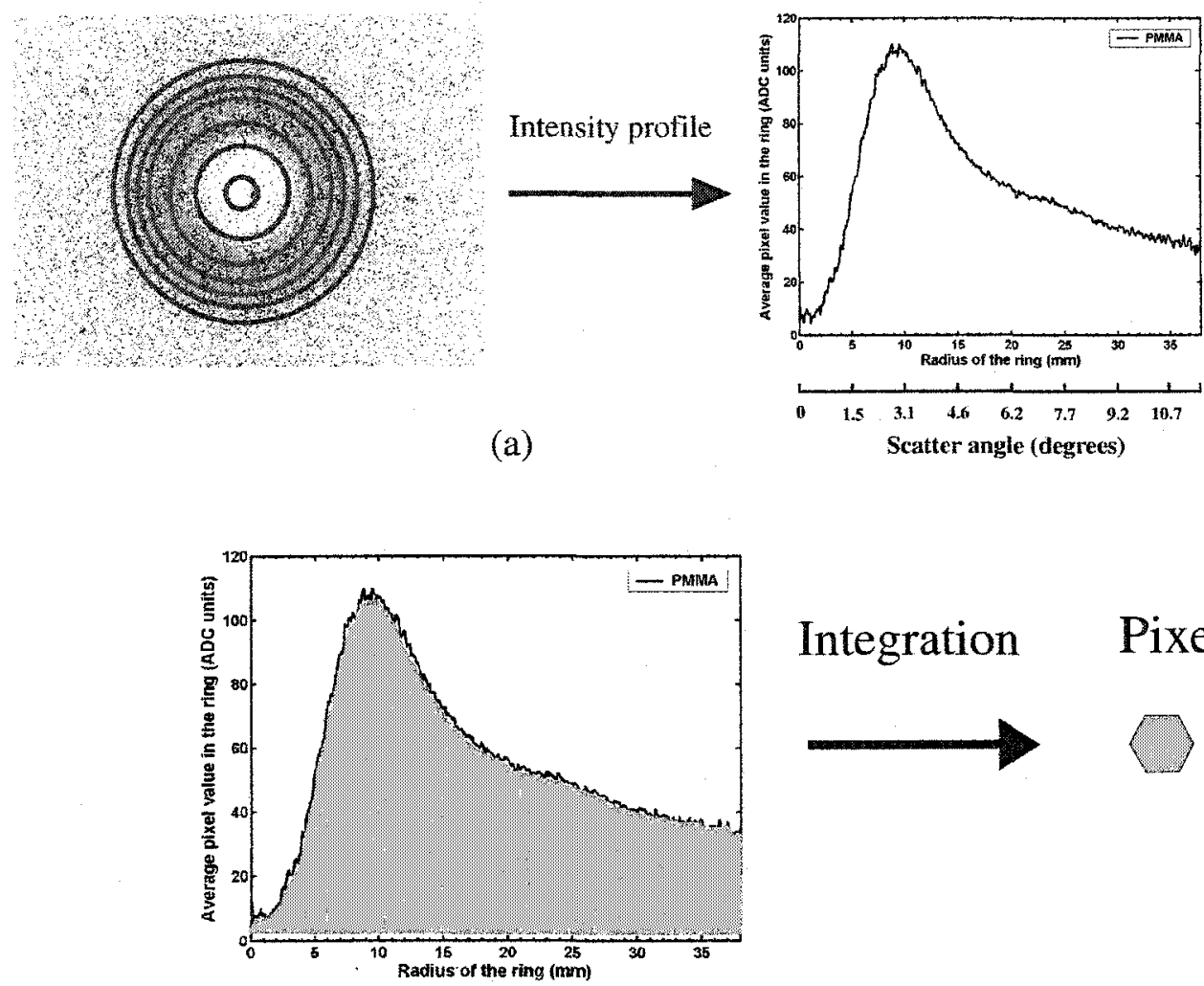

Integration Pixel

(b)

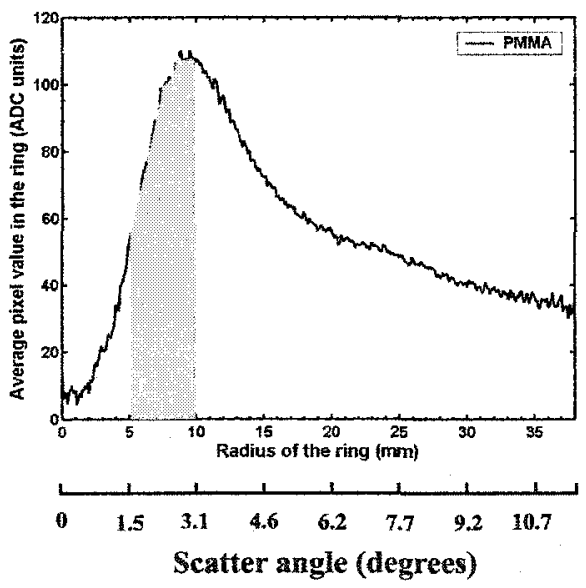

Integration Pixel

(c)

Figure 3.5 (a) Schematic illustration of obtaining the radial intensity profile, (b) integration of the intensity profile and using it as a pixel for the scatter image display, (c) the pixel value obtained by integrating the radial profile over angular range $1.5^{\circ}$ to $3.1^{\circ}$. 


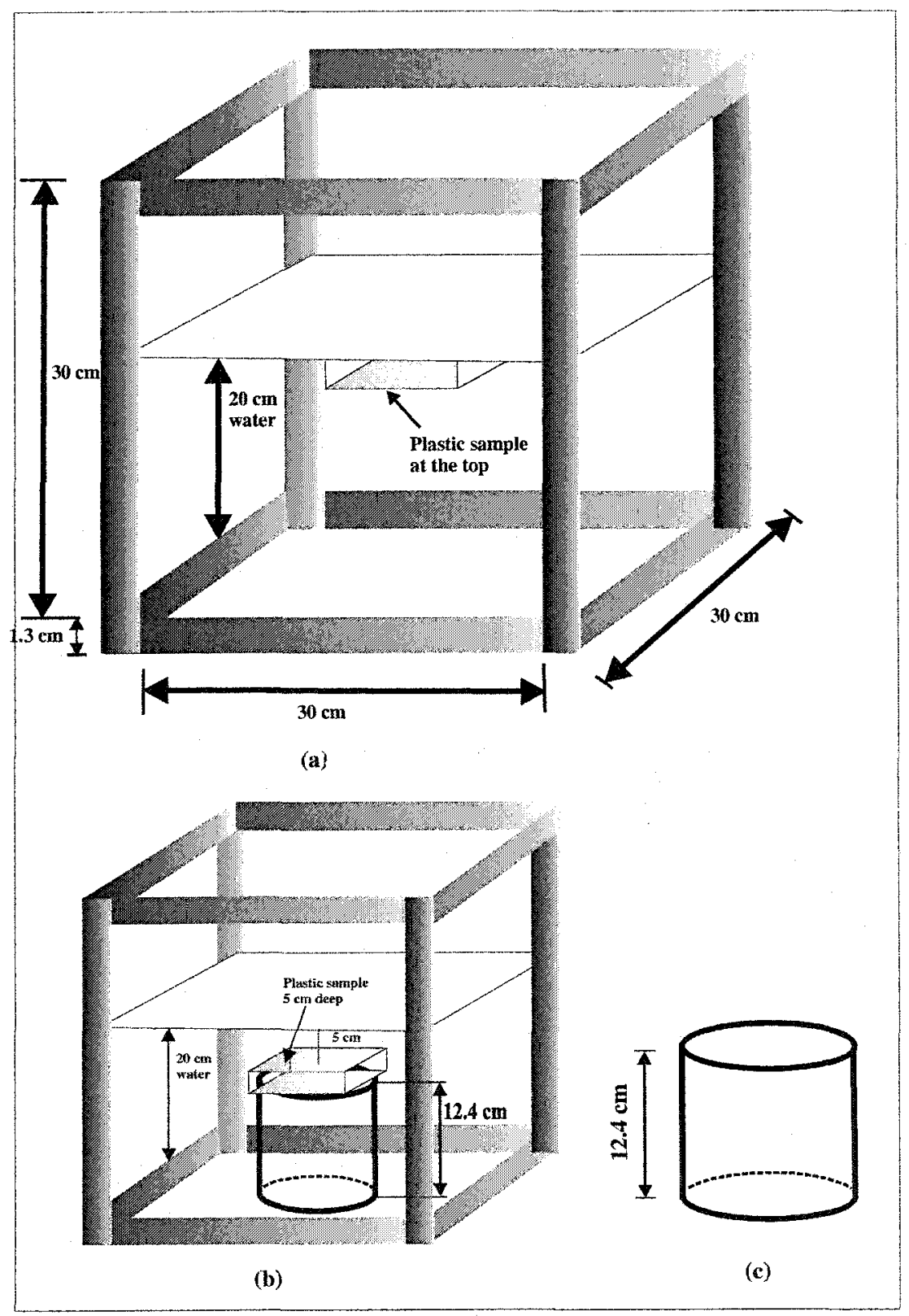

Figure 3.6 The cubical phantom used for thick sample measurements is made of $1.3 \mathrm{~cm}$ thick PMMA. Two locations of $2.6 \mathrm{~cm}$ thick plastic target are shown. (a) Plastic sample at the top in a $20 \mathrm{~cm}$ thick water phantom, (b) plastic sample at $5 \mathrm{~cm}$ depth in a $20 \mathrm{~cm}$ thick water phantom, (c) hollow plastic cylinder used to hold sample in part (b). 


\subsection{Detector (CR plate)}

We used a storage phosphor plate (Bio-Rad, K-type imaging screen ${ }^{31}$ ) to record the diffraction patterns. The screen is composed of a barium fluorobromide material doped with europium as an activator $(\mathrm{BaFBr}: \mathrm{Eu})$ and is relatively insensitive to visible light. The size of the screen is $20 \mathrm{~cm} \times 25 \mathrm{~cm}$ and it is housed in a cassette. This can be used in room light so it is easy to handle. The imaging screen is exposed to bright light from a film view box for about 10 minutes to remove any background or residual image. When the screen is exposed to $\mathrm{x}$ rays some of the energy deposited by the radiation is trapped in the phosphor as a latent image. In the next step the exposed screen is scanned by a laser scanner. As each pixel of the screen is scanned, the electrons in the excited states in the area of the latent image return to the ground state and photons of visible frequency are emitted. These photons are precisely measured with a photomultiplier tube. The computer attached to the scanner builds a digital image by tracking each pixel's signal as the scanner head moves over the screen surface. The image is stored as a 16-bit digital file in host computer with a digital matrix size of 2594 × 2000 pixels. The collected image can be saved with file extension "tif" (Tagged Image File format) and analyzed using a Matlab $^{32}$ software package. After scanning the storage phosphor plate is erased by exposing it again to bright light and it is ready for the next exposure. The sampling interval of the reader is $0.1 \mathrm{~mm}$. The maximum spatial frequency that can be displayed without aliasing is $5 \mathrm{lp} / \mathrm{mm}$. 


\subsection{Target materials}

The target materials used for recording the scatter patterns are listed in table 3.1. Although the plastics look similar, they have different molecular structure. The scatter form factor data needed for designing the scatter imaging system are available for plastics because most of the research groups ${ }^{9,10}$ worked on plastic materials. Also it is much easier to handle the plastic targets than the biological samples. The scatter patterns are recorded putting the target in water as well in air. The sample holder made of PMMA used for water, salt and biological samples has a very thin bottom wall. In the seven beam hexagonal geometry, for the measurements in air the seven different types of samples are positioned on a very thin plastic sheet in such a way that each sample is irradiated with an independent beam. This sheet is then mounted on a $4 \mathrm{~cm}$ high aluminium cylinder as shown in figure 3.7. The plastic samples and the sample holder used for water, salt and biological samples are attached to the plastic sheet by using double sided tape. We also used $10 \mathrm{~cm}$ and $20 \mathrm{~cm}$ thick water phantoms embedded with different plastics at different depths. 


\begin{tabular}{|c|c|c|}
\hline Name & Formula/Composition & Thickness \\
\hline Salt & $\mathrm{NaCl}$ & $1 \mathrm{~cm}$ \\
\hline Water & $\mathrm{H}_{2} \mathrm{O}$ & $\begin{array}{c}1 \mathrm{~cm} \\
10 \mathrm{~cm} \\
20 \mathrm{~cm}\end{array}$ \\
\hline Polycarbonate (Lexan) & $\left(\mathrm{C}_{16} \mathrm{H}_{14} \mathrm{O}_{3}\right)_{\mathrm{n}}$ & $\begin{array}{c}1 \mathrm{~cm} \\
1.23 \mathrm{~cm}\end{array}$ \\
\hline Polyethylene & $\left(\mathrm{C}_{2} \mathrm{H}_{4}\right)_{\mathrm{n}}$ & $\begin{array}{c}1 \mathrm{~cm} \\
1.25 \mathrm{~cm}\end{array}$ \\
\hline Polystyrene & $\left(\mathrm{C}_{8} \mathrm{H}_{8} \mathrm{O}_{3}\right)_{\mathrm{n}}$ & $1 \mathrm{~cm}$ \\
\hline Nylon & $\left(\mathrm{C}_{6} \mathrm{H}_{11} \mathrm{NO}\right)_{\mathrm{n}}$ & $\begin{array}{l}1 \mathrm{~cm} \\
1.28 \mathrm{~cm}\end{array}$ \\
\hline Lucite (PMMA) & $\left(\mathrm{C}_{5} \mathrm{H}_{8} \mathrm{O}_{2}\right)_{\mathrm{n}}$ & $\begin{array}{c}1 \mathrm{~cm} \\
1.25 \mathrm{~cm} \\
2.6 \mathrm{~cm} \\
5.2 \mathrm{~cm}\end{array}$ \\
\hline Fat & $\begin{array}{l}\text { H: } 0.119, \mathrm{C}: 0.63, \mathrm{~N}: 7.97 \times 10^{-3} \\
\text { O: } 0.232, \mathrm{Cl}: 1.19 \times 10^{-3}\end{array}$ & $1 \mathrm{~cm}$ \\
\hline Bone & $\mathrm{H}_{8} \mathrm{O}_{26} \mathrm{P}_{9} \mathrm{Ca}_{6}$ & $1 \mathrm{~cm}$ \\
\hline
\end{tabular}

Table 3.1 Target materials, their compositions, ${ }^{9}$ and the thicknesses used for measurements. 


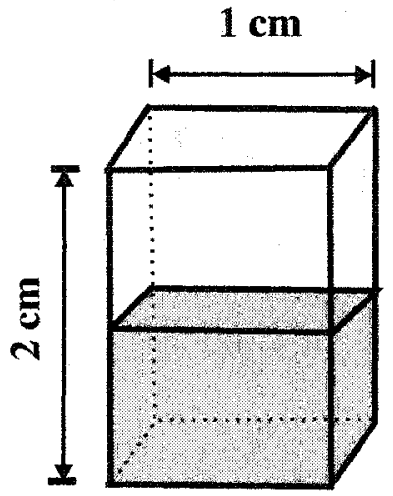

(a)

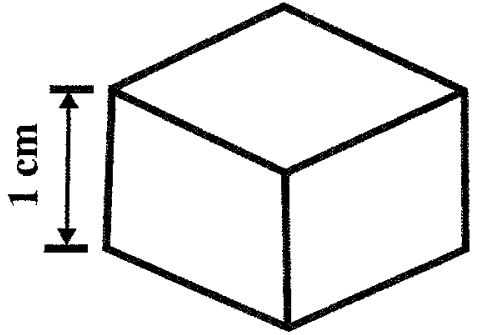

(b)

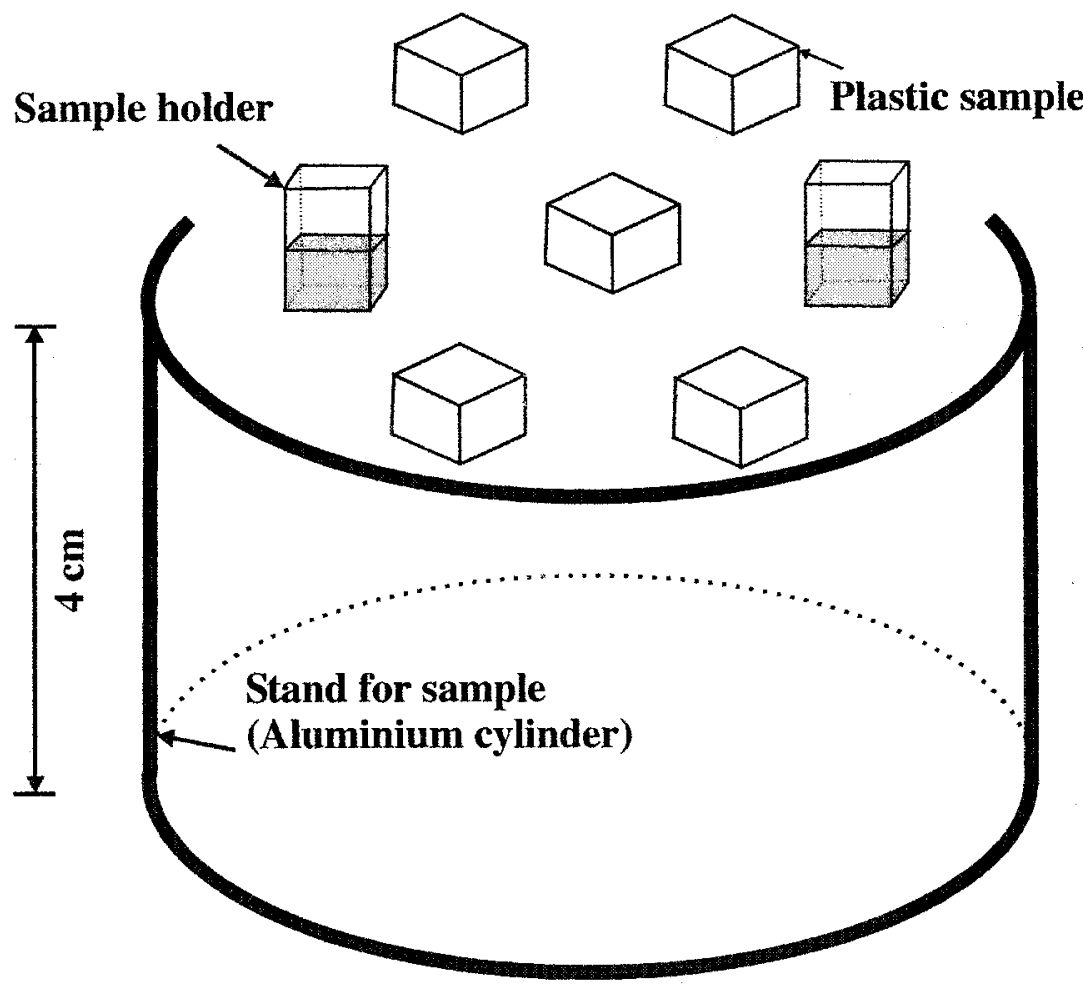

(c)

Figure 3.7 Arrangement of samples: (a) Sample holder for water, salt and tissues, (b) plastic sample, (c) arrangement for seven-beam hexagonal geometry. 


\section{Chapter 4}

\section{Scatter patterns: Single beam geometry}

The diffraction patterns of $1 \mathrm{~cm}$ thick targets obtained using single-beam geometry are analysed in this chapter. The background intensity for the storage phosphor screen is estimated by exposing the screen to intense light. The radial intensity profiles of the ringshaped diffraction patterns are obtained by integrating the patterns. The variation of intensity profiles as a function of scattering angle is also discussed.

\subsection{Background (residual) image}

The background intensity level in the phosphor screen is obtained by exposing the screen to bright light for about 10 minutes. The screen is then scanned and the image is saved as a 16-bit grayscale (background. tif) file in which each pixel can be assigned 65536 $\left(2^{16}\right)$ tones, where the number 0 represents the maximum intensity and the number 65535 represents zero intensity. To check the uniformity of the screen background, 10 different portions of the screen were selected. The mean intensity for these parts of the screen was $65519 \pm 9.7$ and is almost constant for the whole screen

The values of the digital matrix elements of transmission and scatter patterns are subtracted from 65535 in order to have the intensity in complementary ADC units. Then the average background value, which is 16 , is subtracted from the data matrix before analysis. 


\subsection{Effect of primary beam on scatter pattern recording}

In principle, one could measure the conventional and scatter $\mathrm{x}$-ray images simultaneously by using solid state detectors. We used a CR plate for recording the scatter patterns of amorphous materials. Since the fluence of scatter photons is low we need a high exposure to have a reasonably intense signal in terms of scatter patterns. The nature of the detector we used in these measurements requires that the primary be stopped before it hit the screen cassette. When primary hits the detector it not only saturates the screen but also generates significant scattering within the screen cassette. The option of using a box with top cover at a distance from the screen reduces the scattering from the screen holder but there is still saturation of screen due to large exposure. To avoid these problems, the primary was stopped after it passed through the target by using a lead blocker. A typical diffraction pattern, of a $1 \mathrm{~cm}$ thick polyethylene target using $50 \mathrm{kVp}$ potential and tin $\mathrm{K}$ edge filter, is shown in Figure 4.1. Figure 4.1(a) is recorded without using a lead blocker. The central white spot indicates the saturation of the CR plate. The surrounding black portion is due to the scattering within the CR plate cassette. Outside this is the diffraction pattern of the target. Figure 4.1(b) shows the diffraction pattern when a lead blocker is used to stop transmitted primary from reaching the detector. The two distinct rings demonstrate the semi-ordered nature of polyethylene. The radial profile of the ring is shown in figure $4.1(\mathrm{c})$. The two peaks are at $4.6^{\circ}$ and $6.2^{\circ}$. 


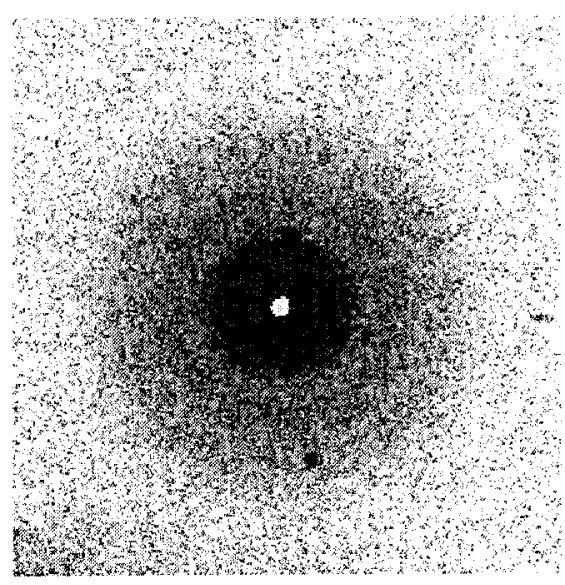

(a)

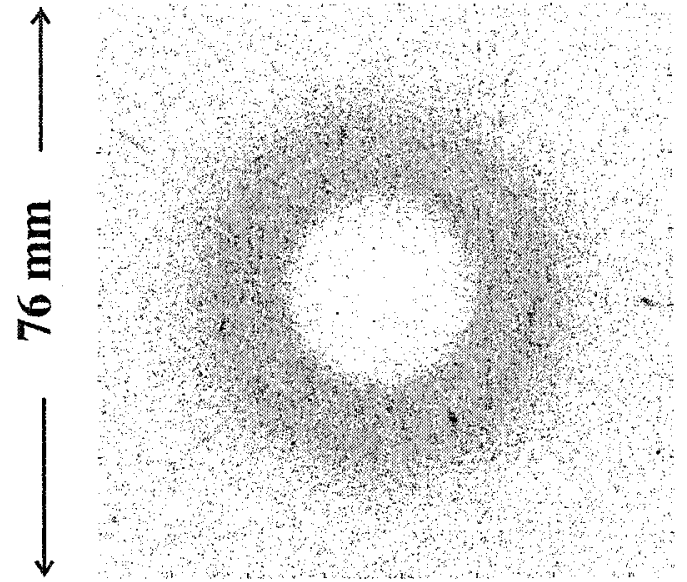

(b)

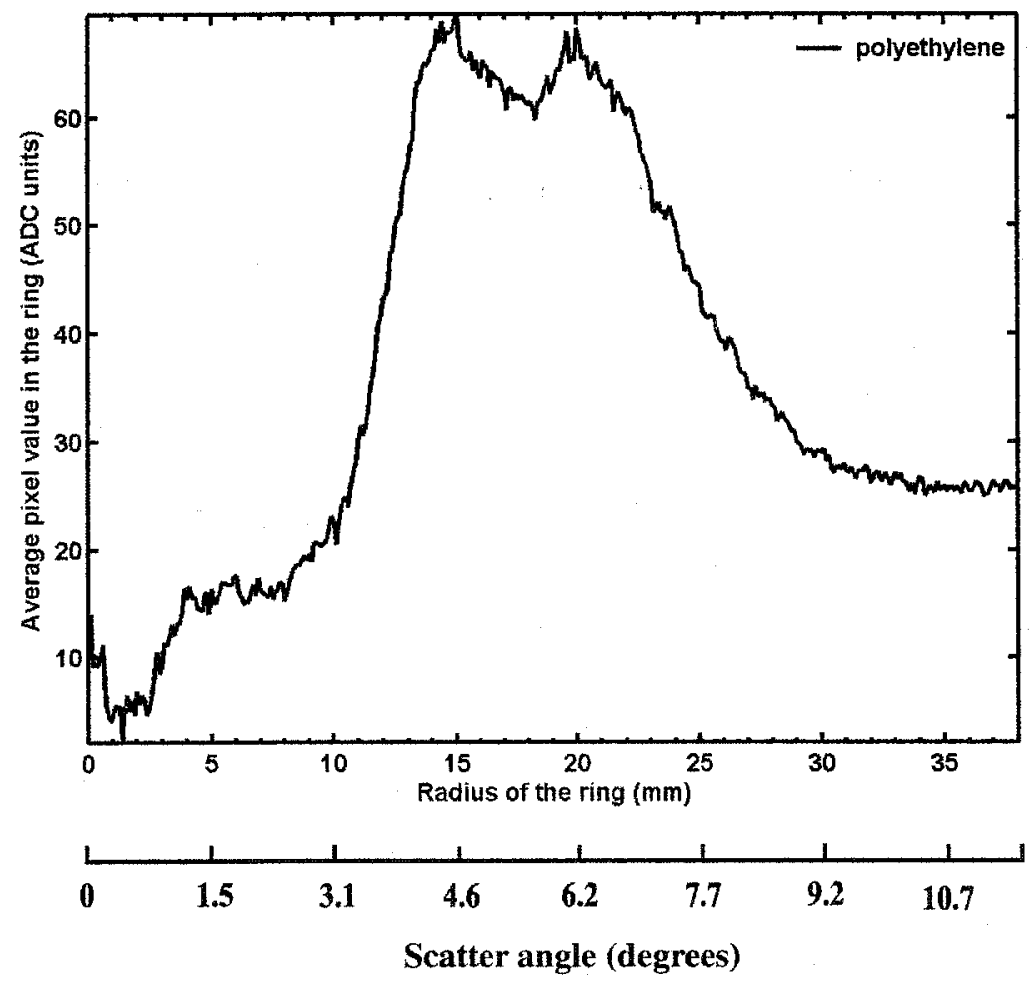

(c)

Figure 4.1 Diffraction pattern of polyethylene. (a) Without lead blocker, (b) with lead blocker, (c) radial intensity profile from (b). 


\subsection{Results and discussion}

\subsubsection{Scatter patterns of plastics}

The scatter patterns of four different types of plastic, $10 \mathrm{~mm}$ thick, are shown in figure 4.2. The diameter of the ring is characteristic of the scatterer and varies from material to material depending upon the molecular structure. The white region in the centre of the ring is due to the lead blocker, used to stop the primary. In the case of nylon, the small black spot at the centre is due to primary which is not completely stopped because of misalignment of the blocker. Among the given materials, the nylon ring has the largest diameter and PMMA has the smallest diameter. These measurements are done with the same experimental conditions. It is obvious from scatter patterns that the number of coherently scattered photons from PMMA is higher than from other given materials.

The radial intensity profiles of the diffraction patterns are shown in figure 4.3. The shape of the profile is characteristic of the scatterer and varies from material to material depending upon the molecular structure. The intensity of PMMA is peaked at about $2.8^{\circ}$ but for polycarbonate (Lexan) the peak occurs at $4.3^{\circ}$. Also the profile for polycarbonate is much broader than PMMA. The peak of polystyrene shown in the figure is the least intense among the four materials. Its peak occurs at about $3.9^{\circ}$ and has the widest profile among the four materials.

Kosanetzky et al. ${ }^{9}$, in their measurements using a diffractometer with monochromatic beam, showed the sharp two peaks-like structure of nylon, demonstrating the semi-ordered nature of the material. The nylon profile in our measurements peaks at 4. $8^{\circ}$. The peak at low angle $\left(\sim 0.5^{\circ}\right)$ in the nylon profile is an artifact as the primary is not completely stopped by the blocker. The artifact can be clearly seen in figure 4.2 as a dark 
spot near the centre of the ring. The nylon profile does not show two distinct peaks but looking at the profile in the range $5.6^{\circ}-7.7^{\circ}$ one can see the increase in intensity at about $6.7^{\circ}$. In the diffractometer measurements by Kosanetzky et al, ${ }^{9}$ the two sharp peaks of polyethylene were well resolved, but in the nylon case two sharp peaks were not fully resolved. In our measurements, because of the nature of the spectrum two unresolved peaks can be observed in polyethylene (figure 4.1) but the two peaks can hardly be separated in the nylon case. Also, due to the larger ring diameter of the scatter pattern of nylon shown in figure 4.2 , the peak occurs at a higher angle. The angle sensitive contrast property of the scatter imaging technique is obvious from the intensity profiles of the materials. For example, if the pixel for making scatter image is obtained by integrating the scatter patterns of PMMA and nylon in the range $2.8^{\circ}-3.9^{\circ}$, PMMA will be much brighter than nylon. The number of coherently-scattered photons is much higher from PMMA than nylon in this range. On the other hand it will be hard to distinguish between PMMA and nylon in the range $4.3^{\circ}-4.8^{\circ}$ on the scatter image display. 


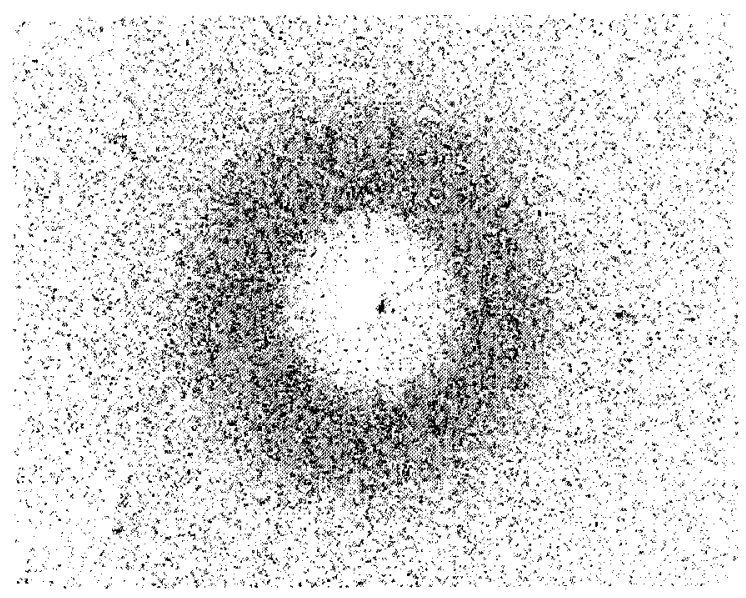

Nylon

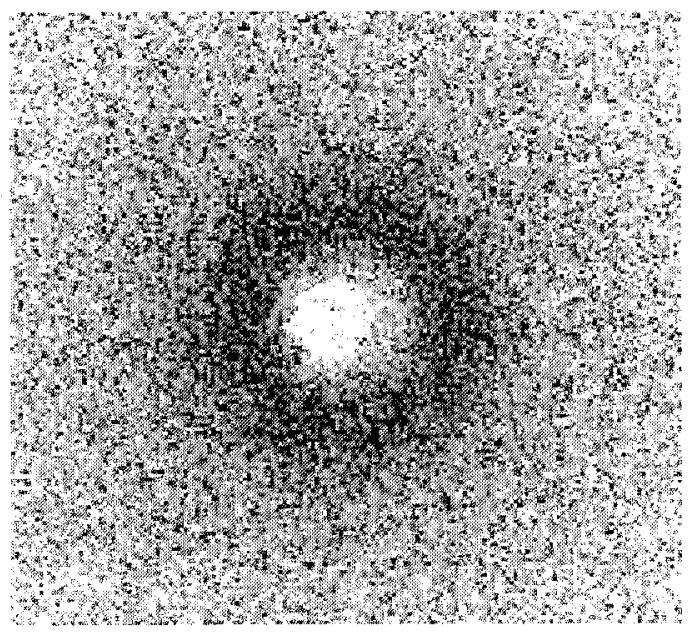

PMMA (Lucite)

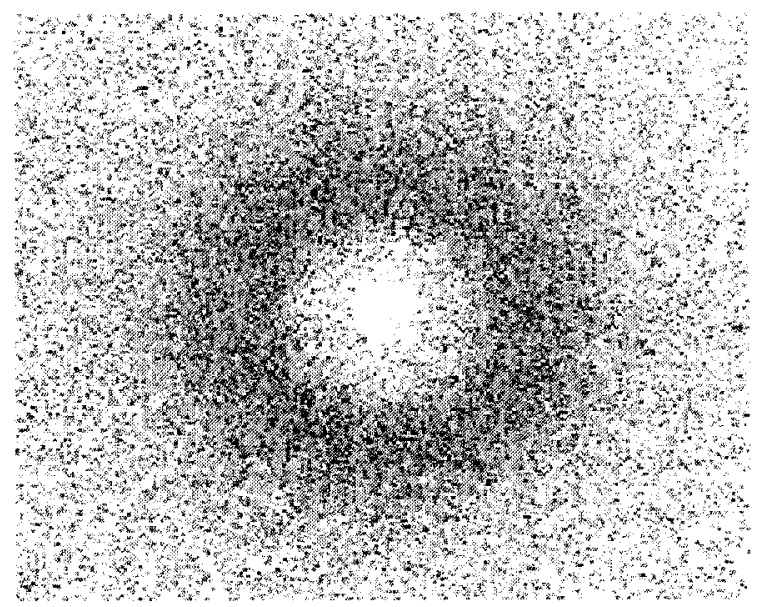

Polycarbonate (Lexan)

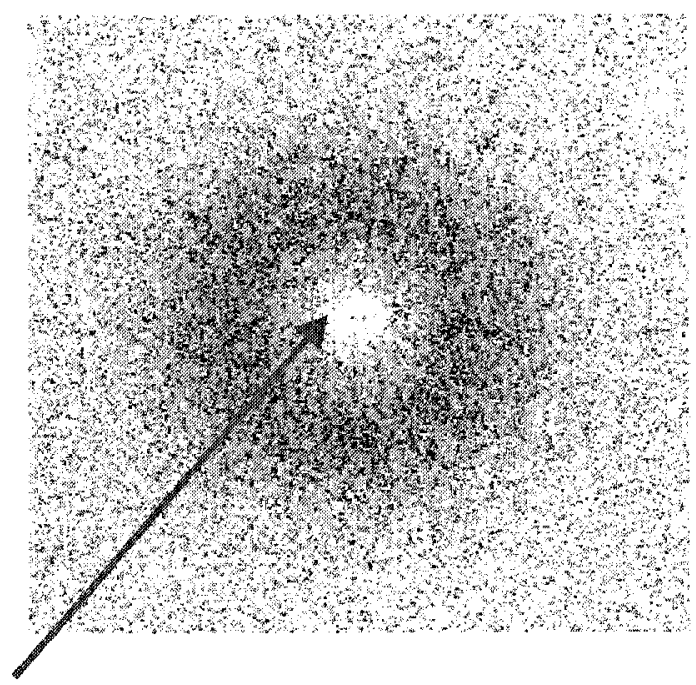

Polystyrene

Figure 4.2 The diffraction patterns of four types of plastics at $50 \mathrm{kVp}, 6000 \mathrm{mAs}$. The white region in the centre of the ring is due to $\mathrm{Pb}$ blocker, used to stop the primary. 


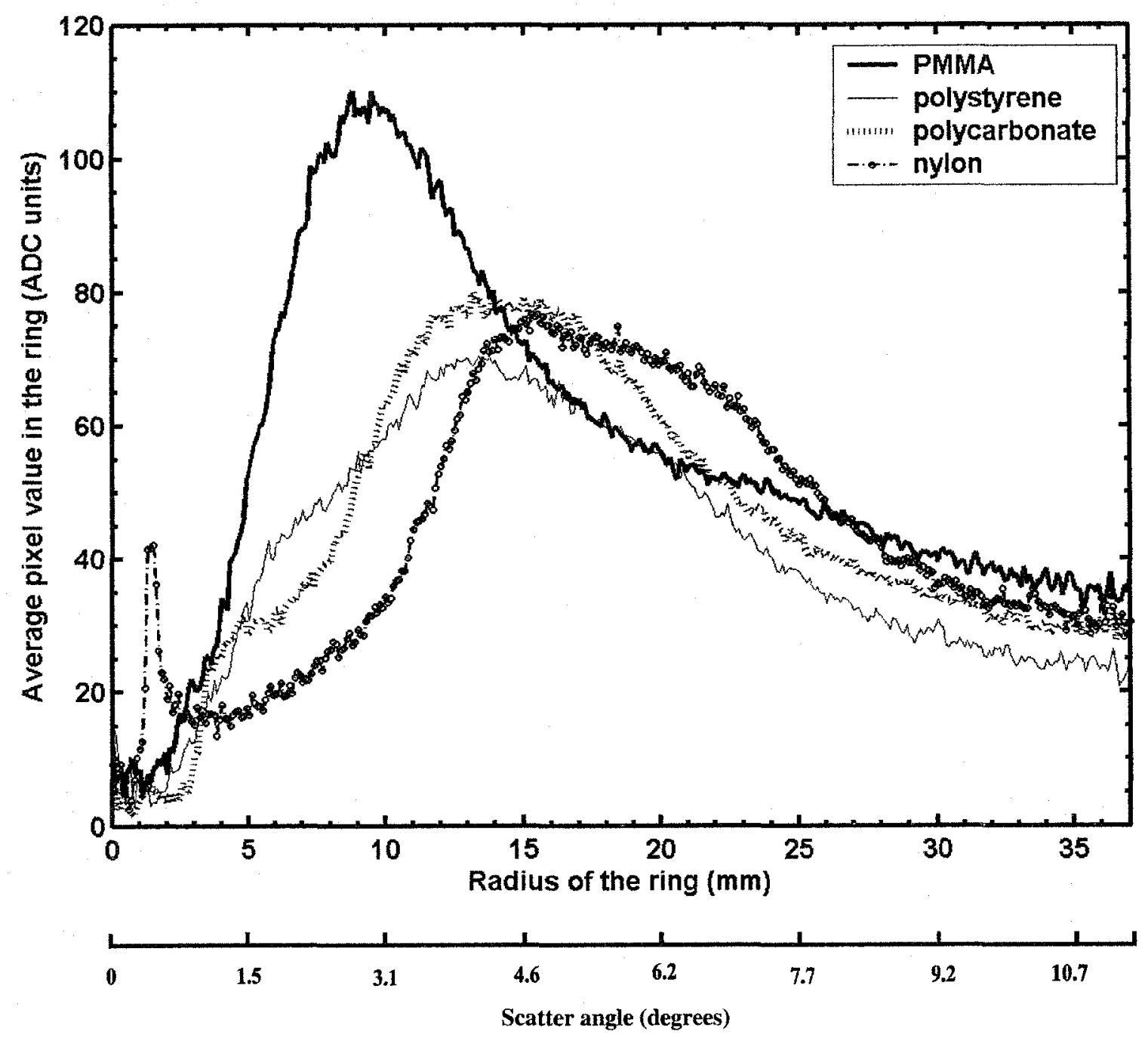

Figure 4.3 The radial intensity profiles for the plastic samples obtained by integrating the diffraction patterns of figure 4.2 .

\subsubsection{Scatter pattern of fat}

Figure 4.4 shows the scatter pattern of fat obtained by using the single-beam geometry. The radial intensity profile of the diffraction pattern is also shown in the figure. The intensity peak of fat occurs at about $4.9^{\circ}$. 

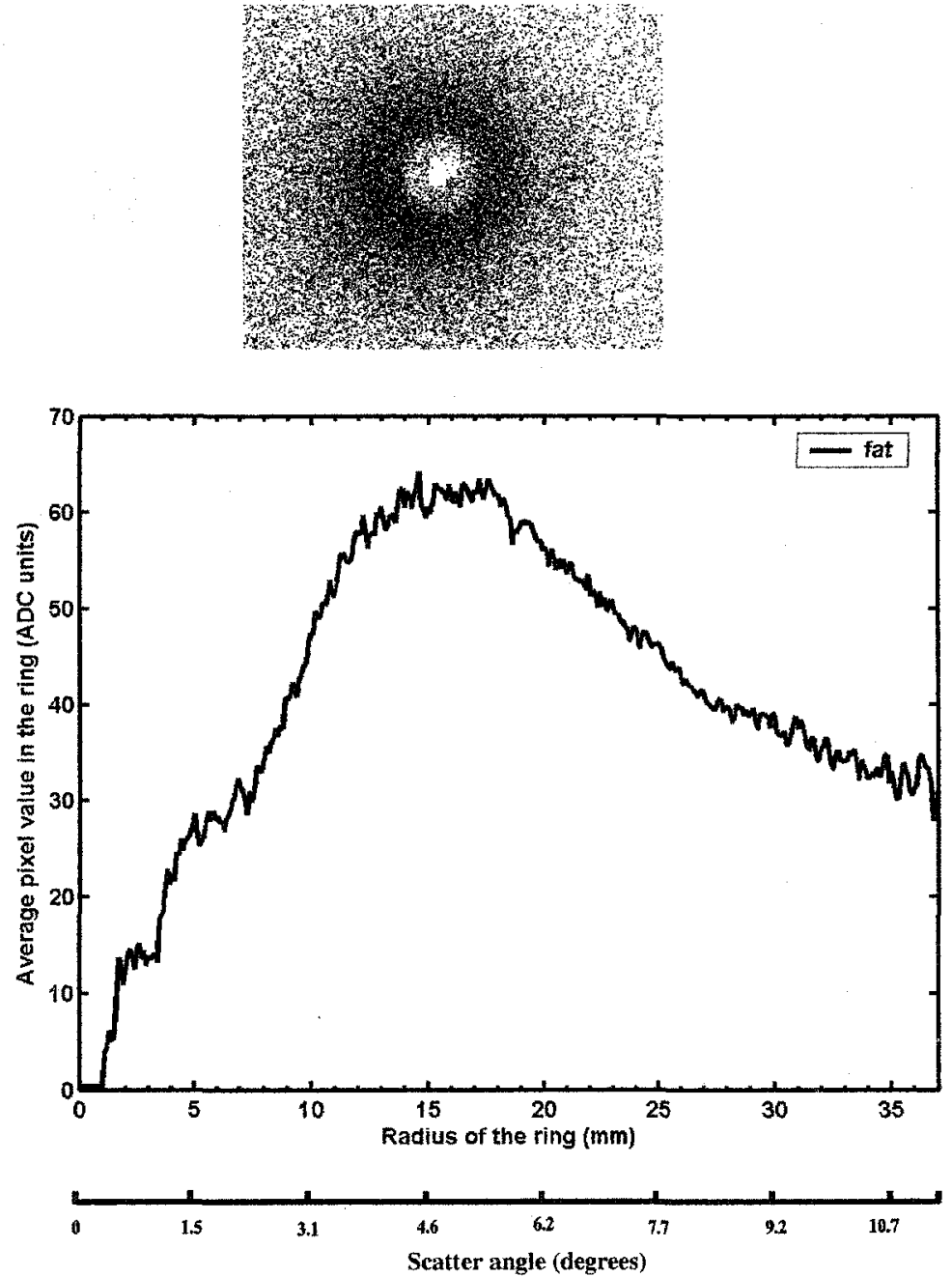

Figure 4.4 The scatter pattern of fat and its radial intensity profile.

\subsubsection{Scatter patterns of salt and bone}

Figure 4.5 shows the scatter patterns of table salt $(\mathrm{NaCl})$ and bone obtained by using the single-beam geometry. The scatter pattern of salt shows dark spots due to crystalline structure and the circular ring shape arises because the scatterer is a powder. The scatter pattern of bone also shows dark spots due to its partially crystalline nature. The dark spots are in the ring shape because the micro crystals are randomly oriented. It resembles a powder diffraction sample. 
The intensity profiles of the diffraction patterns are shown in Figure 4.6. The sharp intensity peak for salt occurs at $3.7^{\circ}$ and the intensity is almost flat in the $4.2^{\circ}-5.3^{\circ}$ range. In the high-angle region at $6.4^{\circ}$ and at $7.4^{\circ}$, small peak-like structures can be seen in the radial profile of salt. In the bone profile the intensity peak is around $4.6^{\circ}$.

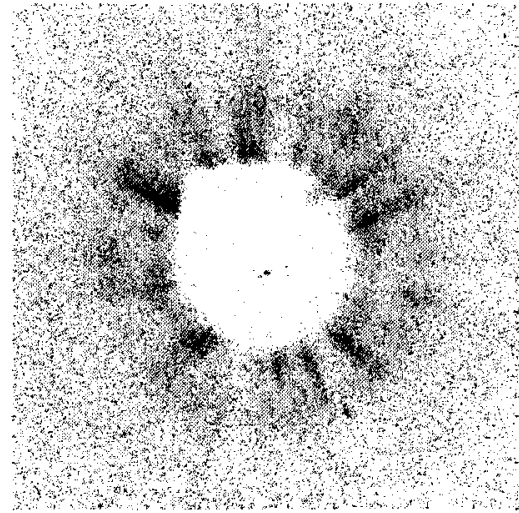

Salt

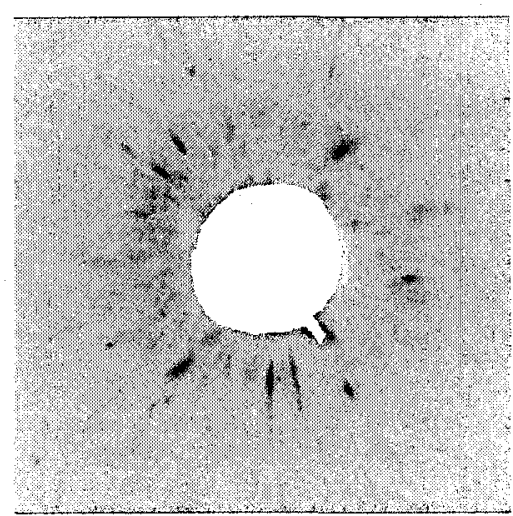

Bone

Figure 4.5 The scatter patterns of table salt and bone.

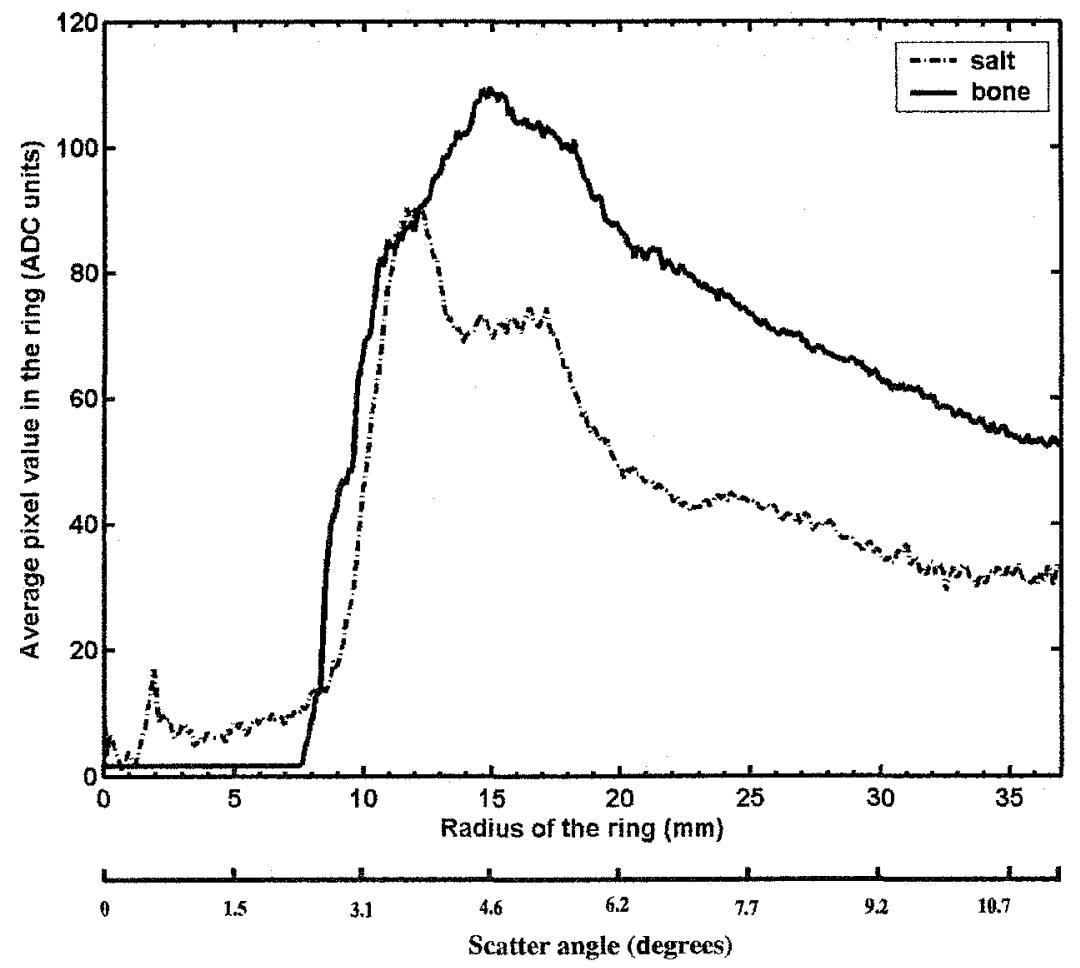

Figure 4.6 The radial intensity profiles of table salt and bone. 


\subsubsection{Scatter pattern of water}

Figure 4.7 shows the scatter pattern of water obtained by using the single-beam geometry. The radial intensity profile of the diffraction pattern is also shown in the figure. The intensity peak of water occurs at about $8.3^{\circ}$. Among the materials we used for our single beam experiments, the water ring has the largest diameter. The experimental conditions for measuring the water pattern were the same as for the other materials except that here the pencil beam diameter was $1.5 \mathrm{~mm}$ rather than $1.0 \mathrm{~mm}$.
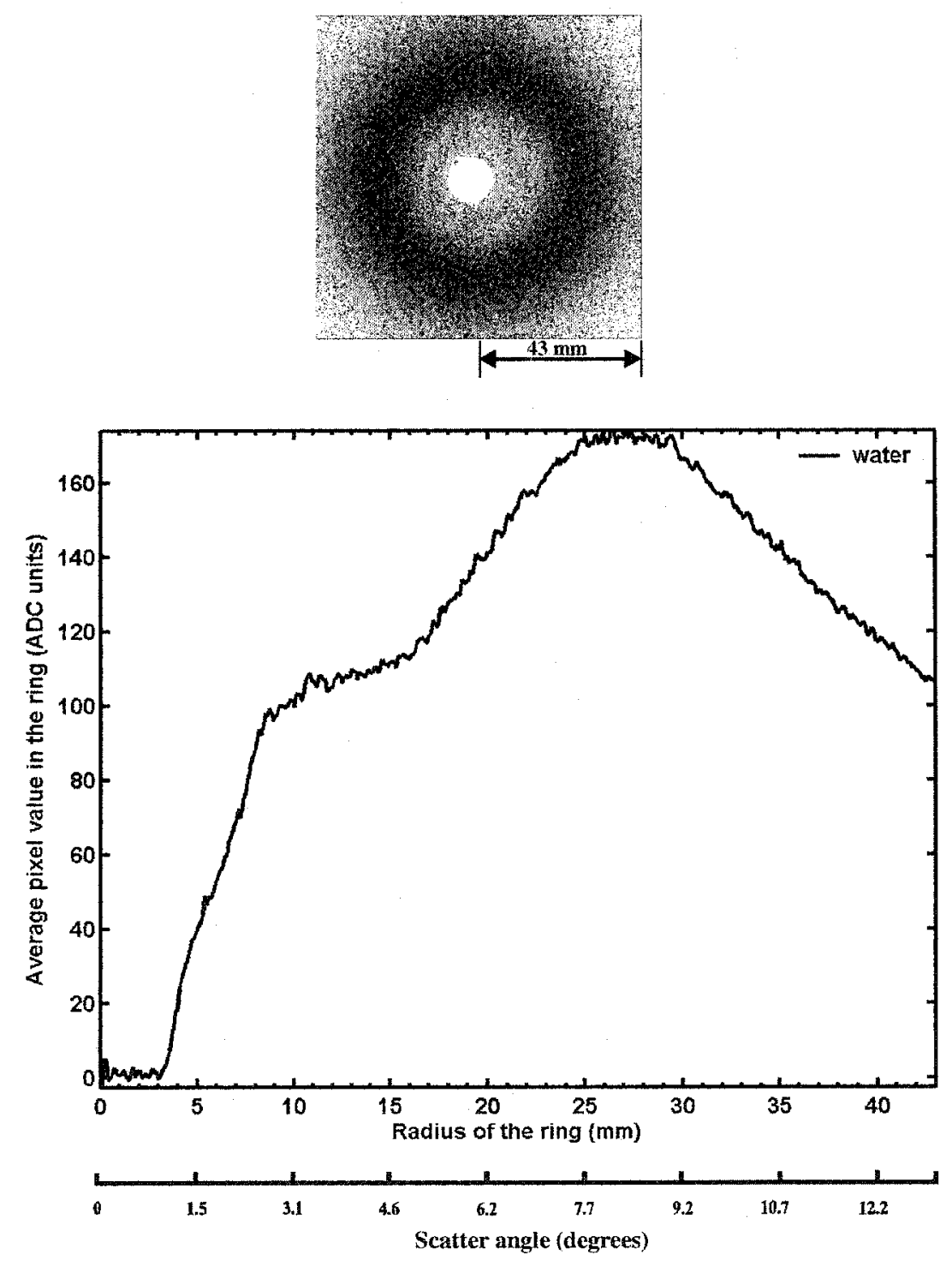

Figure 4.7 The scatter pattern of water and its radial intensity profile. 


\section{Chapter 5}

\section{Projection coherent scatter x-ray images of thin targets}

The transmission and scatter patterns of $1 \mathrm{~cm}$ thick targets obtained using seven-beam geometry are analysed in this chapter. The primary patterns are recorded without using any target to know the intensity for each beam at the detector plane in the seven beam geometry. The transmission and scatter patterns of seven different materials are recorded, each irradiated by a separate beam. Each pattern is then integrated and the value used as a pixel for display of the transmission and the scatter image. The projection images of transmission and coherently scattered $\mathrm{x}$ rays are made from the patterns and their contrast is compared. The variation of contrast as a function of scattering angle is also discussed.

\subsection{Primary image patterns}

To normalize the intensity of the seven beams, the primary image patterns were recorded without placing any target between the seven pinholes and detector. Figure 5.1 shows the primary image from the seven beams and their corresponding radial intensity profiles. The values of the primary patterns are subtracted from 65535 in order to have the intensity in complementary $\mathrm{ADC}$ units. For this image the tube was operated with technique factors $70 \mathrm{kV}, 200 \mathrm{~mA}$ (large focal spot) and $1 / 120 \mathrm{~s}$. The distance from source to detector was $65.7 \mathrm{~cm}$. The average intensity and corresponding relative output for the seven primary beams are listed in table 5.1. The intensity values are the average of four primary images recorded with the same experimental conditions. 


\begin{tabular}{|c|c|c|}
\hline $\begin{array}{l}\text { Location of } \\
\text { primary } \\
\text { beam }\end{array}$ & $\begin{array}{l}\text { Average intensity and standard } \\
\text { deviation (ADC units) } \\
\left(\mathrm{I} \pm \sigma_{\mathrm{R}}\right)\end{array}$ & $\begin{array}{l}\text { Relative intensity and } \\
\text { standard deviation } \\
\qquad\left(\mathrm{I}_{\mathrm{R}} \pm \sigma_{\mathrm{R}}\right)\end{array}$ \\
\hline P1 & $8351 \pm 94$ & 1.0 \\
\hline $\mathrm{P} 2$ & $5606 \pm 106$ & $0.67 \pm 0.01$ \\
\hline $\mathrm{P} 3$ & $7103 \pm 135$ & $0.85 \pm 0.02$ \\
\hline $\mathrm{P} 4$ & $10429 \pm 328$ & $1.25 \pm 0.04$ \\
\hline $\mathrm{P} 5$ & $9897 \pm 129$ & $1.18 \pm 0.02$ \\
\hline P6 & $8937 \pm 129$ & $1.07 \pm 0.02$ \\
\hline $\mathrm{P} 7$ & $6167 \pm 180$ & $0.74 \pm 0.02$ \\
\hline
\end{tabular}

Table 5.1 The average intensity of the primary patterns for seven beams.

The strongest beam is at location $\mathrm{P} 4$, and the weakest one is at location P2. Since the three pinholes in the hexagonal collimation system represented by beams P2, P3 and P7 are to the anode side, the $\mathrm{x}$ ray intensity for these beams is expected to be low due to the heel effect. Taking the central beam at location P1 in figure 5.1(a) as the reference the other six beams are normalized with respect to $\mathrm{P} 1$. We will use these relative output values when we will make the transmission and scatter images of the targets. 


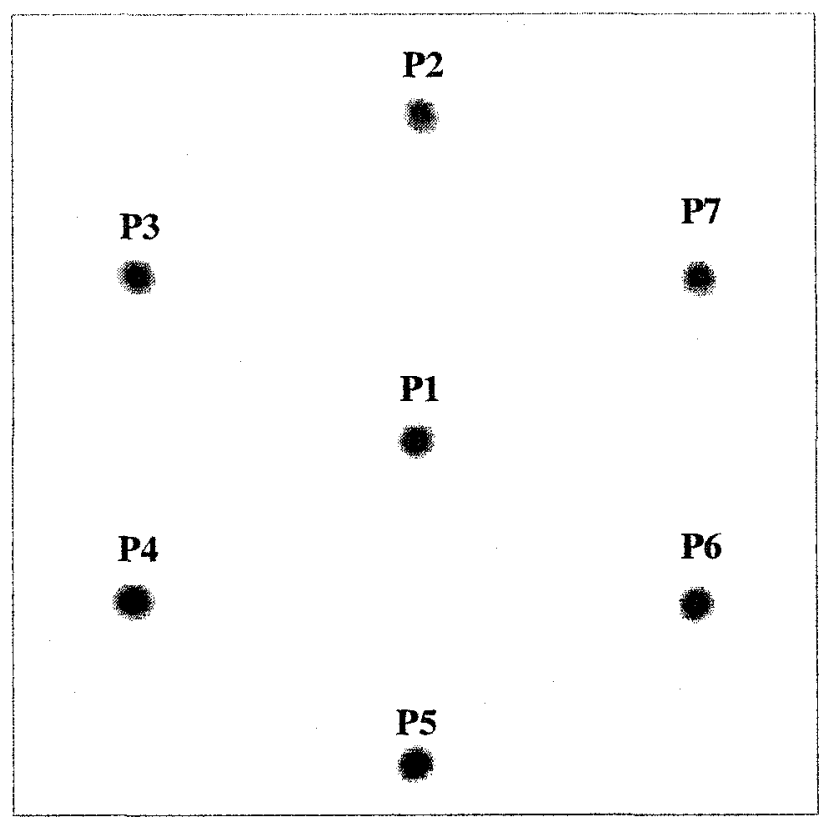

(a)

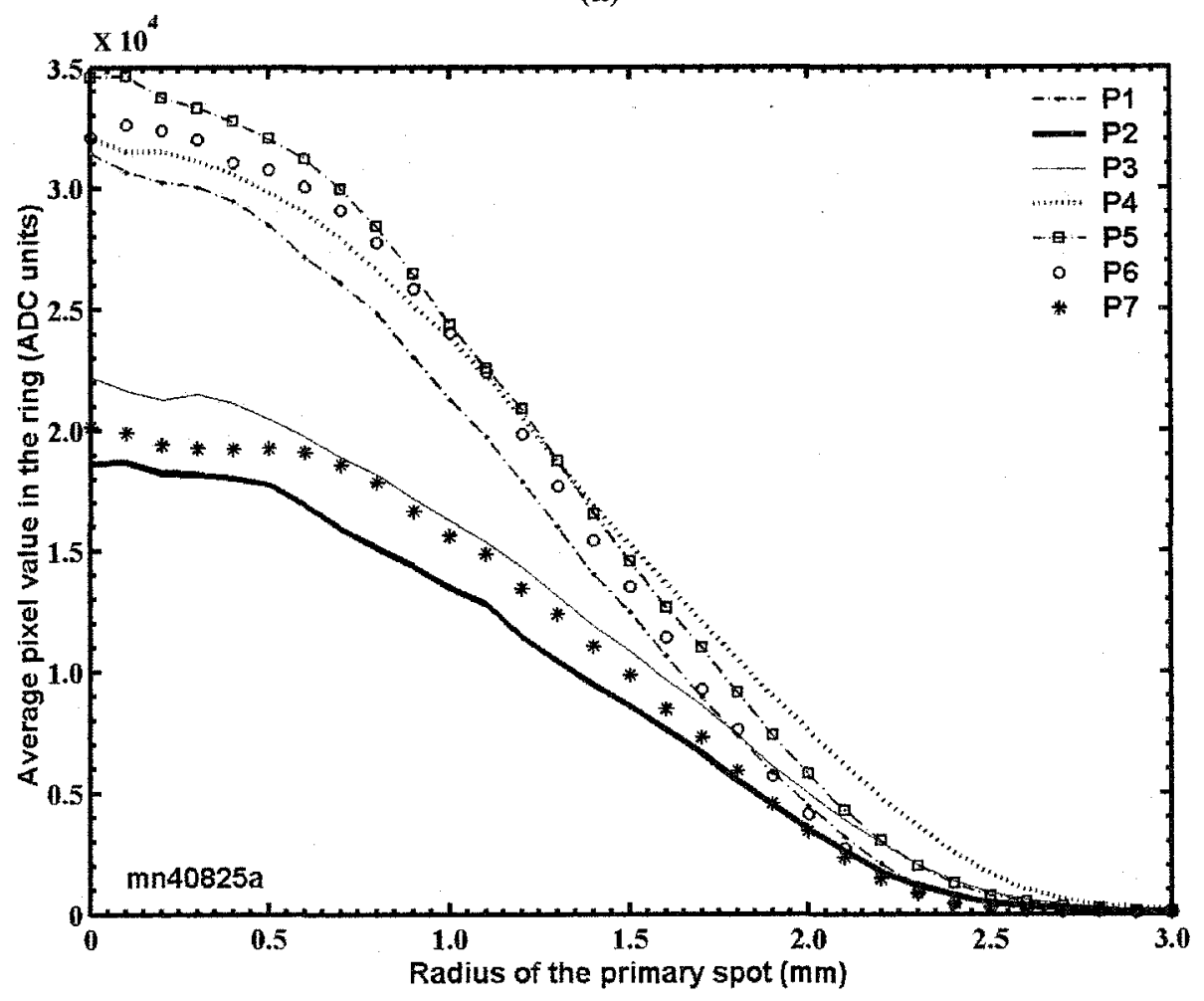

(b)

Figure 5.1 (a) Primary (without target) x-ray spots using 7-beam collimation system, (b) the radial intensity profiles of (a). 


\subsection{Transmission image patterns}

For this image the tube is operated with technique factors $70 \mathrm{kVp}, 100 \mathrm{~mA}$ (small focal spot) and $1 / 120 \mathrm{~s}$. The distance from the $\mathrm{x}$-ray tube focal spot to the centre of the sample is $37.75 \mathrm{~cm}$ and the distance from the centre of the sample to the detector is $14 \mathrm{~cm}$. The seven different targets are adjusted such that each target is irradiated by a separate beam. Each transmission pattern is represented by a digitized matrix of $(33 \times 33)$ pixels. The code mntransmission.m integrates the patterns in terms of concentric rings. The average intensity $\left(\mathrm{I}_{\mathrm{avg}}\right)$ of each ring is corrected as:

$$
I_{\text {cor }}=\frac{I_{\text {avg }}}{I_{R}}
$$

where $I_{R}$ is the relative intensity given in table 5.1 .

The corrected intensity is then plotted versus radius of the ring. The transmission patterns of seven different materials and their radial intensity profiles are shown in figure 5.2. In this image, black indicates high $\mathrm{x}$-ray intensity and white indicates low. The values in the graph have been subtracted from 65535 so that high values indicate high $\mathrm{x}$ ray intensity (or low object attenuation). The maximum transmission is from polystyrene whereas maximum attenuation occurs in water and salt. 


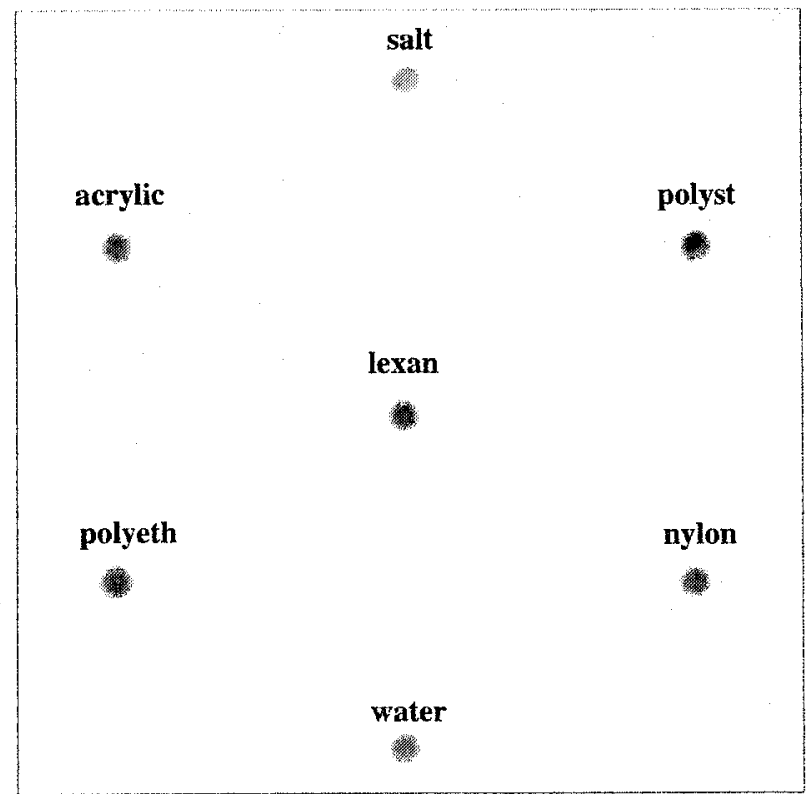

(a)

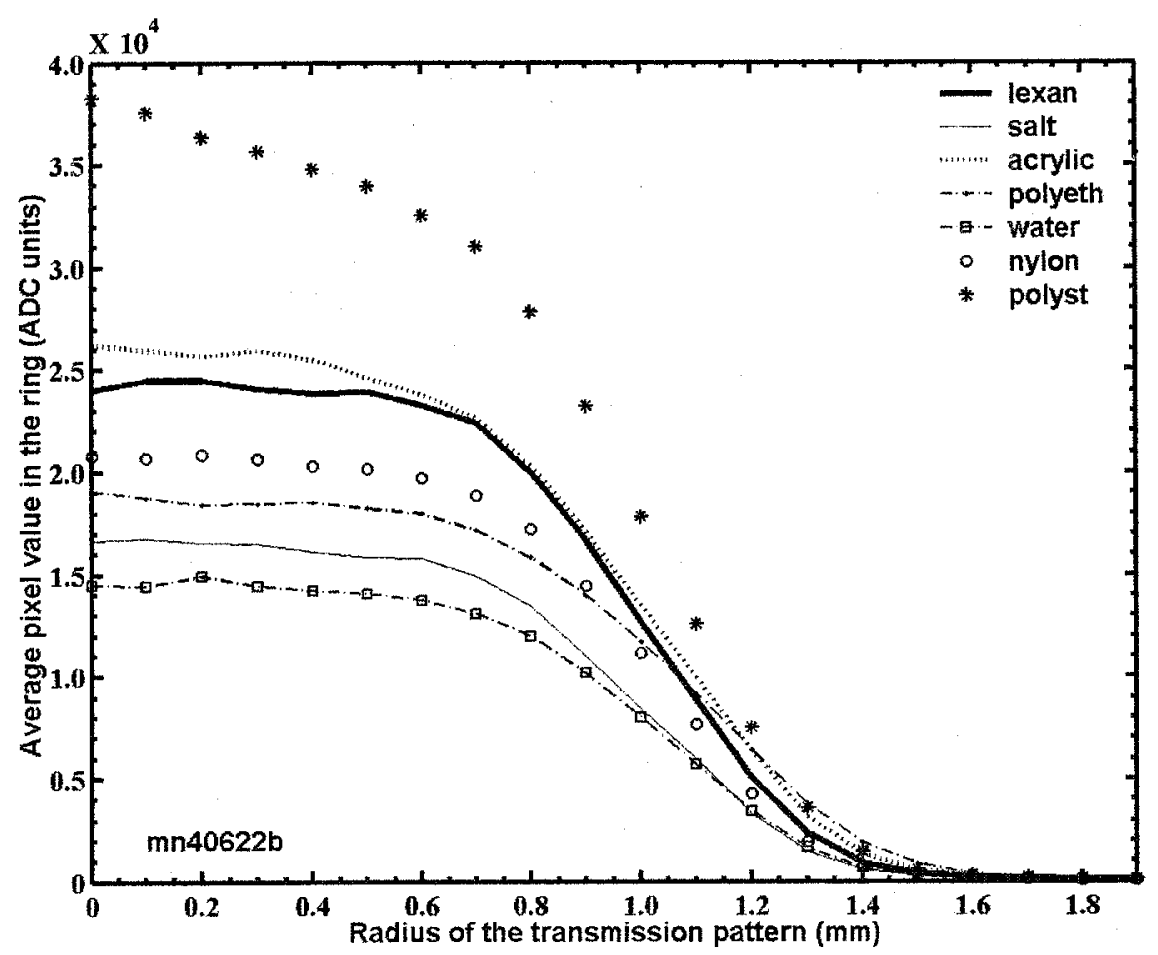

(b)

Figure 5.2 (a) Transmission image (with target) $x$-ray spots using 7-beam collimation system, (b) the radial intensity profiles of (a) after scaling according to table 5.1. 


\subsection{Making projection transmission image}

The transmission patterns of the seven materials shown in figure 5.2 are integrated and the corrected intensity of each pattern is used as a pixel in transmission image display. Figure 5.3 is a 7 pixel image in which the pixels are hexagons. The locations of the target materials are depicted in the above frame. The contrast of the transmission image is due to the attenuation in the target. This conventional technique is useful to distinguish between the high $\mathrm{Z}$ and low $\mathrm{Z}$ materials. The image made by using the primary beam shows more absorption in $\mathrm{NaCl}$ and water than in the plastics. It also shows that polystyrene attenuates primary photons less than do polycarbonate, nylon, acrylic and polycarbonate. The same scenario is depicted by the radial intensity profiles of the observed materials shown in figure 5.2 (b). It is also obvious from the transmission image that the contrast between polycarbonate and acrylic is very low. Also, it is hard to discriminate between polyethylene and nylon but these are distinguishable from the other plastics. 


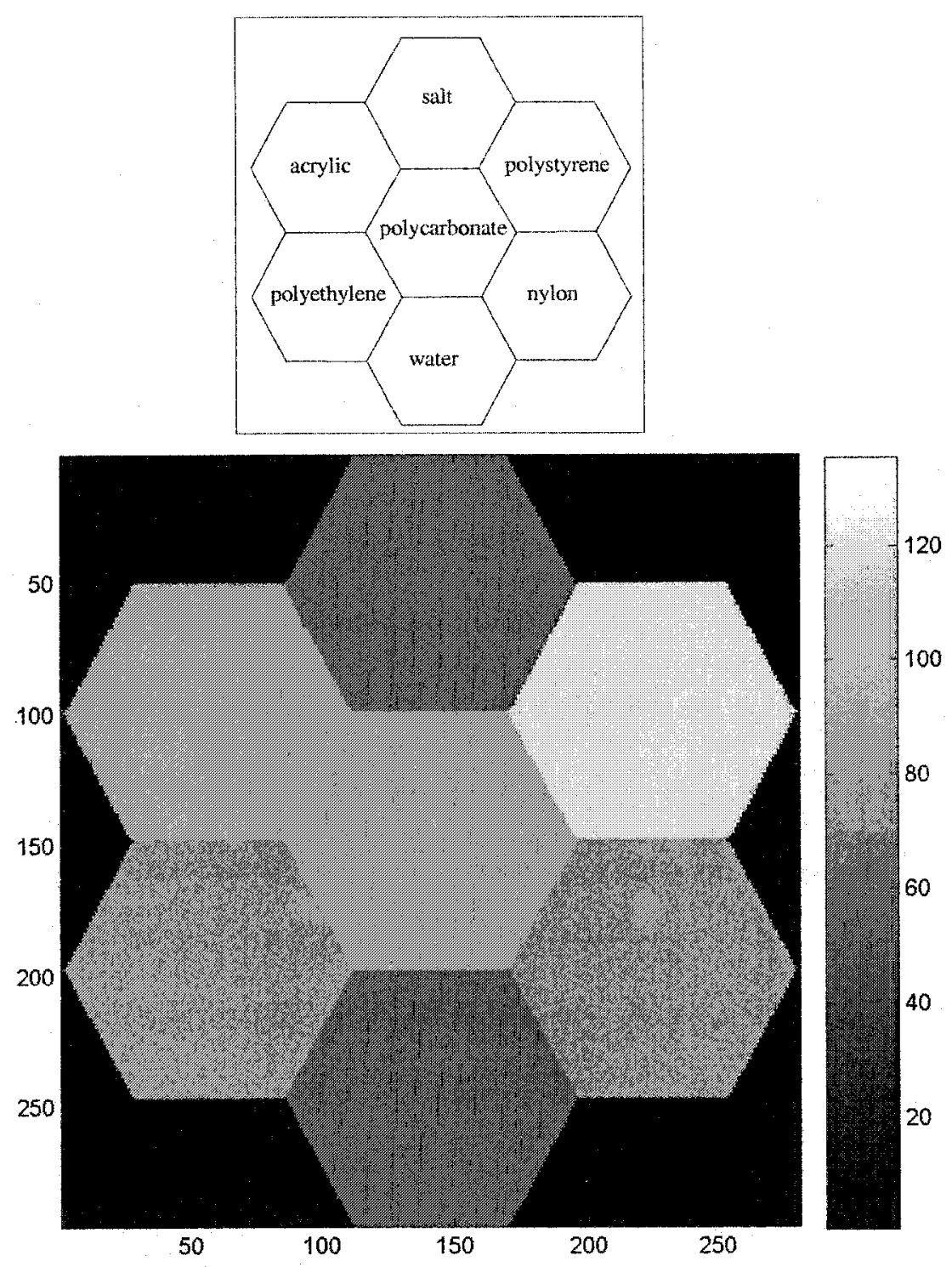

Figure 5.3 Transmission image of seven materials. The locations of the materials are shown at the top. 


\subsection{Scatter patterns using seven-beam hexagonal geometry}

The scatter patterns of seven different materials recorded using the seven-beam hexagonal collimation system are shown in figure 5.4 . The technique factors are $70 \mathrm{kVp}$ and 2500 mAs. In this image, black indicates high $\mathrm{x}$-ray intensity and white indicate low intensity.

The thickness of the targets is $1 \mathrm{~cm}$ and they are located such that each one is irradiated by a separate beam. The scatter patterns of the amorphous materials are circularly symmetric and the radius of the ring specifies the characteristics of the material. At the centre of each ring the central bright portion is due to lead blocker used to stop the primary from reaching the detector. For the plastic targets the lead blocker is not quite aligned especially in the case of acrylic and polystyrene. The very dark structure around the ring centre is because of misalignment of the lead blocker. The primaries transmitted through water and salt are completely stopped by the blocker. As it is clear from the figure the diameter of the scatter patterns varies from material to material.

\subsection{Variation of $\mathrm{mAs}$ versus $\mathrm{kVp}$}

A series of scatter patterns using seven-beam hexagonal geometry for various tube potential is shown in figure 5.5. To have a reasonably intense scatter pattern, we decrease the exposure time as potential increases. The figure shows that by increasing the tube potential the scatter patterns can be obtained at low mAs values.

These measurements also depict the decrease in ring diameter at high potentials. For example, the outside diameter of the polyethylene ring is decreased from $12 \mathrm{~mm}$ to 9 $\mathrm{mm}$ by changing the tube potential from $50 \mathrm{kVp}$ to $120 \mathrm{kVp}$. 

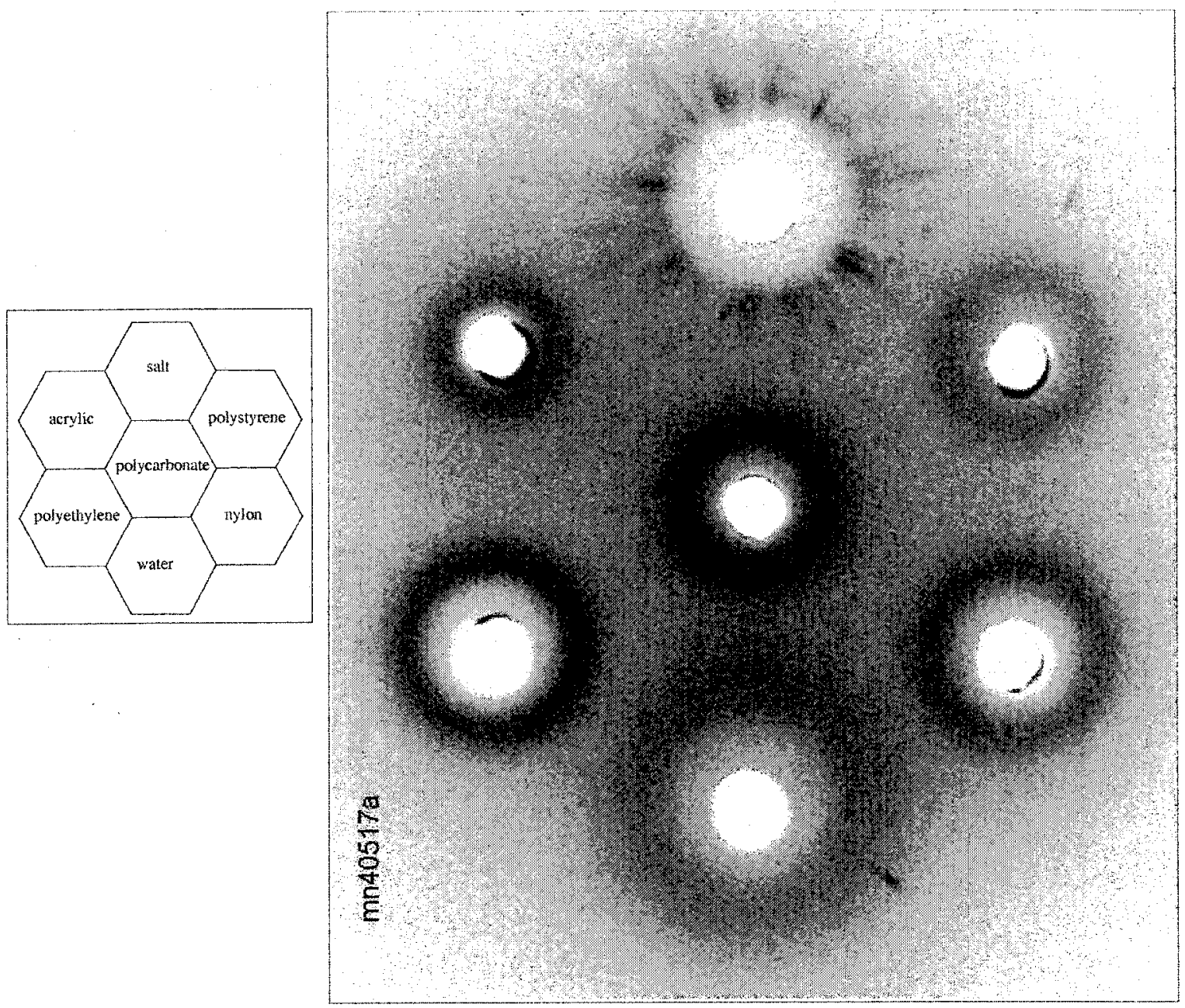

$8.3 \mathrm{~cm}$

Figure 5.4 Scatter patterns using seven-beam hexagonal geometry. The locations of the seven targets are shown at the left. The patterns are not corrected for relative beam intensity. 


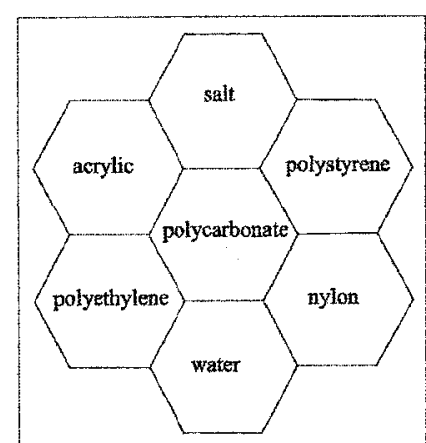

(a) Target arrangement

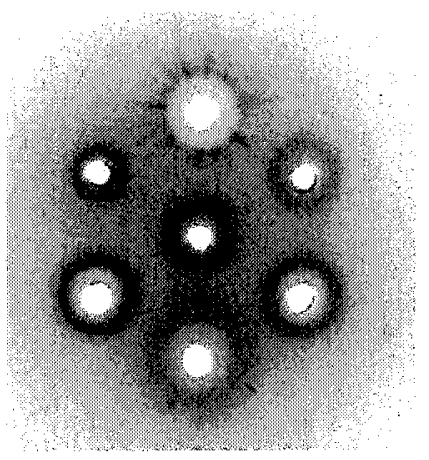

(d) $70 \mathrm{kVp}, 2500 \mathrm{mAs}$

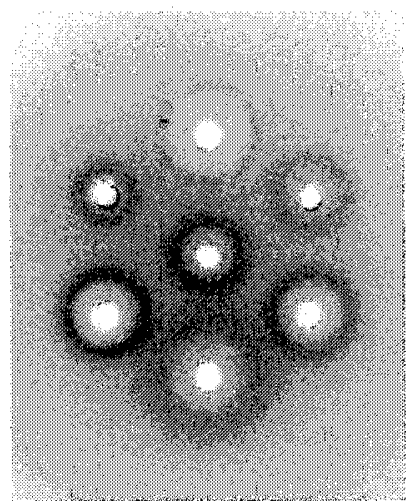

(b) $50 \mathrm{kVp}, 6000 \mathrm{mAs}$

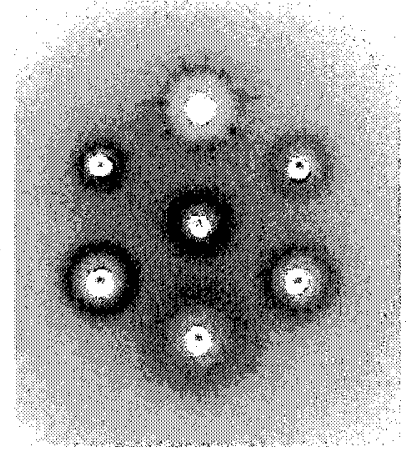

(e) $80 \mathrm{kVp}, 1200 \mathrm{mAs}$

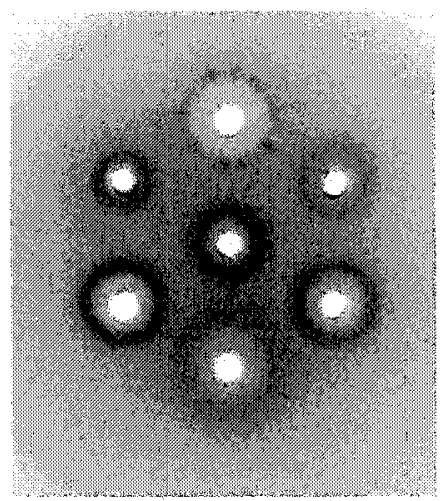

(c) $60 \mathrm{kVp}, 4000 \mathrm{mAs}$

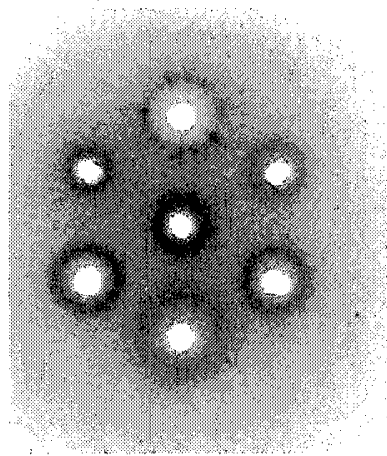

(f) $90 \mathrm{kVp}, 700 \mathrm{mAs}$

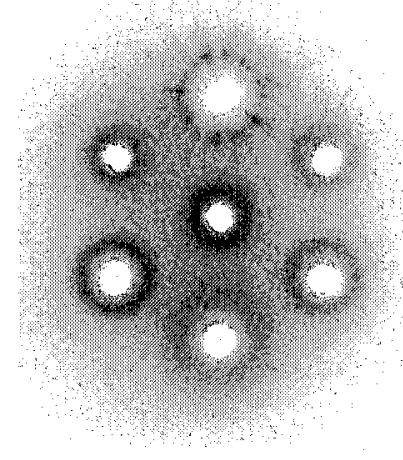

(g) $100 \mathrm{kVp}, 500 \mathrm{mAs}$

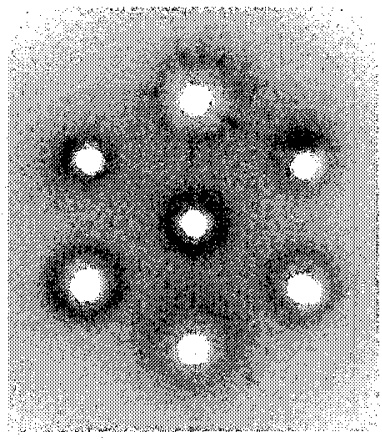

(h) $120 \mathrm{kVp}, 300 \mathrm{mAs}$

Figure 5.5 A series of scatter patterns with varying tube potential from $50 \mathrm{kVp}$ to 120 $\mathrm{kVp}$. The materials are arranged as shown in (a). The patterns are not corrected for relative beam intensity. 
The black spots at the centre of 5.5(e) are because of primary transmission through the lead blocker. In subsequent measurements at even higher potential the thickness of the lead blocker is increased to stop primary completely from reaching the detector.

\subsection{Making projection scatter image by integrating entire ring} structure

Figure 5.6 shows the scatter image of the seven targets. The pixel values of the image were obtained by averaging the sum of pixels in the whole pattern. The intensity of each

pixel $\left(I_{\text {sum }}\right)$ is corrected as $I_{\text {cor }}=\frac{I_{\text {sum }}}{I_{R}}$ where $I_{R}$ is the relative intensity given in table 5.1, and then displayed in the form of a hexagon in the scatter image display. In the image, polyethylene, water and nylon look darker than the other four targets. The bright hexagon representing salt means maximum scattering is due to salt followed by polystyrene, polycarbonate and acrylic. The contrast among polyethylene, water and nylon is very low and it is hard to distinguish them. The variation of contrast can be predicted from the ring size and its radial intensity profile as discussed in chapter 4. 


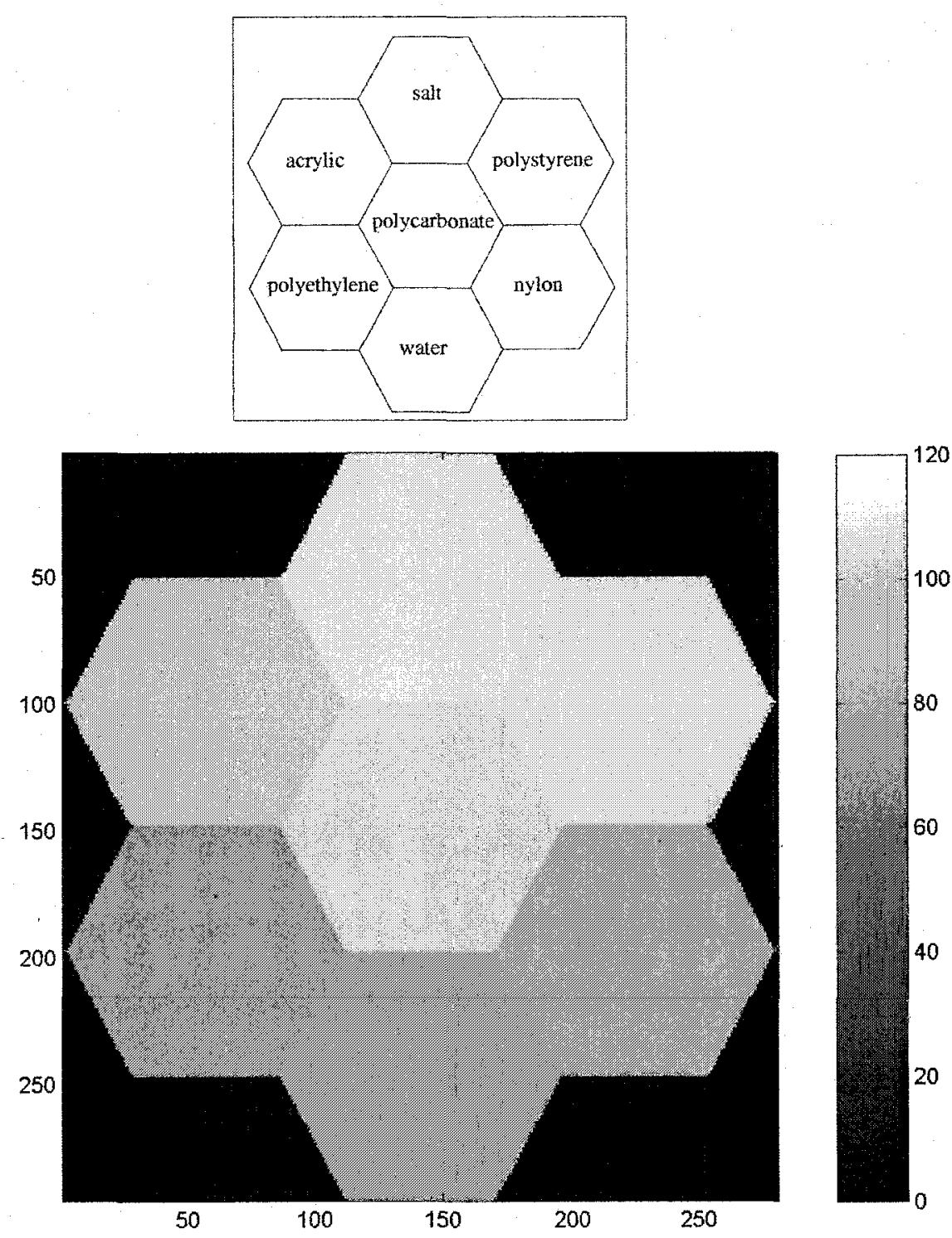

Figure 5.6 Scatter image of seven materials. Each hexagon represents the pixel value obtained by integrating the whole scatter pattern of the material. The locations of the materials are shown at the top.

\subsection{Comparison of transmission and scatter images}

Figures 5.7 (a) and 5.7 (b) show, respectively, the transmission and scatter images. To obtain similar display grey levels for Figs. 5.7 (a) and 5.7 (b), we set the central 
hexagonal pixel value of the transmission image (5.7(a)) equal to the central pixel value of the scatter image $(5.7(\mathrm{~b}))$. The values for the other six pixels of Fig. 5.7(a) are set by multiplying their original values by the conversion factor obtained by equating the central pixel values. Fig. 5.7(b) is different from the transmission image but its contrast is not significantly better. In the transmission image salt is dark showing more attenuation but the number of photons scattered from salt is more so the hexagon for salt is bright in the scatter image.

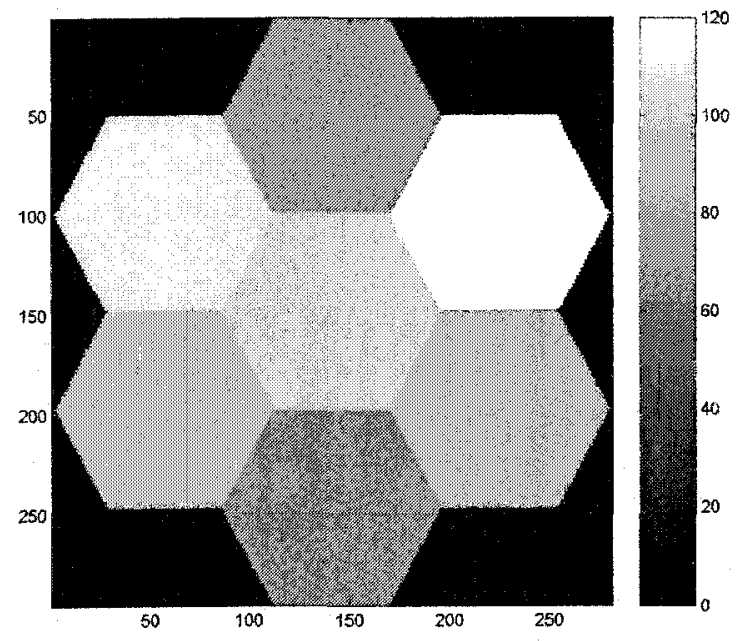

(a)

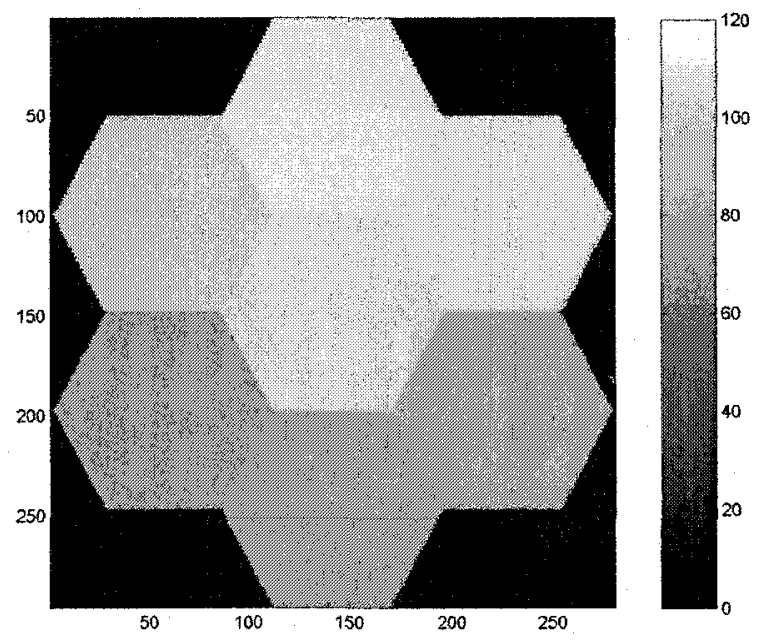

(b)

Figure 5.7 (a) Transmission image, (b) scatter image using whole ring.

\subsection{Making projection scatter image by integrating portion of ring}

\section{structure}

Figures $5.8(\mathrm{~d}),(\mathrm{e}),(\mathrm{f})$ and $(\mathrm{g})$ are made by taking portions of the scatter pattern, that is, they are angle-dependent images. For comparison, the transmission image Fig. 5.8(b) and scatter image using whole ring Fig. 5.8(c) are also shown in the panel. Fig. 5.8(d) is made by taking the average pixel values of the ring for the scattering angle $\theta$ between $1.4^{\circ}$ and 
$2.2^{\circ}$ and dividing it with the corresponding multiplying factor obtained in section 5.1 . The improved contrast between the materials is obvious. Acrylic is brighter than the other target materials. Figs. 5.8(e), (f) show the scatter images of the ring portion with angular range $2.2^{\circ} \leq \theta \leq 2.9^{\circ}$ and $2.9^{\circ} \leq \theta \leq 3.5^{\circ}$ respectively. The contrast of different materials changes as the ring angle changes. In Fig. 5.8(e), polycarbonate and polystyrene are brighter than the lower angle range, also polyethylene, water and nylon are more intense than the previous low-angle image. In Fig. 5.8(f), the contrast among polyethylene, water and nylon is higher as compared to fig. 5.8(d), (e). Also, there is more scatter from salt in this angular range. Fig. $5.8(\mathrm{~g})$ shows the scatter image of the ring portion with the angular range $3.5^{\circ} \leq \theta \leq 4.3^{\circ}$. In this range the numbers of scattered photons from the $\mathrm{NaCl}$ target are maximum. The hexagons representing acrylic, polycarbonate and polystyrene are less intense in this region.

The variation of contrast with angle can be predicted from the scatter patterns shown in Fig. 5.4. For example, comparing the ring size of acrylic and salt for the low angles reveals that scattering from acrylic is higher because of smaller ring size and figure 5.8(d) depicts the same. At higher angles, according to Fig. 5.4 the maximum intensity should be from salt, and that is seen in Fig. 5.8(g). The ring size of nylon and polyethylene are almost equal so there is low contrast between these materials in the scatter image display. A final example is the comparison of contrast between polystyrene and nylon. The contrast is high in Fig. 5.8(d) but decreases as the angular range increases. The intensity of nylon increases at higher angles due to larger ring size as compared to polystyrene. In the case of water which has larger ring size and maximum scattered photons at large angle, the change in intensity for water Fig. 5.8(d)-(g) is in accordance. 


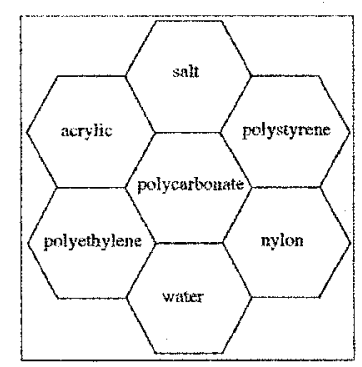

(a)

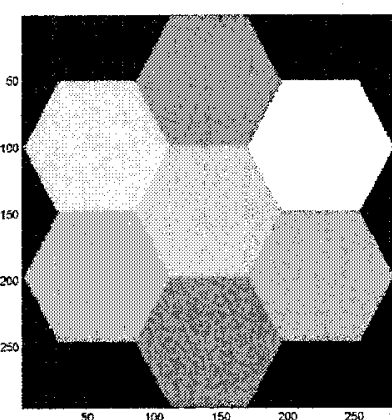

(b)

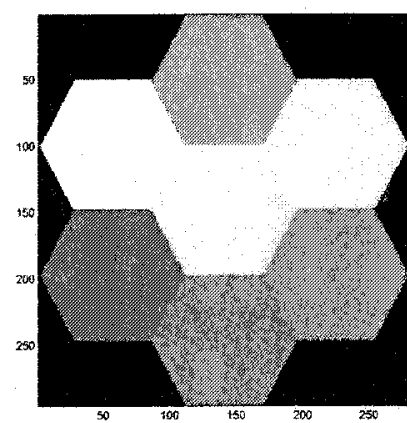

(d)

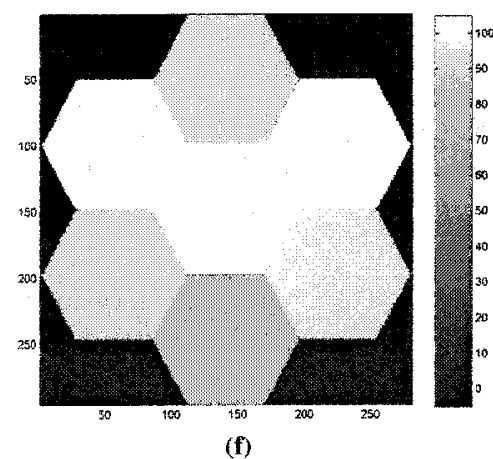

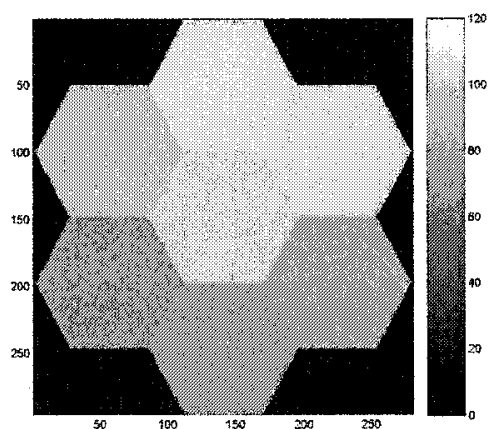

(c)

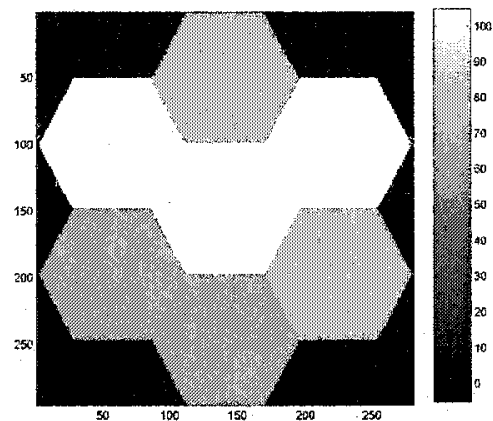

(e)

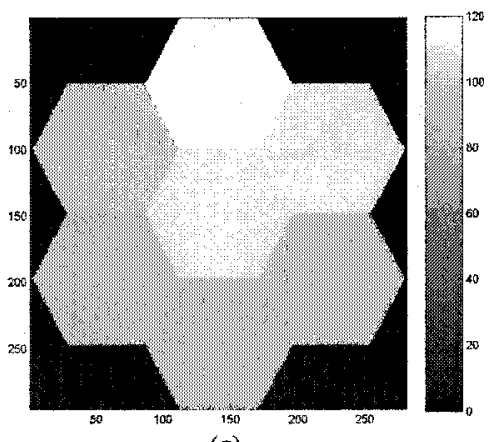

(g)

Figure 5.8 Transmission and scatter images of seven different materials. (a) Location of target materials, (b) transmission image, (c) scatter image using whole ring, (d) scatter image using ring with angular range from $1.4^{\circ}$ to $2.2^{\circ}$, (e) scatter image from $2.2^{\circ}$ to $2.9^{\circ}$, (f) scatter image from $2.9^{\circ}$ to $3.5^{\circ}$, (g) scatter image from $3.5^{\circ}$ to $4.3^{\circ}$. 


\section{Chapter 6}

\section{X-ray scatter pattern measurements of thick water/plastic}

\section{phantoms}

The scatter pattern intensity profiles and projection x-ray scatter images of different amorphous materials described in chapter 4 and chapter 5 indicate the advantages of the projection scatter $\mathrm{x}$-ray imaging technique in terms of image contrast over the conventional $\mathrm{x}$-ray imaging technique. These studies show that the projection scatter $\mathrm{x}$ ray imaging technique works well for thin plastics and amorphous materials. For the potential application of scatter $\mathrm{x}$-ray imaging techniques in the medical field, observations on a thick human size water phantom are needed. Using single beam geometry the diffraction patterns of $10 \mathrm{~cm}$ and $20 \mathrm{~cm}$ thick water phantoms with different types and different thicknesses of plastics at different depths in the water phantom are analysed in this chapter.

\subsection{Scatter patterns for thick water phantom}

The scatter patterns for 10 and $20 \mathrm{~cm}$ thick water phantoms and their radial intensity profiles are shown in figure 6.1 and figure 6.2 respectively. The white region at the centre of ring-shaped scatter patterns is due to the $\mathrm{Pb}$ blocker used to stop primary from reaching the detector. To cover a part of primary which reached the detector white rectangular bars are used during image analysis. 

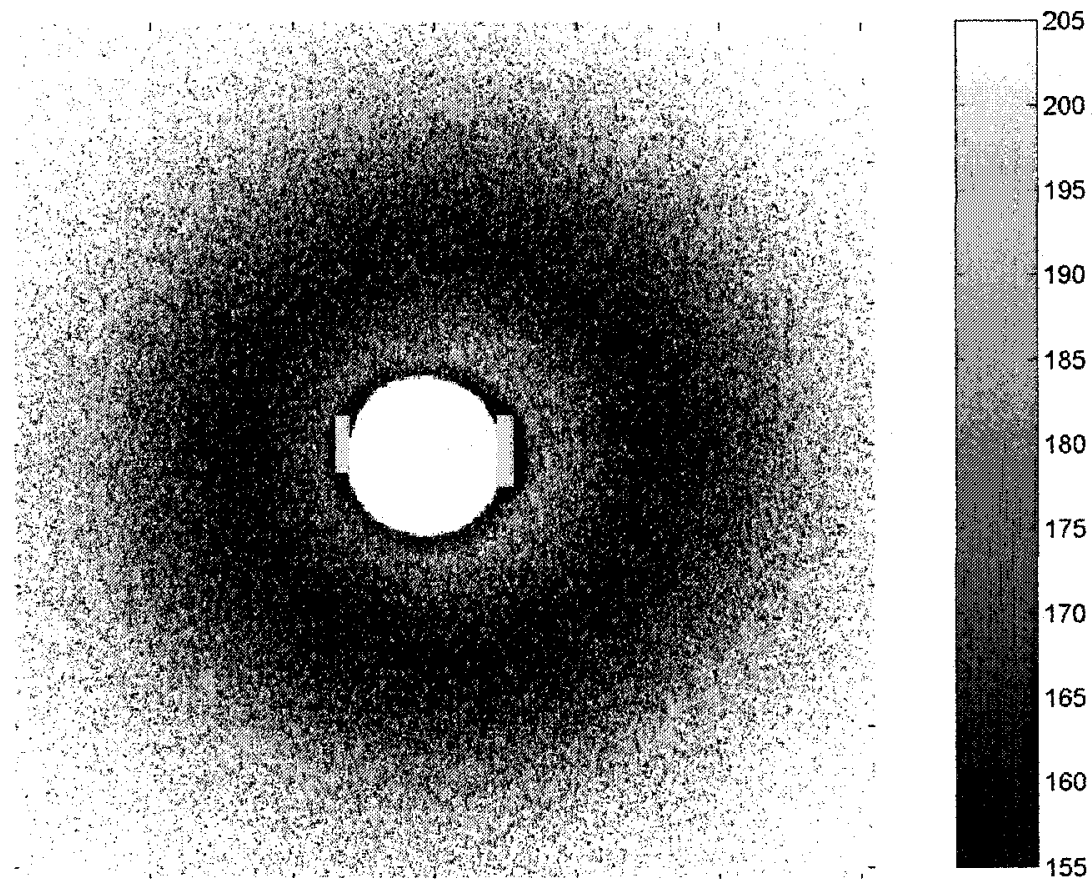

(a)
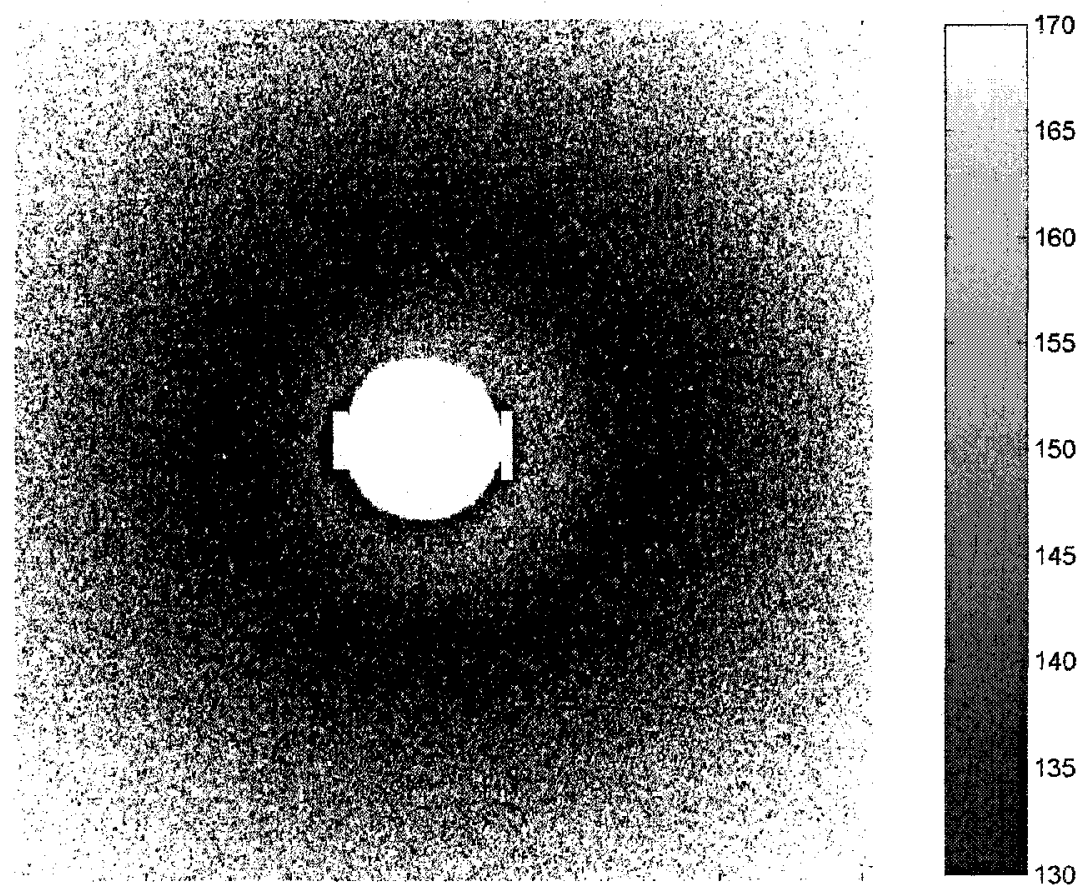

(b)

Figure 6.1 Scatter patterns from (a) $10 \mathrm{~cm}$ and (b) $20 \mathrm{~cm}$ thick water phantom. 


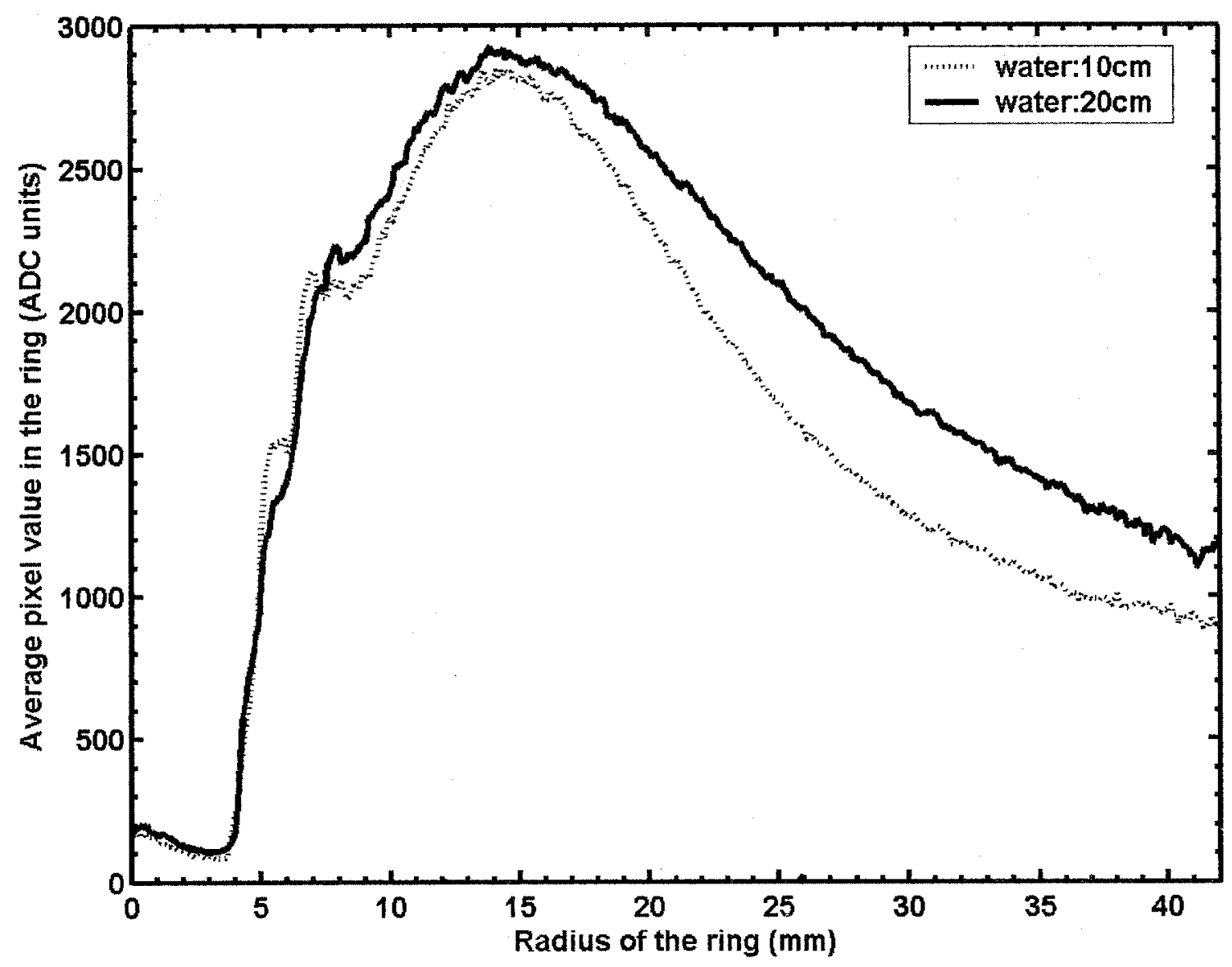

Figure 6.2 Radial intensity profile for a $10 \mathrm{~cm}$ and for a $20 \mathrm{~cm}$ thick water phantom.

The tube was operated at $120 \mathrm{kVp} 1500 \mathrm{mAs}$ (large focal spot) for the $10 \mathrm{~cm}$ thick water phantom measurements and the technique factors for the $20 \mathrm{~cm}$ thick water phantom were $120 \mathrm{kVp}, 7000 \mathrm{mAs}$ (large focal spot). A $127 \mu \mathrm{m}$ thick holmium filter (Z $=67, \mathrm{~K}$-edge $55.6 \mathrm{keV}$ ) was used to narrow the $\mathrm{x}$-ray spectrum. 


\section{$6.210 \mathrm{~cm}$ thick water/plastic phantoms}

The following set of experiments was performed with a $10 \mathrm{~cm}$ thick water/plastic phantom (plastic in water phantom).

(a) The scatter pattern of a $10 \mathrm{~cm}$ water phantom was recorded and analysed.

(b) The scatter patterns of $2.6 \mathrm{~cm}$ thick PMMA placed at different depths in a $10 \mathrm{~cm}$ water phantom were recorded and analysed.

(c) The scatter patterns of four types of plastics having thickness of $1.25 \mathrm{~cm}$ placed at the depth of $5 \mathrm{~cm}$ in a $10 \mathrm{~cm}$ water phantom were recorded and analysed.

All of these scatter patterns were obtained by averaging 15 exposures with the identical experimental conditions. In the radial intensity profile plot the angles are calculated by using the distance from the center of $10 \mathrm{~cm}$ water phantom to the detector.

\subsubsection{Scatter patterns for $10 \mathrm{~cm}$ thick water/PMMA phantom}

The radial intensity profiles for $10 \mathrm{~cm}$ water and $2.6 \mathrm{~cm}$ thick PMMA at different depth in $10 \mathrm{~cm}$ water are shown in figure 6.3 . The tube was operated at $120 \mathrm{kVp} 1500 \mathrm{mAs}$ for these measurements. The scatter patterns are more intense when PMMA is placed at the top of the $10 \mathrm{~cm}$ water phantom $(7.4 \mathrm{~cm}$ from the bottom of the phantom). The important point is that due to the presence of PMMA at the top of water phantom the peak is shifted toward lower angle, however, the profile shape does not change. The angles are calculated using distance from the centre of the water phantom to the screen. Figure 6.3 shows that due to the presence of PMMA at the top of the water phantom the profile peak is shifted to lower angle. This shift in peak location is in accordance with the result described in chapter 4 for thin targets. The intensity profiles in figure 4.3 for thin targets show that peak for PMMA occurs at a lower angle than water. In figure 6.3 , in addition to 
the profile when the target is at the top of $10 \mathrm{~cm}$ water phantom, the profiles for target at the depths of $2.4 \mathrm{~cm}, 5 \mathrm{~cm}$ and at the bottom of the phantom are also shown. The profile when the target is at the bottom of the water phantom is not only less intense as compared to the water phantom profile but also shape of the profile is different in the region between $2.6^{\circ}$ to $3.5^{\circ}$. The intensity for water varies from 2100 to $2700 \mathrm{ADC}$ units but the intensity when PMMA is at the bottom of water phantom remains almost the same in this range. The intensity profiles when the target is at the depth of 2.4 and $5 \mathrm{~cm}$ in water phantom are not only different in shape as compared to water phantom profile but their peaks are also shifted towards the lower angle region. The profiles are almost flat in the range $2.4^{\circ}$ to $3.5^{\circ}$. The presence of PMMA changes the profile shape in the lower angle range. In short, from these studies even the same nature of target situated at different depth of $10 \mathrm{~cm}$ water phantom gives different scatter pattern in terms of intensity and structure.

We are not expecting any change in the profile structure or its intensity by placing the same type and thickness of plastic at different depths. Each pattern was obtained by averaging 15 exposures with the identical experimental conditions. Drifts in collimation alignment were possible because for these single beam measurements the phantom must be removed to change the position of the plastic. There can also be effects due to variation in $\mathrm{x}$-ray tube output. These experiments should be repeated using the multiple beam collimation system. 


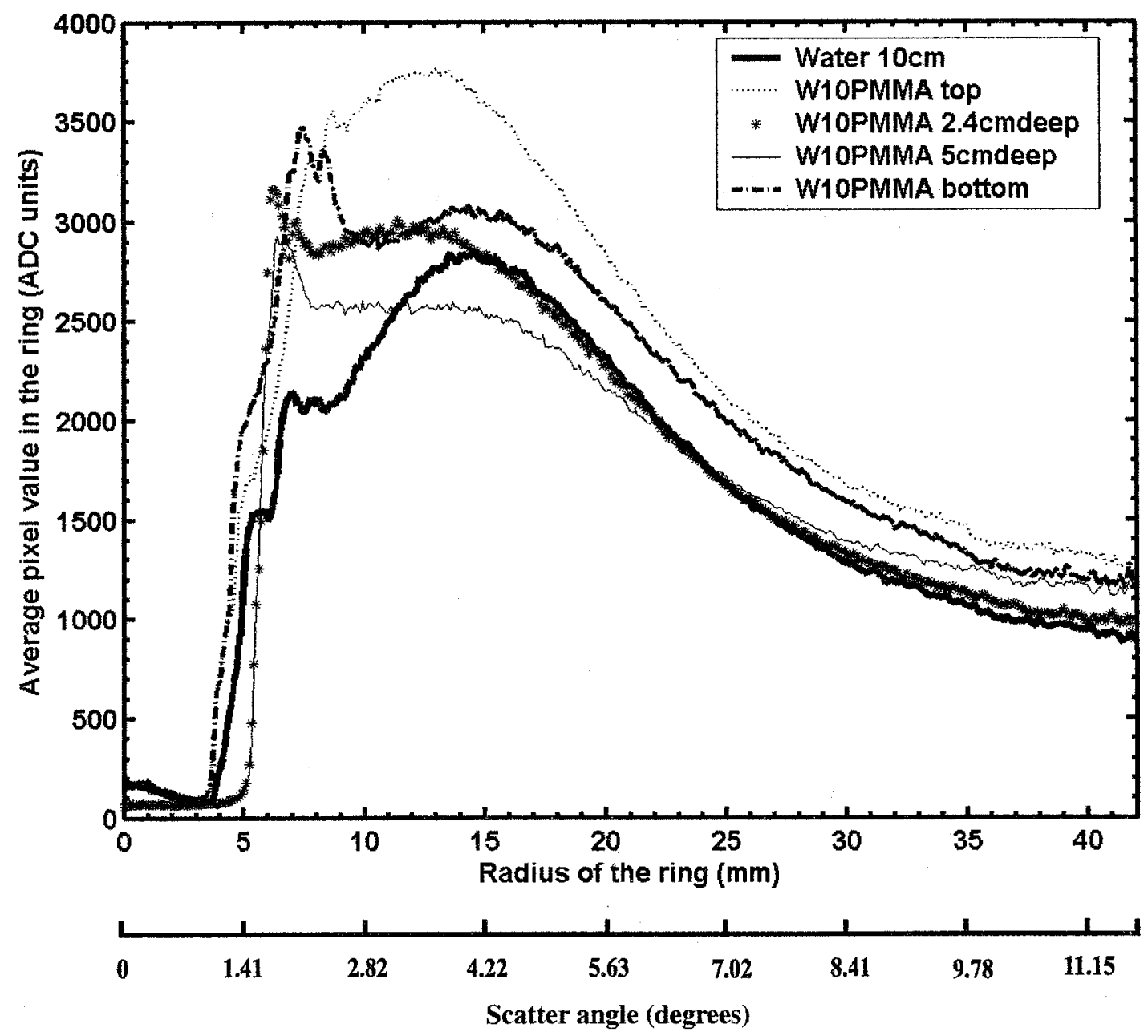

Figure 6.3 The intensity profiles of scatter patterns for $10 \mathrm{~cm}$ thick water/PMMA phantom at $120 \mathrm{kVp}$. PMMA of thickness $2.6 \mathrm{~cm}$ is placed at different depths in a $10 \mathrm{~cm}$ thick water phantom. The intensity profile for $10 \mathrm{~cm}$ water without PMMA is also shown in the panel.

\subsubsection{Scatter patterns for $10 \mathrm{~cm}$ thick water/plastic phantoms}

The radial intensity profiles of $10 \mathrm{~cm}$ thick water and four different types of plastics each with thickness of $1.25 \mathrm{~cm}$ located at the depth of $5 \mathrm{~cm}$ in a $10 \mathrm{~cm}$ water tank are shown in figure 6.4. The tube was operated at $120 \mathrm{kVp}, 1500 \mathrm{mAs}$ for these measurements. It is 
clear from the figure that the intensity and profile structure change when the plastic in the water tank is changed. In terms of intensity, we can divide these materials in three groups. The scatter pattern of polycarbonate/water is more intense than water while PMMA/water and nylon/water are less intense than water. The intensity of polyethylene/water is almost the same as water. The intensity peaks of all the plastic embedded phantoms shifted towards the lower angle. Also for $2.2^{\circ}-3.7^{\circ}$ in the polycarbonate/water and PMMA/water phantoms the profile slope is less than water because the scatter patterns of polycarbonate and PMMA have small ring size as compared to water, polyethylene and nylon. If we make angle-sensitive scatter images for polyethylene/water versus homogeneous water phantom in the ranges $2.3^{\circ}-3.7^{\circ}$ and $4.3^{\circ}$ $5.6^{\circ}$ the contrast will reverse. Polyethylene/water will be brighter than water in the range $2.3^{\circ}-3.7^{\circ}$, but water will be brighter than polyethyleneiwater in the range $4.3^{\circ}-5.6^{\circ}$. Although the nylon/water profile looks like the PMMA/water profile one should be able to distinguish between these plastics in the range $2.8^{\circ}-4.8^{\circ}$ in a scatter image display. In short, these four types of plastics embedded in $10 \mathrm{~cm}$ water tank at the depth of $5 \mathrm{~cm}$ can be easily identified in an angle sensitive coherent scatter image display. Comparison of PMMA profiles for different thicknesses but at the same depth in $10 \mathrm{~cm}$ water shown in figure 6.3 and 6.4 shows that by doubling the plastic thickness the intensity of the scatter pattern increases by $450 \mathrm{ADC}$ units. 


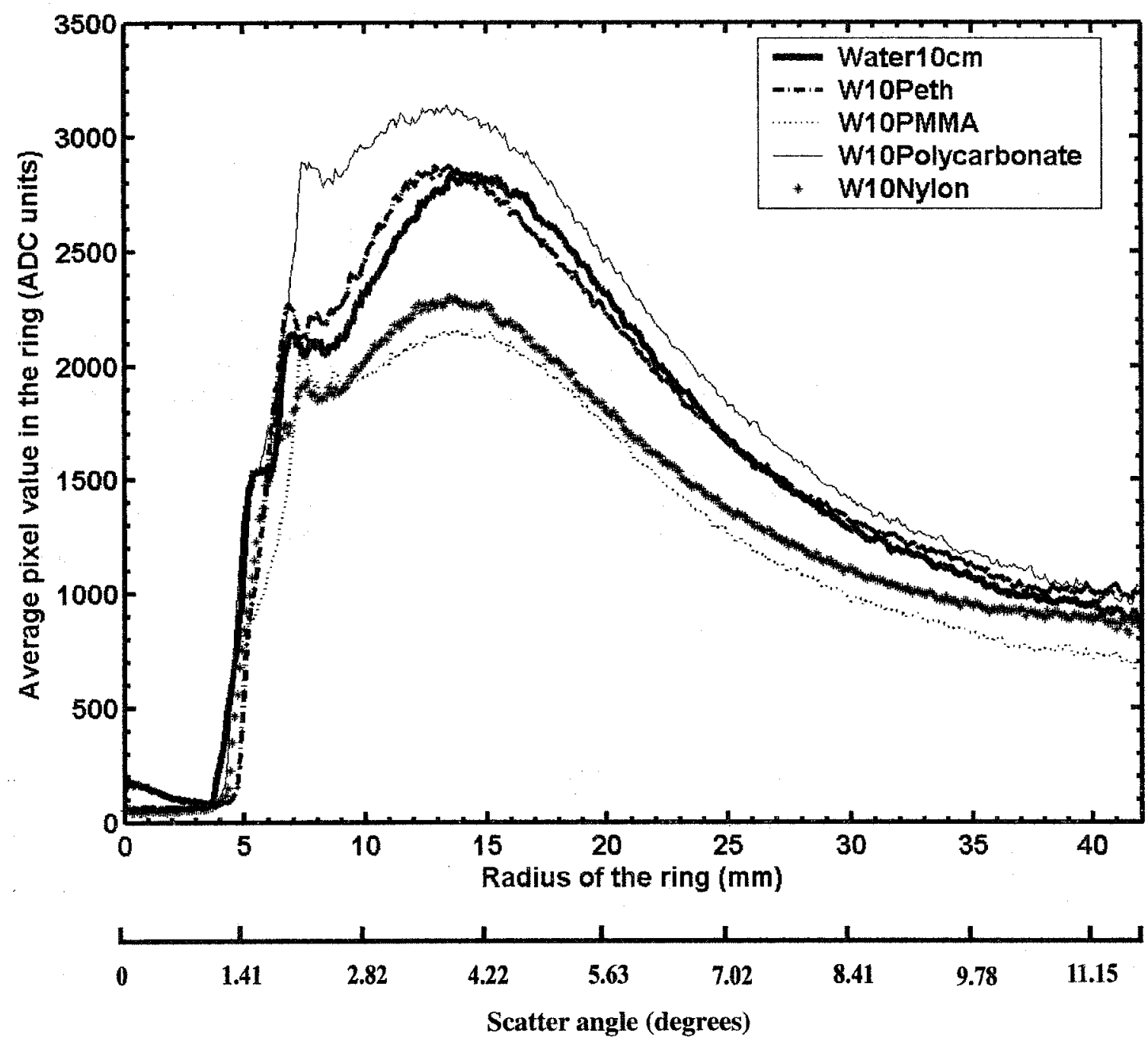

Figure 6.4 The intensity profiles of scatter patterns for $10 \mathrm{~cm}$ thick water/plastic phantom at $120 \mathrm{kVp}$. The thickness of the plastics is $1.25 \mathrm{~cm}$ and they are at the depth of $5 \mathrm{~cm}$ in a $10 \mathrm{~cm}$ thick water phantom. The intensity profile of $10 \mathrm{~cm}$ water with no plastics is also shown. 


\section{$6.320 \mathrm{~cm}$ thick water/plastic phantoms}

The following set of experiments were performed with a $20 \mathrm{~cm}$ thick water/plastics phantom.

(a) The scatter pattern of a $20 \mathrm{~cm}$ water phantom was recorded and analysed.

(b) The scatter patterns of $2.6 \mathrm{~cm}$ thick PMMA placed at different depths in a $20 \mathrm{~cm}$ water phantom were recorded and analysed.

(c) The scatter patterns of four types of plastics having thickness of about $1.25 \mathrm{~cm}$ placed at the depth of $10 \mathrm{~cm}$ and at $15 \mathrm{~cm}$ in a $20 \mathrm{~cm}$ water phantom were recorded and analysed.

(d) The scatter patterns of different thicknesses of PMMA at the depth of $10 \mathrm{~cm}$ in a 20 $\mathrm{cm}$ thick water phantom are recorded and analysed. These scatter patterns were obtained by averaging 70 exposures with the identical experimental conditions.

\subsubsection{Scatter patterns for $20 \mathrm{~cm}$ thick water/PMMA phantom}

The radial intensity profiles for $20 \mathrm{~cm}$ water and $2.6 \mathrm{~cm}$ thick PMMA at different depths in $20 \mathrm{~cm}$ water are shown in figure $6.5(\mathrm{a})$, (b). The tube was operated at $120 \mathrm{kVp}, 7000$ $\mathrm{mAs}$ for these measurements. The peak of the water phantom profile is at about $3.2^{\circ}$. One important difference between these measurements and the $10 \mathrm{~cm}$ thick water/PMMA phantom discussed in section 6.2.1 is that in this case the water/PMMA phantom is always less intense than the homogeneous water phantom. In figure 6.5(a), the intensity profiles of PMMA at the top of water phantom, at the depth of $5 \mathrm{~cm}$, and at $10 \mathrm{~cm}$ are plotted. The profiles when PMMA is at the top $(17.4 \mathrm{~cm}$ from the bottom) and at $5 \mathrm{~cm}$ depth $(12.4 \mathrm{~cm}$ from the bottom) are identical. Although their peak locations are the same 
as for the water phantom, they are less intense than water and can be identified in water in the range $2.9^{\circ}-4.7^{\circ}$ and even at higher range as well. The presence of PMMA in water phantom is more obvious when it is at the depth of $10 \mathrm{~cm}$ or more. The peak of the profile is shifted towards the lower angle $\left(2.9^{\circ}\right)$ and also it is more intense than water phantom in the range $1.8^{\circ}-2.6^{\circ}$. It is less intense than water in the range $2.6^{\circ}<\theta<6.5^{\circ}$ but its intensity increases again at $\theta>6.5^{\circ}$. A good contrast reversal should be observable in angle sensitive scatter image display. It is also obvious that PMMA located at the depth of $10 \mathrm{~cm}$ can be distinguished from other two locations between the range $1.8^{\circ}-2.9^{\circ}$ and $4.7^{\circ}-7.8^{\circ}$. In figure 6.5(b) the profiles for PMMA at the depth of $10 \mathrm{~cm}, 12.4 \mathrm{~cm} 15 \mathrm{~cm}$ and at the bottom are plotted. The intensity decreases as the PMMA goes deeper. The location of the peak at the depth of $12.4 \mathrm{~cm}$ and $15 \mathrm{~cm}$ is same as for water phantom but shifted towards the higher angle when PMMA is at the bottom of the phantom $\left(3.6^{\circ}\right)$. The profiles for these locations are well separated from each other and from water phantom profile. In short, these observations show that by changing the PMMA position in the water phantom the intensity and structure of the scatter pattern changes and PMMA effects are more significant when it is at the depth of $10 \mathrm{~cm}$ or more in $20 \mathrm{~cm}$ thick water phantom. 


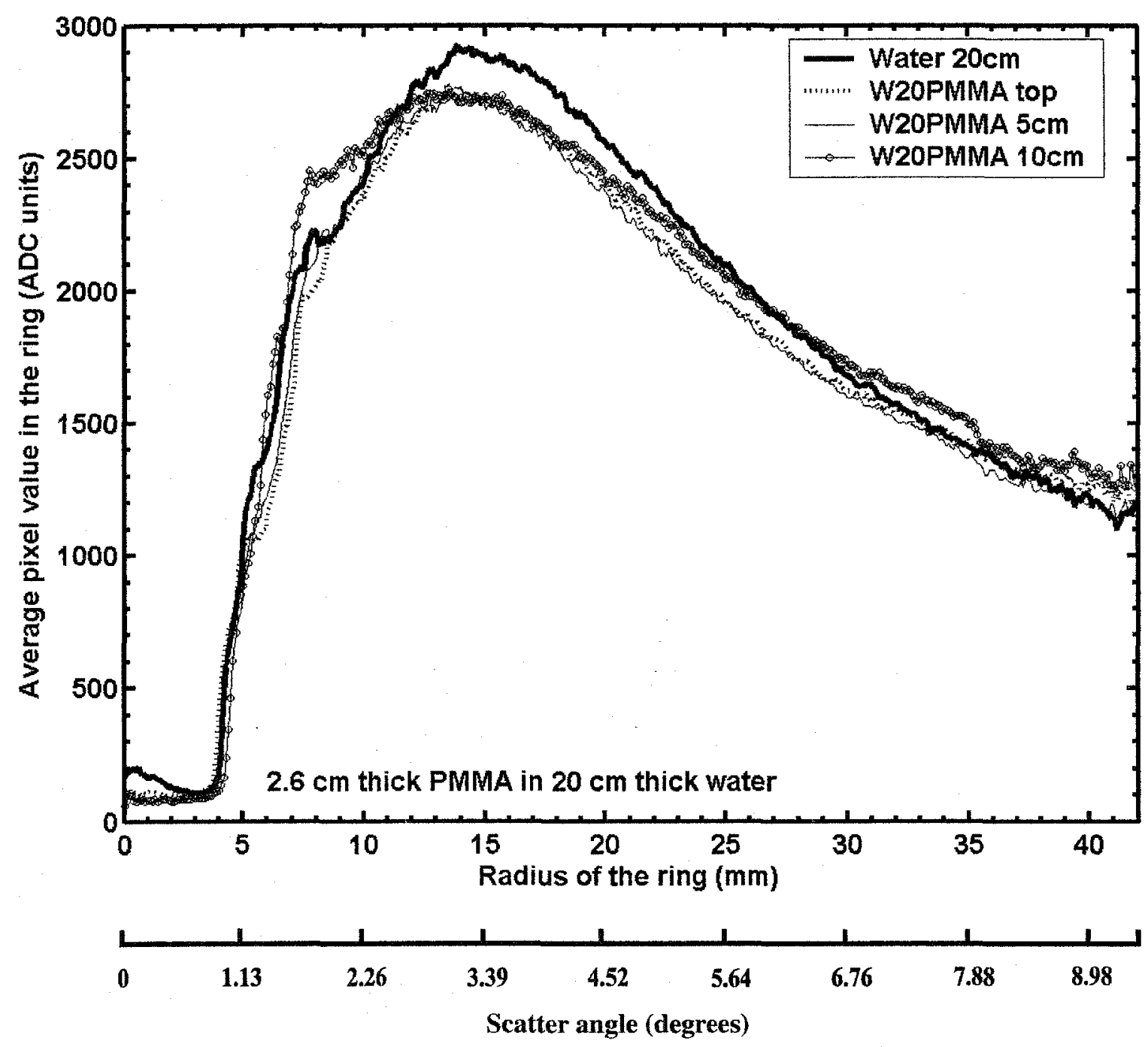

Figure 6.5 The intensity profiles of scatter patterns for $20 \mathrm{~cm}$ thick water/plastic phantom at $120 \mathrm{kVp}$. PMMA of thickness $2.6 \mathrm{~cm}$ is placed at different depths in $20 \mathrm{~cm}$ thick water phantom. The intensity profile for $20 \mathrm{~cm}$ thick water without PMMA is also shown in the panel. (a) Depths of 0,5 , and $10 \mathrm{~cm}$. [continued on page 70 ]. 


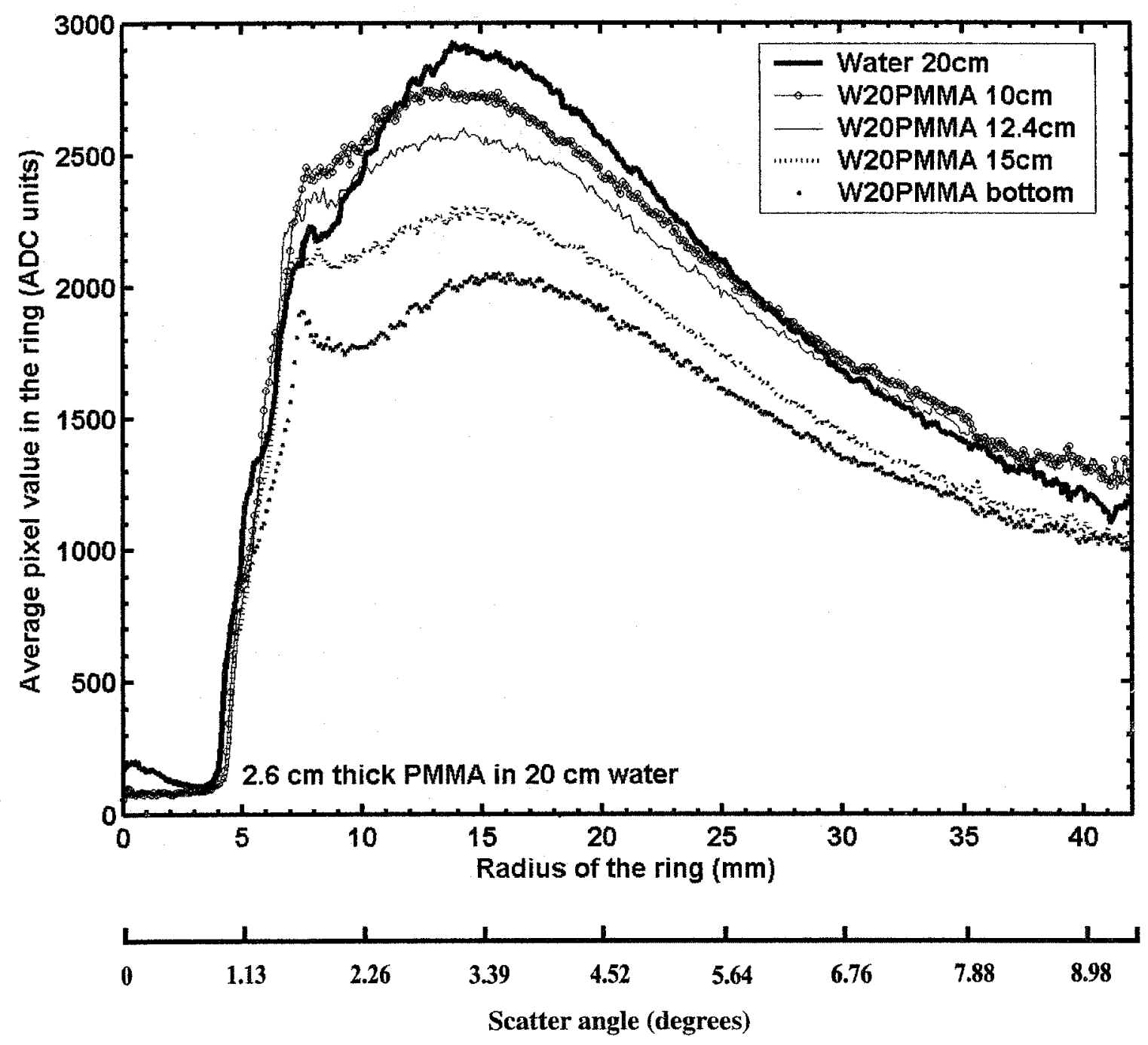

Figure 6.5 (continued). (b) Depths of $10,12.5,15$, and bottom which is $17.6 \mathrm{~cm}$. 


\subsubsection{Scatter patterns for $20 \mathrm{~cm}$ thick water/plastic phantoms}

The scatter patterns of four different types of plastics each with thickness of $1.25 \mathrm{~cm}$ at the depth of $10 \mathrm{~cm}$ and at $15 \mathrm{~cm}$ in a $20 \mathrm{~cm}$ thick water phantom are investigated.

\subsubsection{Plastics at $10 \mathrm{~cm}$ depth}

The intensity profile of $20 \mathrm{~cm}$ thick water and plastics at the depth of $10 \mathrm{~cm}$ are plotted in figure 6.6. The intensity of the scatter patterns is less when plastics are placed in the water phantom as compared to a homogeneous water phantom, but there is no effect on the peak locations. The profiles for water/plastic phantoms can be divided into two groups. The water/polyethylene and water/PMMA are equally intense as the water phantom but they can be distinguished from water at $3^{\circ} \leq \theta \leq 8.5^{\circ}$. It is also possible to differentiate these plastics in a $20 \mathrm{~cm}$ thick water phantom in the range $3.0^{\circ}-4.3^{\circ}$. The profiles for water/polycarbonate and water/nylon phantom overlap and it is not possible to distinguish them at this depth. The other two plastics, however, can be differentiated from these because these are about $1100 \mathrm{ADC}$ units less intense than the water phantom.

\subsubsection{Plastics at $15 \mathrm{~cm}$ depth}

The intensity profile of $20 \mathrm{~cm}$ thick water and plastics at depth $15 \mathrm{~cm}$ are plotted in figure 6.7. The water/PMMA is less intense than the water phantom and also the peak location coincide like at $10 \mathrm{~cm}$ depth as discussed in previous section. The profile structure is changed by changing the locations of the plastics in the water phantom. 


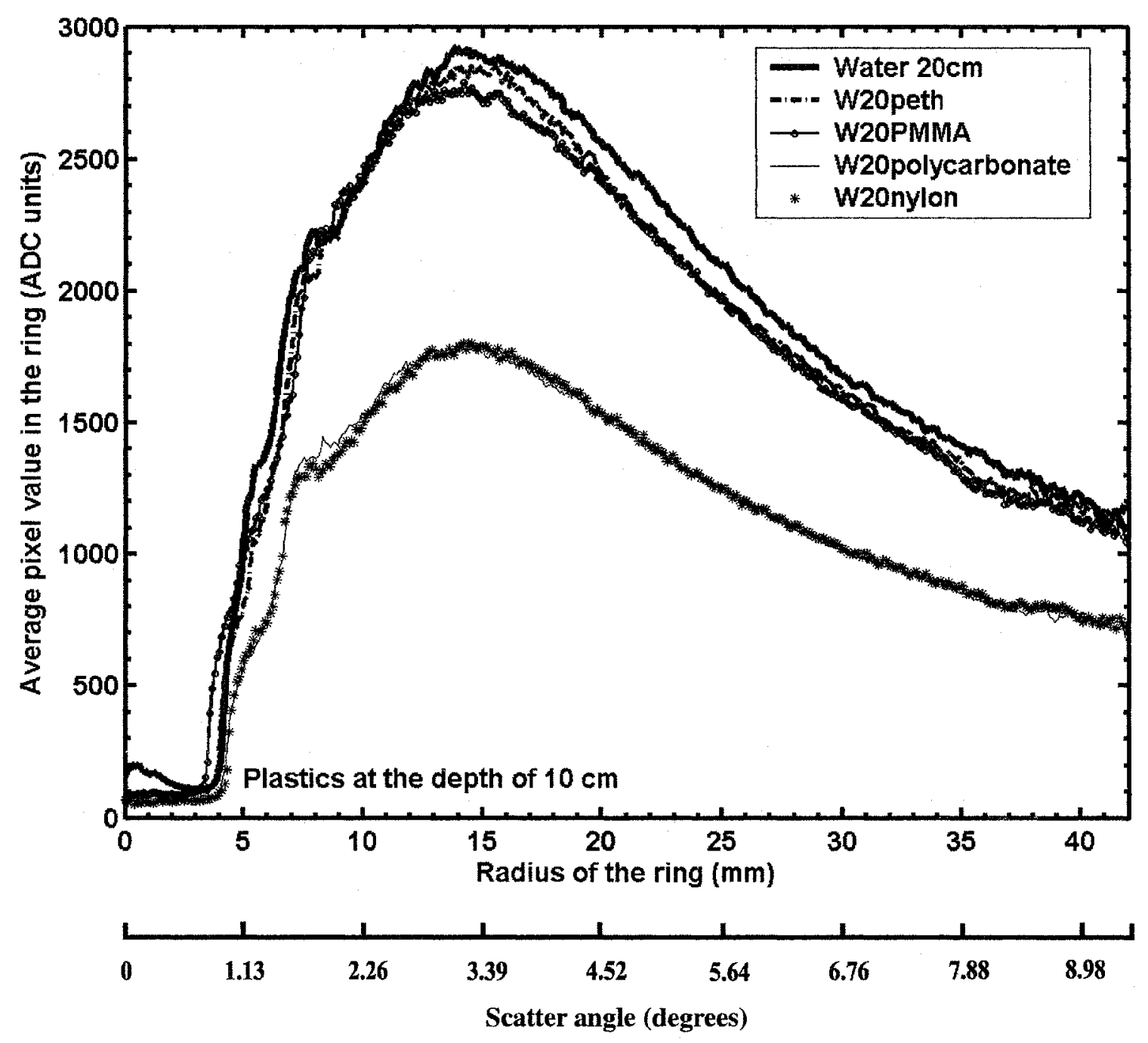

Figure 6.6 The intensity profiles of scatter patterns for $20 \mathrm{~cm}$ thick water/plastic phantom at $120 \mathrm{kVp}$. The thickness of the plastics is $1.25 \mathrm{~cm}$ and they are $10 \mathrm{~cm}$ from the top of a $20 \mathrm{~cm}$ thick water phantom. The intensity profile of $20 \mathrm{~cm}$ water with no plastic is also shown. 


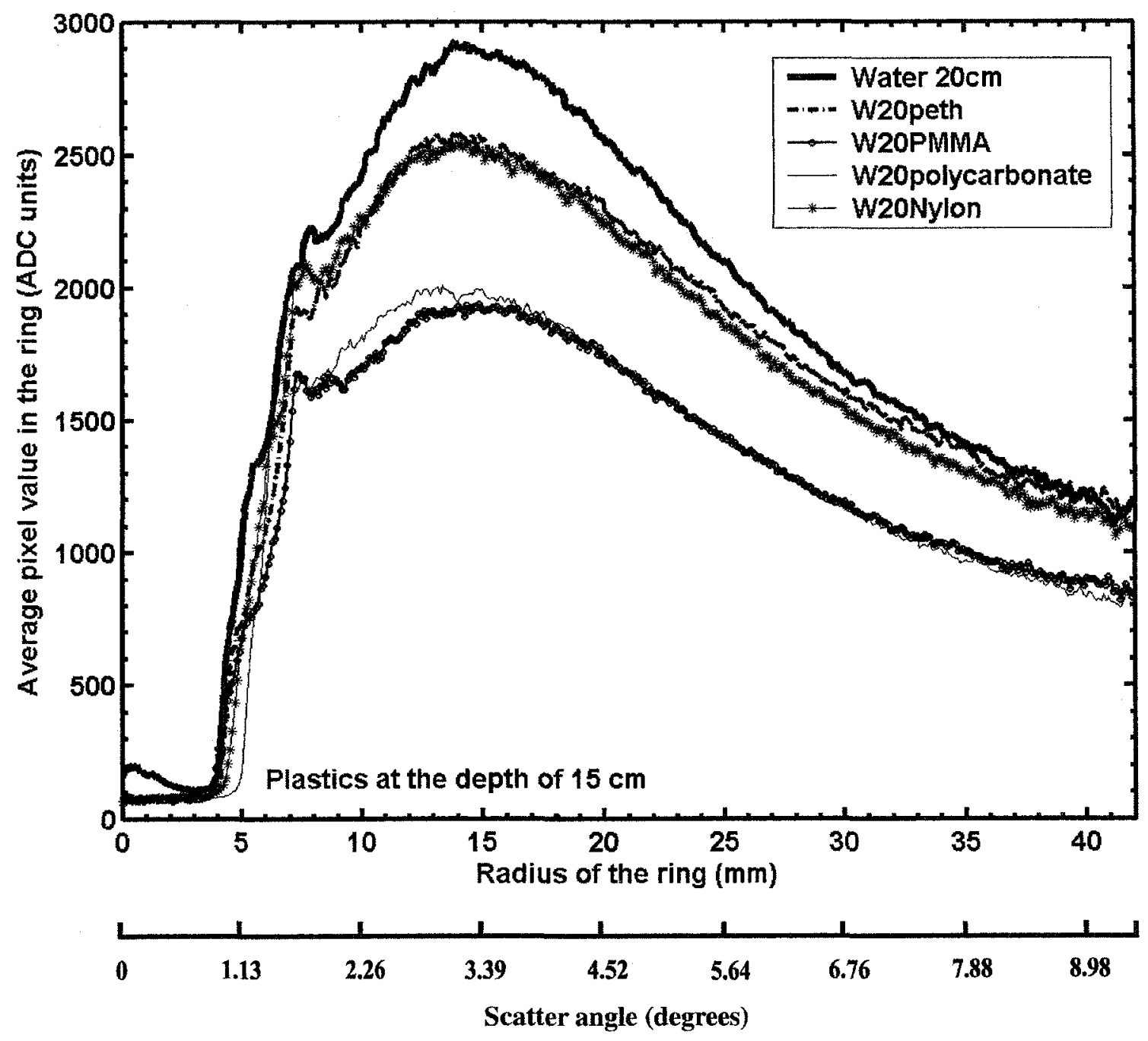

Figure 6.7 The intensity profiles for scatter patterns of $20 \mathrm{~cm}$ thick water/plastic phantom at $120 \mathrm{kVp}$. The thickness of the plastics is $1.25 \mathrm{~cm}$ and they are $15 \mathrm{~cm}$ from the top of a $20 \mathrm{~cm}$ thick water phantom. The intensity profile for $20 \mathrm{~cm}$ thick water without plastic is also shown. 
Also, the intensity of polyethylene/water and nylon/water phantom is $400 \mathrm{ADC}$ units less than that of the water phantom. Profiles of water/polyethylene and water/nylon phantom overlap each other except at range $\theta>5.2^{0}$. The profiles of the less intense group, i.e. water/PMMA and water/polycarbonate phantom, also overlap each other except in range $1.9^{0}-3.2^{0}$. This group is about $1000 \mathrm{ADC}$ unit less intense than water phantom. The important point is that the intensity of water/PMMA phantom decreases to $800 \mathrm{ADC}$ units by shifting PMMA from $10 \mathrm{~cm}$ to $15 \mathrm{~cm}$ depth and intensity of water/nylon phantom increases by 800 units by shifting nylon from $10 \mathrm{~cm}$ to $15 \mathrm{~cm}$ depth. Also, there is no effect on profile structure in terms of peak shifts or flat regions at low angles discussed in sections 6.3.2 and 6.2.3, perhaps because the plastics are too thin.

\subsection{PMMA of different thicknesses in a $20 \mathrm{~cm}$ thick water phantom}

The radial intensity profiles for $20 \mathrm{~cm}$ thick water with $1.25 \mathrm{~cm}, 2.6 \mathrm{~cm}$, and $5.2 \mathrm{~cm}$ thick PMMA at the depth of $10 \mathrm{~cm}$ in a $20 \mathrm{~cm}$ water phantom are shown in figure 6.8 . The tube was operated at $120 \mathrm{kVp}, 7000 \mathrm{mAs}$ for these measurements. The effects of $1.25 \mathrm{~cm}$ and $2.6 \mathrm{~cm}$ thick PMMA at $10 \mathrm{~cm}$ depth are discussed in the previous sections. There is a significant change in the radial profile when $5.2 \mathrm{~cm}$ thick PMMA is in $20 \mathrm{~cm}$ thick water. The intensity of the profile is dropped about 1060 ADC units. The peak is shifted towards the lower angle and profile is almost flat between the range $1.7^{\circ}-3.2^{\circ}$. Although it is clear from this figure that $2.6 \mathrm{~cm}$ thick PMMA at $10 \mathrm{~cm}$ depth alters the scatter pattern, it would be interesting to check the thicknesses between $2.6 \mathrm{~cm}$ and $5.2 \mathrm{~cm}$. 


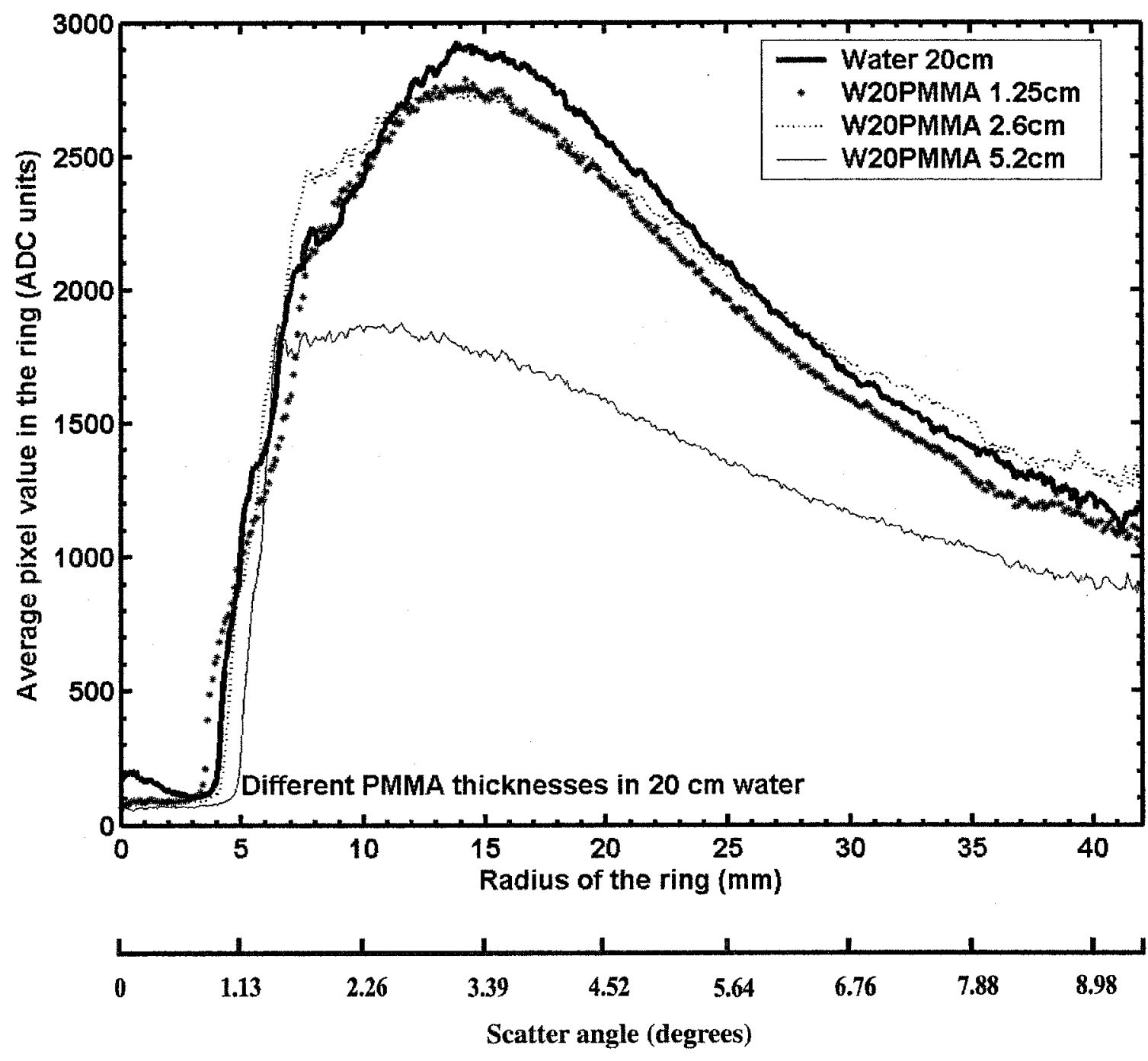

Figure 6.8 The intensity profiles of scatter patterns of $20 \mathrm{~cm}$ thick water/plastic phantom at $120 \mathrm{kVp}$. PMMA of three different thicknesses is placed at the depth of $10 \mathrm{~cm}$ in a 20 $\mathrm{cm}$ thick water phantom. The intensity profile of a $20 \mathrm{~cm}$ homogeneous water phantom is also shown. 


\section{Chapter 7}

\section{Conclusion and future work}

\subsection{Conclusion}

I have designed and tested a seven beam hexagonal geometry collimation system to record the scatter patterns of amorphous materials. The scatter patterns of seven different materials each irradiated by a separate beam show characteristics of the material in terms of ring size. The projection scatter images were made using these data and their contrast was compared with transmission images.

Using single beam geometry the experiments on thick water/plastic phantoms with different types and thicknesses of plastics embedded in water were also performed. The results show that the presence of different plastics can be detected using the coherent scatter imaging technique.

Our experiments on thick phantoms also show that by changing the depth of the plastic (same type and thickness) in the water phantom the shape and intensity of scatter pattern profile changes.

In conclusion, the angle-sensitive projection scatter images of amorphous materials show variation of contrast with variation in scatter angle. These images show better contrast for different plastic targets as compared to the transmission images of these materials. The experiments on thick water/plastic phantoms show that identification of plastics in thick phantoms is possible using this technique. These results reveal that the projection coherent scatter imaging technique can be used for better diagnostic information. 


\subsection{Future work}

\subsubsection{Measurements with thick water/plastic phantoms}

Using simple single beam geometry the measurements of $2.6 \mathrm{~cm}$ thick PMMA embedded in $10 \mathrm{~cm}$ and $20 \mathrm{~cm}$ water suggest that the shape of the scatter pattern radial profile and its relative intensity varies as the depth of PMMA changes in the water phantom. This is an unexpected result. These results should be verified using the seven beam geometry by recording the scatter patterns with PMMA or any other type of plastic at different depths in water phantom. This will allow us to rule out possible erroneous causes such as drifts in collimation alignment during the single-beam experiments. Also there will be no effect possible due to the variation in $\mathrm{x}$-ray tube output since all seven beams are activated simultaneously.

\subsubsection{Scanning of an inhomogeneous target}

Using the seven beam collimation system, an inhomogeneous target can be scanned for making better contrast projection scatter image. For scanning, a target holder with precise mechanical movements is required. The spatial resolution of the system can be increased by filling the gaps between the collimated beams. Using this collimation geometry the scanning time is seven-fold faster than a single-beam geometry. 


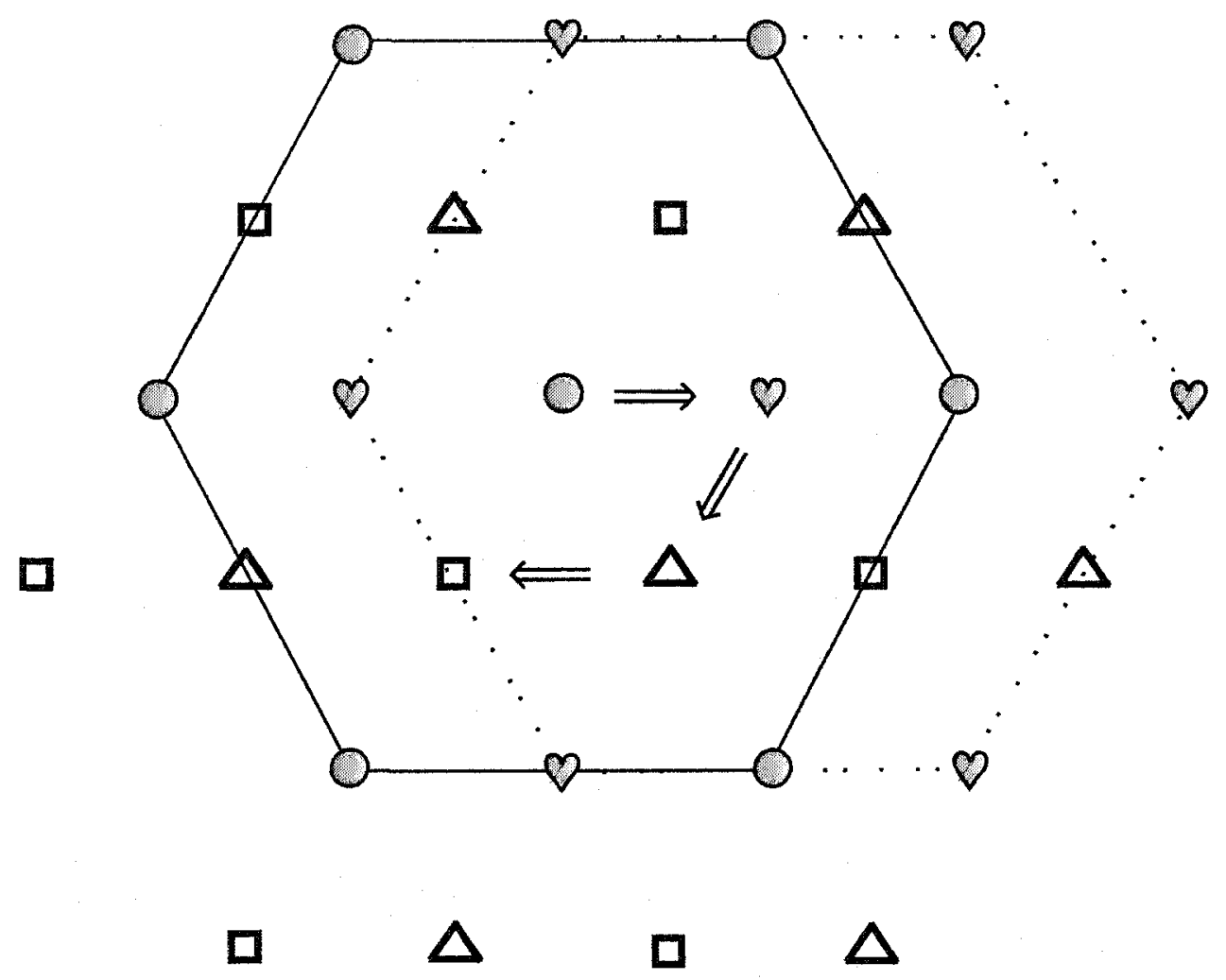

Figure 7.1 The scanning of a target using seven beam hexagonal collimation geometry. The arrows indicate four movements of the target during the scan.

The arrows in figure 7.1 indicate four movements of the target during scanning procedure. Using this geometry four positions of the target can be recorded on one CR plate by exposing a part of the plate for each position and covering the rest of the plate with a lead sheet. So, for each position of the target we need to move the detector as well. 


\subsubsection{Improvement in spatial resolution}

The spatial resolution of the scanning system can be improved by reducing the beam size of the collimation system. The collimation system with limiting aperture of $1 \mathrm{~mm}$ or even less can be used depending upon the nature of the experiment. However, the small beam size will reduce the intensity of the scatter signal which requires more exposure and also scanning time will be increased.

\subsubsection{Scanning of thick phantom}

This collimation system can be used to scan a thick human body size inhomogeneous phantom. In a thick phantom the multiple scattering events will also be important. Due to these events, there could be a substantial increase in background signal. In order to minimize their effects, a hexagonal shape lead grid with holes the diameter of the scatter patterns at the exit of phantom will be helpful not only to demark the patterns but also stop the multiple scatter photons from reaching the detector. 


\section{References}

[1] H. E. Johns and J. R. Cunningham, The Physics of Radiology, 4th Edition, C.C. Thomas, Springfield III. U.S., 1983.

[2] R. H. Morgan, "An analysis of the physical factors controlling the diagnostic quality of Roentgen images, Part III. Contrast and the intensity distribution function of a Roentgen image", Am. J. Roentgenol. 55, 67-89, 1946.

[3] J. W. Motz and M. Danos, "Image information content and patient exposure", Med. Phys. 5, 8-22, 1978.

[4] L. D. Speller and J. A. Horrocks, "Photon scattering - a 'new' source of information in medicine and biology?", Phys. Med. Biol. 36, 1-6, 1991.

[5] P. C. Johns and M. J. Yaffe, "Coherent scatter in diagnostic radiology", Med. Phys. $10,40-50,1983$.

[6] L. R. M. Morin and A. Berroir, "Calculation of x-ray single scattering in diagnostic radiology", Phys. Med. Biol. 28, 789-797, 1983.

[7] E. P. Muntz, T. Fewell, R. Jennings and H. Bernstein, "On the significance of very small angle scattered radiation to radiographic imaging at low energies", Med. Phys. 10, 819-823, 1983.

[8] G. Harding, J. Kosanetzky and U. Neitzel, "Elastic scatter computed tomography", Phys. Med. Biol. 30, 183-186, 1985.

[9] J. Kosanetzky, B. Knoerr, G. Harding and U. Neitzel, "X-ray diffraction measurements of some plastic materials and body tissues", Med. Phys. 14, 526-532, 1987. 
[10] M. S. Westmore, A. Fenster and I. A. Cunningham, "Angular-dependent coherent scatter measured with a diagnostic x-ray image intensifier-based imaging system", Med. Phys. 23, 723-733, 1996.

[11] M. S. Westmore, A. Fenster and I. A. Cunningham, "Tomographic imaging of the angular-dependent coherent-scatter cross section", Med. Phys. 24, 3-10, 1997.

[12] D. L. Batchelar and I. A. Cunningham, "Material-specific analysis using coherentscatter imaging", Med. Phys. 29, 1651-1660, 2002.

[13] P. C. Johns and M. J. Yaffe, "X-ray characterisation of normal and neoplastic breast tissues", Phys. Med. Biol. 32, 675-695, 1987.

[14] G. Kidane, R. D. Speller, G. J. Royle and A. M. Hanby, "X-ray scatter signatures for normal and neoplastic breast tissues", Phys. Med. Biol. 44, 1791-1802, 1999.

[15] R. J. Leclair and P. C. Johns, "A semianalytic model to investigate the potential applications of x-ray scatter imaging”, Med. Phys. 25, 1008-1020, 1998.

[16] R. J. Leclair and P. C. Johns, "Analysis of spectral blur effects in X-ray scatter imaging", Med. Phys. 26, 1811-1816, 1999.

[17] R. J. Leclair and P. C. Johns, "X-ray forward-scatter imaging: Experimental validation of model", Med. Phys. 28, 210-219, 2001.

[18] R. J. Leclair and P. C. Johns, “Optimum momentum transfer arguments for X-ray forward scatter imaging", Med. Phys. 29, 2881-2890, 2002.

[19] P. C. Johns, R. J. Leclair, and M. P. Wismayer, "Medical x-ray imaging with scattered photons", presentation CA07-513 at Opto-Canada: SPIE Regional Meeting on Optoelectronics, Photonics, and Imaging (Ottawa, 9 May 2002): SPIE TD01, 355-357, 2002. 
[20] P. C. Johns and M. P. Wismayer, "Measurement of coherent X-ray scatter form factors for amorphous materials using diffractometers", Phys. Med. Biol. 49, 5233-5250, 2004.

[21] M. Z. Hasan, "Measurement of X-ray scattering form factors over a wide momentum transfer range", M.Sc. thesis, Dept. of Physics, Carleton University, Ottawa, Canada, 2004.

[22] R. D. Luggar and W. B. Gilboy, "Application of Rayleigh scattered photons to substance identification", Nucl. Instr. Meth. Phys. Res. A 353, 650-653, 1994.

[23] R. D. Luggar and W. B. Gilboy, "Recent developments in industrial applications of elastic scatter X-ray inspection", Radiat. Phys. Chem. 56, 213-227, 1999.

[24] G. Harding, "On the sensitivity and application possibilities of a novel Compton scatter imaging system", IEEE Trans. Nucl. Sci. NS-29, 1260-1265, 1982.

[25] G. Harding and R. Tischler, "Dual-energy Compton scatter tomography", Phys. Med. Biol. 31, 477-489, 1986.

[26] A. M. Jacobs and E. S. Kenney, "Dynamic radiography: a new imaging technique using penetrating radiation", in Proc. SPIE 29, 17-22, 1972.

[27] M. D. Herr, J. J. McInerney, D. G. Lamser and G. L. Copenhaver, “A flying spot Xray system for Compton backscatter imaging", IEEE Trans. Med. Imag., 13, 461-469, 1994.

[28] M. Nisar and P. C. Johns, "Projection imaging of plastic materials using coherently scattered x rays", Poster \# MO-POS-144 at Can. Org. of Medical Physicists / Can. Assoc. of Physicists Conf., Winnipeg, 16-20 June, 2004. (Abstract: Physics in Canada 60, 145, 2004). 
[29] M. Nisar and P. C. Johns, "Coherent Scatter X-Ray Imaging of Plastic / Water Phantoms", in Photonics North 2004: Applications in Astronomy, Biomedicine, Imaging, Materials Processing, and Education, Proc. SPIE 5578, 445-453 (Ottawa, 29 September 2004).

[30] D. W. L. Hukins, X-ray Diffraction by Disordered and Ordered Systems, 1st Edition, Pergamon Press, Oxford, U.K., 1981.

[31] Image screen - K size $(20 \times 25 \mathrm{~cm})$ : Bio-Rad Laboratories, 1000 Alfred Nobel Drive, Hercules, CA 94547 USA [http://www.biorad.com].

[32] Matlab: The MathWorks Inc., 3 Apple Hill Drive, Natick, MA 01760-2098, USA [http://www.mathworks.com]. 


\section{Appendix}

\section{Computer code for generating radial profile of scatter pattern}

This Matlab program integrates the scatter pattern in terms of concentric rings. The average intensity of each ring is then plotted versus radius of the ring to get the radial intensity profile of the pattern.

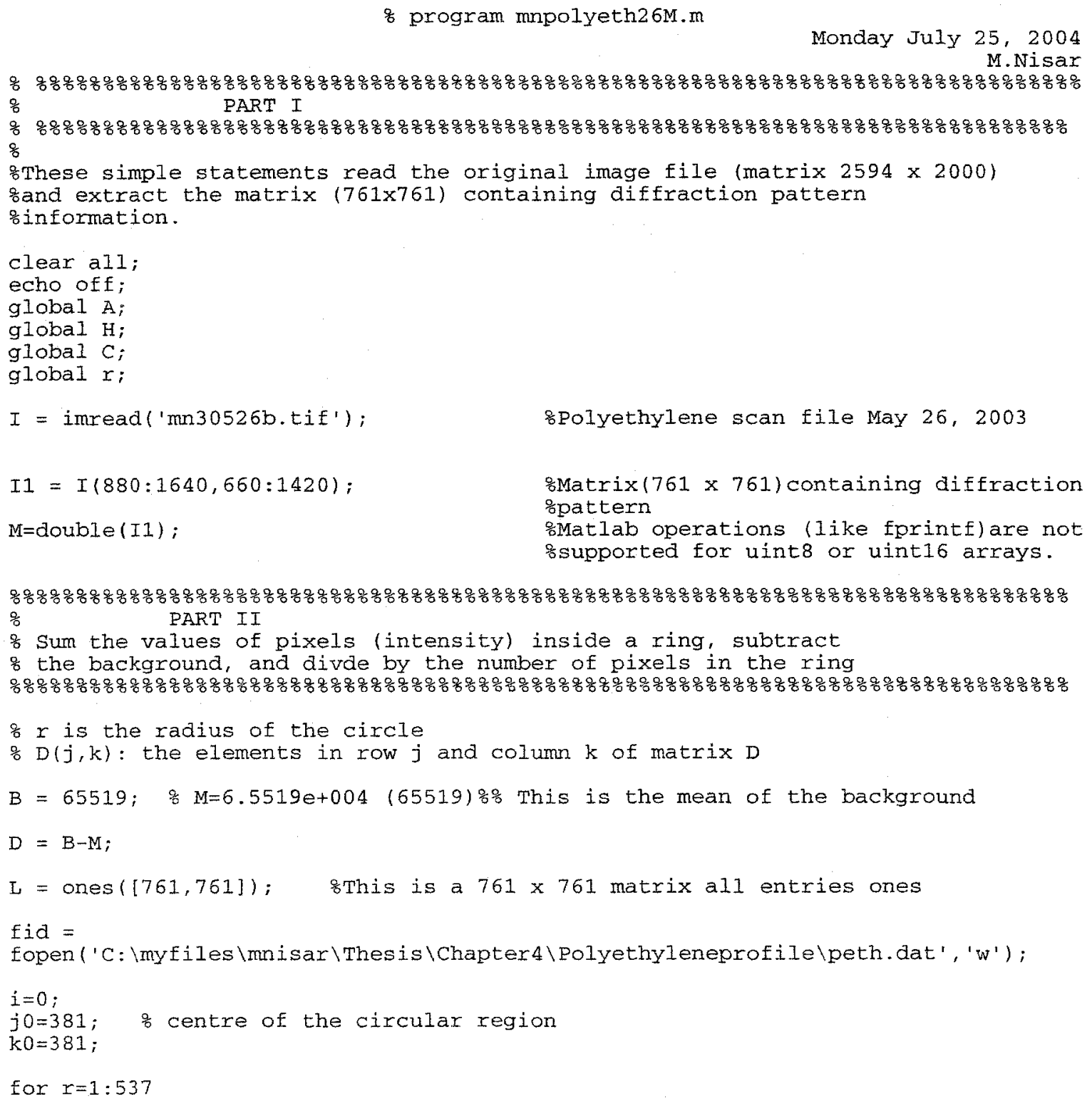




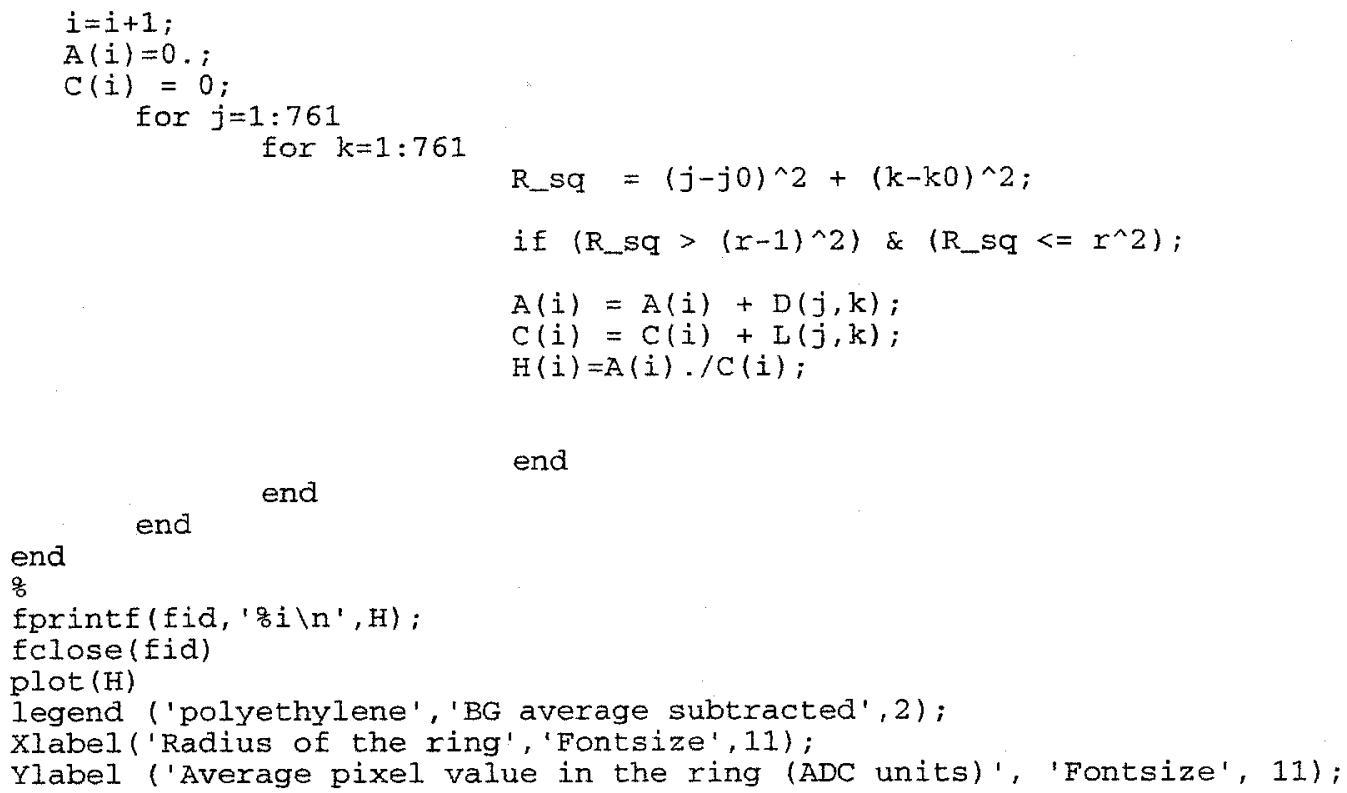

